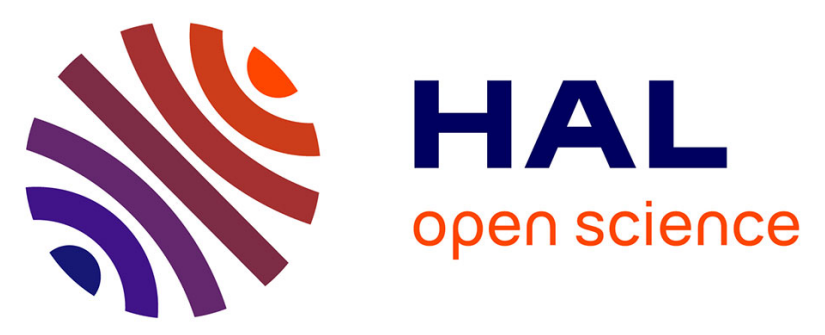

\title{
HIV-Tat induces a decrease in I Kr and I Ks via reduction in phosphatidylinositol- $(4,5)$-bisphosphate availability
}

Zeineb Es-Salah-Lamoureux, Mariam Jouni, Nadjet Belbachir, Zeina Reda, Al Sayed, Marine Gandon-Renard, Guillaume Lamirault, Chantal Gauthier, Isabelle Baró, Flavien Charpentier, et al.

\section{To cite this version:}

Zeineb Es-Salah-Lamoureux, Mariam Jouni, Nadjet Belbachir, Zeina Reda, Al Sayed, et al.. HIV-Tat induces a decrease in I $\mathrm{Kr}$ and I $\mathrm{Ks}$ via reduction in phosphatidylinositol- $(4,5)-$ bisphosphate availability. Journal of Molecular and Cellular Cardiology, 2016, [Epub ahead of print]. 10.1016/j.yjmcc.2016.08.022 . inserm-01360585

\section{HAL Id: inserm-01360585 https://www.hal.inserm.fr/inserm-01360585}

Submitted on 6 Sep 2016

HAL is a multi-disciplinary open access archive for the deposit and dissemination of scientific research documents, whether they are published or not. The documents may come from teaching and research institutions in France or abroad, or from public or private research centers.
L'archive ouverte pluridisciplinaire HAL, est destinée au dépôt et à la diffusion de documents scientifiques de niveau recherche, publiés ou non, émanant des établissements d'enseignement et de recherche français ou étrangers, des laboratoires publics ou privés. 


\section{HIV-Tat induces a decrease in $I_{K r}$ and $I_{K s}$ via reduction in phosphatidylinositol-(4,5)-bisphosphate availability}

Zeineb Es-Salah-Lamoureux ${ }^{\mathrm{a} *}$, Mariam Jouni ${ }^{\mathrm{a} *}$, Olfat A. Malak ${ }^{\mathrm{a}}$, Nadjet Belbachir ${ }^{\mathrm{a}}$, Zeina Reda Al Sayed $^{\mathrm{a}}$, Marine Gandon-Renard ${ }^{\mathrm{a}}$, Guillaume Lamirault ${ }^{\mathrm{a}-\mathrm{b}}$, Chantal Gauthier ${ }^{\mathrm{a}}$, Isabelle Baró ${ }^{\mathrm{a}}$, Flavien Charpentier $^{\mathrm{a}-\mathrm{b}}$, Kazem Zibara ${ }^{\mathrm{c}}$, Patricia Lemarchand ${ }^{\mathrm{a}-\mathrm{b}}$, Bruno Beaumelle ${ }^{\mathrm{d}}$, Nathalie Gaborit ${ }^{\mathrm{a}}$, Gildas Loussouarn $^{\mathrm{a} \S}$.

a. l'institut du thorax, Inserm, CNRS, Université de Nantes, CHU de Nantes, Nantes, France

b. CHU de Nantes, Nantes, France

c. ER045, PRASE, Laboratory of stem cells, Lebanese university, Beirut, Lebanon

d. Centre d'études d'agents Pathogènes et Biotechnologies pour la Santé, CNRS, Université de Montpellier, Montpellier, France

*, . These authors contributed equally to this work.

Address correspondence to:

Dr. Nathalie Gaborit

L'institut du thorax

INSERM UMR 1087 / CNRS UMR 6291

IRS-UN, 8 Quai Moncousu BP 70721

44007 Nantes cedex 1, France

Tel: +33 (0)2 28080132

Fax: +33 (0)2 28080130

E-mail: nathalie.gaborit@univ-nantes.fr 


\begin{abstract}
Patients with HIV present with a higher prevalence of QT prolongation, of which molecular bases are still not clear. Among HIV proteins, Tat serves as a transactivator that stimulates viral genes expression and is required for efficient HIV replication. Tat is actively secreted into the blood by infected T-cells and affects organs such as the heart. Tat has been shown to alter cardiac repolarization in animal models but how this is mediated and whether this is also the case in human cells is unknown. In the present study, we show that Tat transfection in heterologous expression systems led to a decrease in hERG (underlying cardiac $\mathrm{I}_{\mathrm{Kr}}$ ) and human KCNE1-KCNQ1 (underlying cardiac $\mathrm{I}_{\mathrm{Ks}}$ ) currents and to an acceleration of their deactivation. This is consistent with a decrease in available phosphatidylinositol-(4,5)bisphosphate $\left(\mathrm{PIP}_{2}\right)$. A mutant Tat, unable to bind $\mathrm{PIP}_{2}$, did not reproduce the observed effects. In addition, WT-Tat had no effect on a mutant KCNQ1 which is PIP $_{2}$-insensitive, further confirming the hypothesis. Twenty four-hour incubation of human induced pluripotent stem cells-derived cardiomyocytes with Wild-type Tat reduced $\mathrm{I}_{\mathrm{Kr}}$ and accelerated its deactivation. Concordantly, this Tat incubation led to a prolongation of the action potential (AP) duration. Events of AP alternans were also recorded in the presence of Tat, and were exacerbated at a low pacing cycle length. Altogether, these data obtained on human $\mathrm{K}^{+}$ channels both in heterologous expression systems and in human cardiomyocytes strongly suggest that Tat sequesters $\mathrm{PIP}_{2}$, leading to a reduction of $\mathrm{I}_{\mathrm{Kr}}$ and $\mathrm{I}_{\mathrm{Ks}}$, and provide a molecular mechanism for QT prolongation in HIV-infected patients.
\end{abstract}

\title{
Key words:
}

$\mathrm{I}_{\mathrm{Kr}}$; $\mathrm{I}_{\mathrm{Ks}}$; phosphatidylinositol-(4,5)-bisphosphate; HIV-Tat protein; induced pluripotent stem cell-derived cardiomyocytes; long QT syndrome 


\section{INTRODUCTION}

As a consequence of the development of antiretroviral therapies (ART), life expectancy of HIV-positive individuals has greatly increased. For this population, excess mortality is moderate in industrialized countries and comparable with populations having other chronic conditions [1]. Life expectancy of HIV-positive individuals has also increased in middle income countries, gaining for instance 10 years between 2004 and 2011 in South Africa [2]. Worldwide, the increasing access of patients to ART, from 31\% in 2008 to $36 \%$ in 2014 [3, 4] leads to further increase in aging HIV-positive individuals. This aging population faces additional pathologies that are over-represented as compared to the general population. This is pointed out by a study on sudden cardiac death (SCD) in HIV positive individuals, showing a mean SCD rate 4.5 fold higher than in the general population [5]. Furthermore, up to $20 \%$ of the HIV patients are presenting with a long QT syndrome (LQTS), a greater prevalence than in the general population; prolonged QT interval is a risk factor for malignant arrhythmia [58]. However, the mechanistic link between LQTS and HIV remains unidentified.

Many drugs and combinations of drugs may be potential triggers of LQTS through inhibition of a major cardiac repolarizing current, $\mathrm{I}_{\mathrm{Kr}}$, conducted by the voltage-gated potassium channel hERG [9]. Among them, numerous drugs currently prescribed to HIV-positive individuals have been associated with a QT prolongation, such as macrolides, pentamidine, azole antifungals, fluoroquinolones [10] and methadone [11]. On the other hand, QT prolongation on ECGs of HIV-positive individuals is correlated to the duration of HIV infection rather than the anti-HIV treatment [12]. Moreover, QT prolongation is observed in HIV-positive individuals under no medication recognized to prolong QT [13], suggesting a role for the virus itself in inducing LQTS. In addition, several studies using animal models suggest a rather direct implication of HIV in LQTS. For instance, prolonged cardiac repolarization and decreased repolarizing potassium currents were observed in mice expressing the whole HIV-1 genome $[14,15]$.

Among the $\sim 15$ proteins encoded by the virus, Tat appears as a potential candidate for inducing ventricular arrhythmias, as it prolongs the action potential of guinea-pig ventricular cardiomyocytes through a reduction in the hERG-related current, $\mathrm{I}_{\mathrm{Kr}}$ [16]. Noteworthy, serum levels of Tat remain high in treated patients, which could explain the high prevalence in prolonged QT interval despite antiretroviral therapies [12, 17]. Among the documented properties of Tat in cells, it was shown that its affinity for phosphatidylinositol-(4,5)bisphosphate $\left(\mathrm{PIP}_{2}\right)$ is very high, the dissociation constant $\left(\mathrm{K}_{\mathrm{d}}\right)$ being in the low nanomolar 
range [18]. QT prolongation is majorly associated with the inhibition of two major cardiac delayed rectifier potassium currents: $\mathrm{I}_{\mathrm{Ks}}$ and $\mathrm{I}_{\mathrm{Kr}}$, respectively carried by KCNQ1 channels associated with the regulatory subunit KCNE1 and hERG channels [19]. Interestingly enough, both KCNQ1 and hERG are positively regulated by $\mathrm{PIP}_{2}$ [20, 21]. We thus hypothesized that Tat inhibits these channels by sequestering membrane $\mathrm{PIP}_{2}$, leading to long QT syndrome in HIV patients.

In order to test this hypothesis, we evaluated the effect of Tat on cells expressing KCNQ1 or hERG channels. Tat over-expression led to a decrease in hERG and KCNE1-KCNQ1 currents and modification of their biophysical parameters, in particular an acceleration of deactivation. A mutant Tat with a profound decrease in $\mathrm{PIP}_{2}$ affinity has no effect on these current and WTTat has no effect on a PIP $_{2}$ insensitive mutant KCNQ1 channel, consistent with Tat acting through a reduction in available $\mathrm{PIP}_{2}$. In human cardiomyocytes derived from induced pluripotent stem cells, 24-h Tat incubation led to a decrease in cardiac $\mathrm{I}_{\mathrm{Kr}}$ and acceleration of its deactivation, and these effects were associated with a prolongation of the action potential duration. Altogether, these observations suggest that in HIV-positive individuals, Tat sequesters $\mathrm{PIP}_{2}$, leading to a decrease in $\mathrm{I}_{\mathrm{Kr}}$ and $\mathrm{I}_{\mathrm{Ks}}$ currents, providing a basis for QT prolongation. 


\section{MATERIALS AND METHODS}

\subsection{Tat protein preparation}

Recombinant Tat was purified from Escherichia coli as previously described [22], resuspended as a $200 \mu \mathrm{g} / \mathrm{ml}$ stock solution in citrate buffer $(110 \mathrm{mM}$ sodium chloride, $30 \mathrm{mM}$ sodium citrate, $20 \mathrm{mM}$ sodium phosphate, $\mathrm{pH} 7.3$ ), and stored at $-80^{\circ} \mathrm{C}$. BCA protein assay (Pierce) was used to measure Tat protein concentration. Tat transactivation activity was confirmed as previously described [23]. Briefly, COS-7 cells were cultured in 24-well plates and cotransfected using FuGENE 6 (Promega) with $0.22 \mu \mathrm{g} /$ well pGL3-LTR, encoding firefly luciferase under the control of Tat-activated HIV-1-LTR promoter, and $1.78 \mu \mathrm{g} / \mathrm{well} \mathrm{pRL}-\mathrm{TK}$ (Promega), encoding Renilla luciferase under the control of Herpes simplex virus thymidine kinase promoter, to normalize the results. After $24 \mathrm{~h}, 2.3 \mu \mathrm{g} / \mathrm{ml}$ recombinant Tat (or the citrate buffer) and $100 \mu \mathrm{M}$ chloroquine (for Tat uptake) were added. One day later, cells were lysed for determination of dual firefly/Renilla luciferase activity ratio (Supplemental figure 1). Twenty-four hours before patch-clamp measurements and immunofluorescence assays, Tat was diluted and cells were incubated at concentrations of $200 \mathrm{ng} / \mathrm{ml}(\sim 20 \mathrm{nM})$ or $400 \mathrm{ng} / \mathrm{ml}$ $(\sim 40 \mathrm{nM})$, consistent with patient serum levels [17].

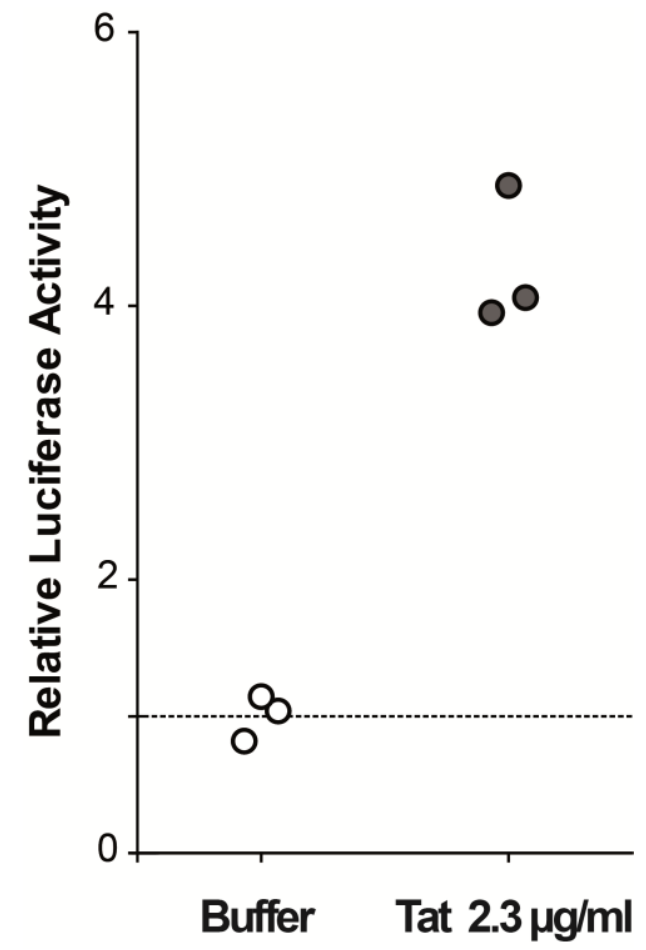

Supplemental figure 1: Tat protein is active in COS-7 cells. Firefly/Renilla luciferase activity ratio in luciferase-transfected COS-7 cells, either untreated (Buffer) or incubated with WT-Tat (Tat), in presence of chloroquine. Firefly luciferase expression is driven by a Tatdependent promoter while Renilla luciferase expression is insensitive to the presence of Tat and serves as an internal control. 


\subsection{Cell culture and transfection}

HEK293 cells stably expressing hERG (HEK-hERG; CreaCell; protein accession number: NP_000229.1) and COS-7 cells (American Type Culture Collection) were cultured in Dulbecco's modified Eagle's medium (Invitrogen) supplemented with 10\% fetal calf serum (Eurobio) and antibiotics (100 IU/ml penicillin and $100 \mu \mathrm{g} / \mathrm{ml}$ streptomycin; Gibco) at 5\% $\mathrm{CO}_{2}$ and $37^{\circ} \mathrm{C}$ in a humidified incubator. For HEK-hERG cells, hERG expression was maintained by the application of the selection antibiotic G418 (1200 $\mu \mathrm{g} / \mathrm{ml}$; Life Technologies).

When reaching 60-80\% cell confluence, COS-7 cells were transiently transfected in $35-\mathrm{mm}$ plates with $2 \mu \mathrm{g}$ of total DNA (as described below) complexed with FuGENE 6. For Tat and KCNE1-KCNQ1 co-transfection experiments, the ionic currents were obtained from a fusion protein of the human KCNE1 (protein accession number: AAA58418.1) linked to the Nterminus of the human KCNQ1 (protein accession number: NP_000209.2), a kind gift of Dr Robert S. Kass (Columbia University, New York, USA). DNA amounts were $200 \mathrm{ng}$ of pCDNA3.1-WT-KCNE1-KCNQ1 [21] or pCDNA3.1-KCNE1-R539W-KCNQ1 + $1.6 \mu \mathrm{g}$ of bidirectional pBI-WT-Tat or pBI-W11Y-Tat or pEGFP-C1 (Clontech) + 200 ng of pUHD15.1 (required for expression from pBI vector [18]). For Tat and hERG co-transfection experiments, DNA amounts were $600 \mathrm{ng}$ of pSI-hERG (protein accession number: NP_000229.1) [21] $+1.2 \mu \mathrm{g}$ of pBI-WT-Tat/GFP or pBI-W11Y-Tat/GFP bidirectional plasmid, or pEGFP-C1 (Clontech) + $200 \mathrm{ng}$ of pUHD-15.1. For Tat incubation experiments, DNA amounts were $600 \mathrm{ng}$ of pSI-hERG $+1.4 \mu \mathrm{g}$ of pEGFP-C1 (Clontech) or $200 \mathrm{ng}$ of pCDNA3.1-KCNE1-KCNQ1 + $1.8 \mu \mathrm{g}$ of pEGFP-C1 (Clontech). Cells were isolated, using trypsin, $24 \mathrm{~h}$ after transfection (of ion channels cDNA) for Tat incubation experiments or $48 \mathrm{~h}$ after transfection for Tat transfection experiments, and cultured in $35 \mathrm{~mm}$ plastic Petri dishes. In the latter case, medium was renewed $8 \mathrm{~h}$ before cells were split. For Tat incubation experiments, Tat or citrate buffer diluted in culture medium were applied 4-6 hours after cells splitting and treated cells were incubated at $37^{\circ} \mathrm{C}$. Experiments were performed the day after cell splitting.

\subsection{Culture of human induced pluripotent stem cells}

The previously characterized foreskin fibroblast-derived human induced pluripotent stem (hiPS) cell clone C2a was used [24]. The hiPS cell line was maintained on mitoticallyinactivated MEFs in DMEM/F12 medium supplemented with $2 \mathrm{mM}$ L-glutamine, $0.07 \% \beta$ mercaptoethanol, 20\% knockout serum replacement, $5 \mathrm{ng} / \mathrm{ml}$ bFGF and 1\% NEAA under low 
oxygen atmosphere $\left(4 \% \mathrm{O}_{2}\right)$. Cells were passaged by manual dissection of cell clusters every 6 to 7 days. Before cardiac differentiation, hiPS cells were manually transferred from MEFs to hESC-qualified matrigel-coated plates $(0.05 \mathrm{mg} / \mathrm{ml}, \mathrm{BD}$ Biosciences $)$ and cultured in StemMACS (iPS-Brew XF) medium (Miltenyi Biotec). Passages were performed using Gentle Cell Dissociation Buffer (StemCell Technologies).

\subsection{Differentiation of hiPS cells into cardiomyocytes and dissociation}

Human iPS cells were differentiated into cardiomyocytes using the Matrix sandwich method, as previously described $[25,26]$. Cardiomyocytes derived from hiPS cells (hiPS-CMs) were dissociated around day 20 of differentiation, for $20 \mathrm{~min}$ in collagenase II (200 U/ml; Gibco) at $37^{\circ} \mathrm{C}$. Isolated cells were then incubated at room temperature for $30 \mathrm{~min}$ in Kraft-Bruhe solution containing (in mmol/L): $\mathrm{KCl} 85, \mathrm{~K}_{2} \mathrm{HPO}_{4} 30, \mathrm{MgSO}_{4} 5$, EGTA 1, Na 2 -ATP 2, Napyruvate 5 , creatine 5 , taurine 20, and glucose 20, pH 7.2 [27]. For Tat immunofluorescence studies, dissociated hiPS-CMs were plated on IBIDI plates (Biovalley). Beating hiPS-CMs were cultured in RPMI1640 medium supplemented with B27 complete (Life Technologies) and $1 \%$ NEAA and changed every other day and used between day 10 and day 14 postdissociation.

\subsection{Single-cell electrophysiology in COS-7 and HEK-hERG cells}

In HEK-hERG and transfected COS-7 cells, currents were recorded at room temperature using the patch-clamp technique. The cells were continuously superfused with a HEPES buffered Tyrode solution containing (in mmol/L): $\mathrm{NaCl} 145, \mathrm{KCl} 4, \mathrm{MgCl}_{2} 1, \mathrm{CaCl}_{2} 1$, HEPES 5, glucose 5, $\mathrm{pH}$ adjusted to 7.4 with $\mathrm{NaOH}$. For $\mathrm{K}^{+}$current recordings, pipettes (Kimble Chase; tip resistance: 1.8 to $2.5 \mathrm{M} \Omega$ ) were filled with an intracellular medium containing (in mmol/L): $\mathrm{KCl} 100$, Kgluconate 45, $\mathrm{MgCl}_{2}$ 1, EGTA 5, HEPES 10, pH adjusted to 7.2 with $\mathrm{KOH}$. All products were purchased from Sigma. Stimulation and data recording were performed with Axon pClamp 10 through an A/D converter (Digidata 1440A) using an Axopatch 200B (all Molecular Devices). hERG current ( $\left.\mathrm{I}_{\mathrm{hERG}}\right)$ density was measured using a depolarization from $-80 \mathrm{mV}$ to $+60 \mathrm{mV}$ for $2 \mathrm{~s}$ and repolarization to $-40 \mathrm{mV}$ for $2 \mathrm{~s}$ where the tail current was measured (stimulation frequency: $0.125 \mathrm{~Hz}$ ). Activation curve was obtained by a series of 2-s depolarizations from -80 to $+50 \mathrm{mV}$ (same holding potential and frequency as above, increment: $10 \mathrm{mV}$ ) followed by a 2-s repolarization to $-40 \mathrm{mV}$. Inactivation was studied with a three-pulse protocol: a 1-s depolarization from $-80 \mathrm{mV}$ to $+40 \mathrm{mV}$ was followed by a $15-\mathrm{ms}$ repolarization to potentials ranging from +30 to $-130 \mathrm{mV}$ and a $500-\mathrm{ms}$ 
depolarization to $+40 \mathrm{mV}$ where the remaining current was measured $(0.2 \mathrm{~Hz})$. Kinetics of deactivation were evaluated by a two-exponential regression of the decaying current recorded at various potentials from -70 to $-130 \mathrm{mV}$ (3-s duration), after a 2-s depolarization from -80 $\mathrm{mV}$ to $+40 \mathrm{mV}(0.125 \mathrm{~Hz})$. The same protocol was used to evaluate the recovery from inactivation kinetics by fitting the rising phase of the current, before deactivation, with a single exponential function. Finally, inactivation kinetics were studied with another threepulse protocol: a 1-s depolarization from $-80 \mathrm{mV}$ to $+60 \mathrm{mV}$ was followed by a $25-\mathrm{ms}$ repolarization to $-110 \mathrm{mV}$ and 500 -ms-depolarizations to potentials ranging from +60 to -60 $\mathrm{mV}$ where the inactivating current was fitted with a single exponential function $(0.2 \mathrm{~Hz})$. KCNE1-KCNQ1 current density was measured using depolarizations from a holding potential of $-80 \mathrm{mV}$ to various potentials from $-60 \mathrm{mV}$ to $+80 \mathrm{mV}$ for $4 \mathrm{~s}$ (or from $-60 \mathrm{mV}$ to $+120 \mathrm{mV}$ when comparing WT-Tat effect on WT KCNE1-KCNQ1 and KCNE1-R539W-KCNQ1) and repolarization to $-40 \mathrm{mV}$ for $1.2 \mathrm{~s}$ where the tail current was measured (increment: $20 \mathrm{mV}$, stimulation frequency: $0.125 \mathrm{~Hz}$ ). Fit of the non-normalized activation curves was used to estimate full-activated KCNE1-KCNQ1 current density for each cell.

\subsection{Action potential, $I_{K r}$, and $I_{C a, L}$ recordings in cardiomyocytes derived from hiPS cells}

Before recording, cells were incubated for $24 \mathrm{~h}$ either with citrate buffer or with $200 \mathrm{ng} / \mathrm{ml}$ $(20 \mathrm{nmol} / \mathrm{L})$ of Tat protein. Cells were continuously superfused with a cardiomyocyte Tyrode solution containing (in mmol/L): $\mathrm{NaCl} 140, \mathrm{KCl} 4, \mathrm{CaCl}_{2} 1, \mathrm{MgCl}_{2}$ 0.5, glucose 10, HEPES $10 ; \mathrm{pH} 7.4(\mathrm{NaOH})$ at $35 \pm 2{ }^{\circ} \mathrm{C}$ as previously described [26].

For action potential (AP) recording the permeabilized-patch configuration was used. The pipette (Sutter; tip resistance: 2 to $3 \mathrm{M} \Omega$ ) solution contained (in $\mathrm{mmol} / \mathrm{L}$ ): K-gluconate 125, $\mathrm{KCl} 20, \mathrm{NaCl} 5$, amphotericin B $0.85 \times 10^{-3}$, HEPES 5; pH $7.2(\mathrm{KOH})$. APs were recorded at spontaneous rate or stimulated by 1.3-1.5 ms current pulses of 300-1500 pA at various pacing cycle lengths. APs were classified as nodal-, atrial- and ventricular-like, based on their duration, maximum upstroke velocity $\left(\mathrm{dV} / \mathrm{dt}_{\max }\right)$, peak to peak duration, amplitude $(\mathrm{mV})$ and maximum diastolic potential, as previously defined [26].

For currents recording, the ruptured-patch configuration was used.

For $\mathrm{I}_{\mathrm{Kr}}$ recording, the pipette was filled with a solution containing (in $\mathrm{mmol} / \mathrm{L}$ ): K-gluconate 125, $\mathrm{KCl} 20$, HEPES 10, EGTA 10; pH $7.2(\mathrm{KOH})$. A local gravity microperfusion system allowed application of $4 \mu \mathrm{mol} / \mathrm{L}$ nifedipine to block $\mathrm{I}_{\mathrm{Ca}, \mathrm{L}}$ and $1 \mu \mathrm{mol} / \mathrm{L}$ E-4031 to block $\mathrm{I}_{\mathrm{Kr}}$ [28], dissolved in cardiomyocyte Tyrode solution plus mannitol $30 \mathrm{mmol} / \mathrm{L}$. 
$\mathrm{I}_{\mathrm{Kr}}$ tail current density was measured as the E-4031-sensitive current using a depolarization from $-50 \mathrm{mV}$ to $+60 \mathrm{mV}$ for $4 \mathrm{~s}$ and repolarization to $-50 \mathrm{mV}$ where the tail current was measured (stimulation frequency: $0.08 \mathrm{~Hz}$ ). Activation was evaluated by a series of 4-s depolarizations from -60 to $+20 \mathrm{mV}$ (holding potential: $-50 \mathrm{mV}$, increment: $10 \mathrm{mV}$, same frequency as above) followed by a repolarization to $-50 \mathrm{mV}$. Deactivating currents were fitted by a standard bi-exponential function.

$\mathrm{I}_{\mathrm{Ca}, \mathrm{L}}$ was recorded at room temperature. Wax-coated pipettes were filled with an intracellular medium containing (in mmol/L): $\mathrm{CsCl}_{2}$ 145, $\mathrm{NaCl} 5, \mathrm{CaCl}_{2}$ 2, MgATP 5, EGTA 5, HEPES 10, $\mathrm{pH}$ adjusted to 7.2 with $\mathrm{CsOH}$. During recording, the microperfusion system allowed application of an extracellular solution containing (in mmol/L): TEA-Cl 160, $\mathrm{CaCl}_{2} 5, \mathrm{MgCl}_{2}$ 1, glucose 10, HEPES 10, TTX 0.01, mannitol 20; pH $7.4(\mathrm{CsOH})$.

$\mathrm{I}_{\mathrm{Ca}, \mathrm{L}} \mathrm{I} / \mathrm{V}$ curve was evaluated by a series of $200-\mathrm{ms}$ depolarizations from a 3-s pre-pulse to -50 $\mathrm{mV}$ to potentials ranging from -60 to $+50 \mathrm{mV}$ (increment: $5 \mathrm{mV}$, stimulation frequency: 0.125 $\mathrm{Hz}$ ) followed by a repolarization to the holding potential at $-80 \mathrm{mV}$. Inactivation was studied with a two-pulse protocol: a 3-s depolarization to potentials ranging from -65 to $-5 \mathrm{mV}$ was followed by a 400-ms depolarization to $0 \mathrm{mV}$ where the peak current was measured (holding potential: $-50 \mathrm{mV}, 0.125 \mathrm{~Hz}$ ).

\subsection{IKATP recordings in mouse neonatal cardiomyocytes}

Single cell suspensions from 1-2 day-old mouse neonatal hearts were prepared in a semiautomated procedure by using the Neonatal Heart Dissociation kit and the gentleMACS ${ }^{\mathrm{TM}}$ Dissociator. Hearts were first excised from the mice then the ventricles were separated from the atrium. After gentleMACS ${ }^{\mathrm{TM}}$ dissociation, the cell supernatant was removed by centrifugation and the pellet was resuspended in culture medium containing Dulbecco's modified Eagle's medium (DMEM) supplemented with 10\% horse serum, 5\% fetal bovine serum and penicillin $(100 \mathrm{U} / \mathrm{mL}) /$ streptomycin $(100 \mu \mathrm{g} / \mathrm{mL})$, then the cells were plated on 65 $\mathrm{mm}$ diameter Petri dish $\left(\mathrm{Nunc}^{\mathrm{TM}}\right)$. After $2 \mathrm{~h}$ of initial plating, myocytes were resuspended in the same culture medium and plated on $35 \mathrm{~mm}$ diameter Petri dishes at a density of $6 \times 10^{4}$ cells per plate. Myocytes were maintained in culture for 48 hours.

Cells were continuously superfused with a cardiomyocyte Tyrode solution, as above, at $35 \pm$ $2{ }^{\circ} \mathrm{C}$. The pipette was filled with a solution containing (in $\mathrm{mmol} / \mathrm{L}$ ): $\mathrm{K}$-aspartate $85, \mathrm{KCl} 44$, Na-pyruvate 5, HEPES 10, EGTA 0.01; $\mathrm{MgCl}_{2} 3 ; \mathrm{pH} 7.2$ (KOH). During recording, a local gravity microperfusion system allowed application of $20 \mu \mathrm{mol} / 1$ glibenclamide [28], dissolved 
in an extracellular solution containing (in mmol/L): $\mathrm{NaCl} 140, \mathrm{KCl} 4, \mathrm{CoCl}_{2} 1, \mathrm{MgCl}_{2} 0.5$, mannitol 30, HEPES 10; pH $7.4(\mathrm{NaOH})$. From a holding potential of $-70 \mathrm{mV}$, followed by a 20 -ms step to $-20 \mathrm{mV}$, current was measured at the end of a $350 \mathrm{~ms}$ pulse to $+40 \mathrm{mV}(0.2 \mathrm{~Hz})$. After patch rupture, the outward current increased gradually due to dilution of cytosolic ATP into the pipette. When the current reached steady state, glibenclamide was added to the external solution to block the $\mathrm{I}_{\text {KATP }}$ current. A ramp protocol was used to monitor the current decrease upon glibenclamide application. From a holding potential of $-70 \mathrm{mV}$, a $20 \mathrm{~ms}$ step to $-110 \mathrm{mV}$ was applied followed by a $500 \mathrm{~ms}$ ramp from -110 to $+40 \mathrm{mV}$ (stimulation frequency, $0.2 \mathrm{~Hz}$ ). A step protocol was applied before and after glibenclamide application to measure the glibenclamide-sensitive current.

\subsection{Tat immunofluorescence}

Two types of histological analyses were performed, (1) one to study localization of transfected Tat in COS-7 cells, (2) another to study localization of incubated Tat in both COS7 and hiPS-CMs. (1) COS-7 cells were transfected with hERG and either WT- or W11YTat/GFP bidirectional plasmids as for patch-clamp experiments. Forty eight hours after transfection, cells were plated on IBIDI plates for $24 \mathrm{~h}$. (2) COS-7 cells were transfected with hERG plasmid only, and forty eight hours after transfection, cells were plated on IBIDI plates. Both COS-7 cells and dissociated hiPS-CMs were then incubated with Tat protein at $200 \mathrm{ng} / \mathrm{ml}$ for $24 \mathrm{~h}$.

Cells were fixed with $3.7 \%$ formaldehyde, permeabilized with $0.5 \%$ saponin and blocked with $1 \%$ PBS-BSA. All cells were then stained with mouse monoclonal antibody directed against HIV-1 Tat (SC-65912, Santa Cruz) and cells incubated with Tat were co-stained with goat polyclonal antibody directed against hERG (SC-15968, Santa Cruz) diluted in PBS. For all immunostainings, secondary antibody staining was performed using respectively Alexa 568 conjugated anti-mouse antibody and Alexa 488 conjugated anti-goat antibody (Molecular Probes). DAPI was used for nuclear staining. For Tat-transfected COS-7 cells, GFP was directly observed. Conventional imaging was performed using Nikon Confocal A1RSi and Super-resolution imaging using N-SIM (Structured Illumination Microscopy) microscope system (Nikon) equipped with a SR Apo $100 \times 1.49$ N.A.

\section{9. mRNA and Protein expression analysis}

For gene expression analysis, total RNA was extracted and reverse transcribed, from hiPSCMs and HEK-hERG cells, as previously described [26]. PCR amplification was performed 
using FAM-labeled TaqMan probes: ACTB (Hs99999903_m1), KCNH2 (Hs04234270-g1) and Troponin I (Hs00165957-m1).

For Western blot analysis, $60 \mu \mathrm{g}$ of protein lysate from hiPS-CMs or $10 \mu \mathrm{g}$ of protein lysate from HEK-hERG, both treated for $24 \mathrm{~h}$ with $200 \mathrm{ng} / \mathrm{ml}$ Tat or buffer were incubated with mouse antisera against hERG protein (Santa Cruz). Secondary antibody staining was performed using goat anti-mouse IgG-HRP antibody (Santa Cruz). Stain Free gel technology (Bio-Rad) was used as loading control for protein normalization: the amount of total proteins in each lane of the blot was calculated and used for normalization [29, 30].

\subsection{Data analysis}

Steady-state activation and inactivation curves were fitted with a single Boltzmann function using GraphPad Prism 5.02. Data are presented as mean \pm SEM when normally distributed or Tukey boxplots (Q1-Q3 boxes) when not. Statistical significance was estimated using Student's t-test, Mann-Whitney test, or two-way ANOVA for repeated measures when appropriate. Post-hoc test for multiple comparison (Holm-Sidak method) was performed when needed. A value of $\mathrm{p}<0.05$ was considered as the threshold for statistical significance. 


\section{RESULTS}

\subsection{Tat transfection leads to a decrease in hERG and KCNE1-KCNQ1 currents and acceleration of deactivation, consistent with a decrease in PIP $_{2}$ availability}

We first evaluated the effects of Tat co-expression with hERG or KCNQ1 fused to KCNE1 (KCNE1-KCNQ1) in COS-7 cells. This set of experiments allowed us to compare the effects of WT-Tat with those of W11Y-Tat, which presents a profoundly reduced $\mathrm{PIP}_{2}$ affinity, although having a normal transactivation activity [18]. In contrast with WT-Tat, this mutant cannot enter the cells and thus, testing the effects of its intracellular application requires its transfection. Figure 1A shows representative hERG current recordings in cells co-transfected with GFP, WT-Tat, or W11Y-Tat. $\mathrm{I}_{\mathrm{hERG}}$ density was reduced in presence of WT-Tat as compared to GFP. In order to test whether this is due to a reduction in $\mathrm{PIP}_{2}$ availability, we evaluated the effects of the W11Y-Tat. Consistent with the hypothesis, we did not observe any alteration of the hERG current. It was shown that a decrease in $\mathrm{PIP}_{2}$ leads to a destabilization of hERG open state, provoking a reduction in the current amplitude and an acceleration in channel deactivation without any shift of the activation curve to positive potentials [21]. In accordance with a $\mathrm{PIP}_{2}$-reduction effect, WT-Tat and not W11Y-Tat led to the same changes in current density and deactivation without any shift in the activation curve (Figure 1B-D, Table 1). These data suggest that Tat inhibits hERG by sequestering $\mathrm{PIP}_{2}$.

For KCNE1-KCNQ1 also, a decrease in $\mathrm{PIP}_{2}$ availability leads to a decrease in current density and an acceleration of deactivation [20]. Again, WT-Tat but not W11Y-Tat led to the same effects as when the channel interaction with $\mathrm{PIP}_{2}$ is altered (Figure 1E-H, Table 1). To confirm the hypothesis that Tat reduces the current amplitude of delayed rectifier currents through a decrease in available PIP $_{2}$, we tested the effect of Tat on the mutant KCNE1R539W-KCNQ1 channel that is insensitive to PIP $_{2}$ depletion, when triggered by wortmannin application or by CiVSP phosphatase activation [31]. We compared current amplitude in cells expressing KCNE1-R539W-KCNQ1 in the absence and presence of Tat (Figure 2). As opposed to WT KCNE1-KCNQ1, Tat expression did not affect KCNE1-R539W-KCNQ1 current amplitude measured after channel full activation, reinforcing the interpretation that Tat decreases KCNE1-KCNQ1 channel activity through a decrease in available PIP 2.

Altogether, these data strongly suggest that Tat inhibits hERG and KCNE1-KCNQ1 currents by sequestering $\mathrm{PIP}_{2}$. 


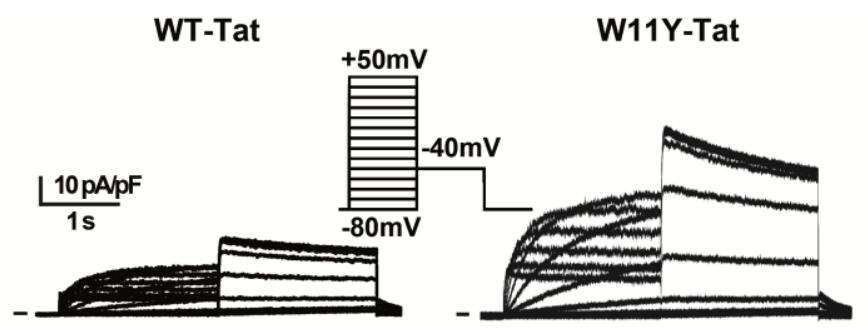

B

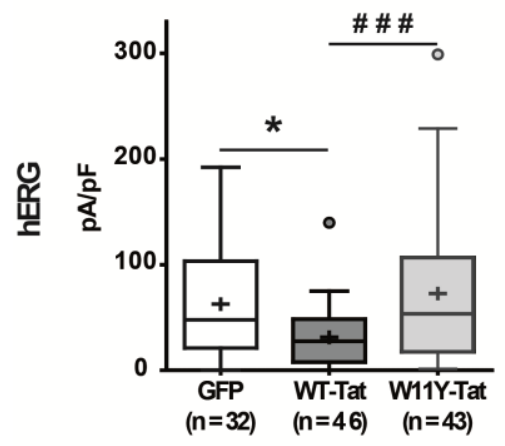

E
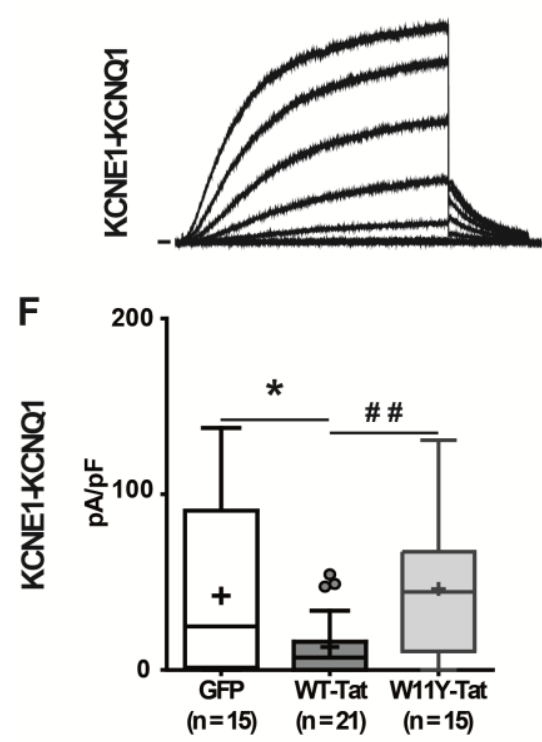

C

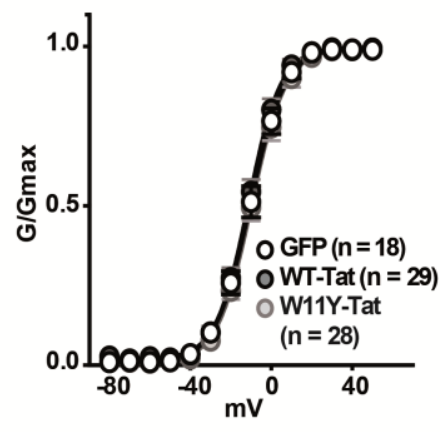

WT-Tat
D

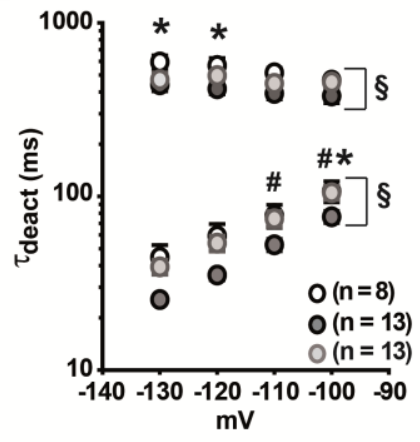

W11Y-Tat

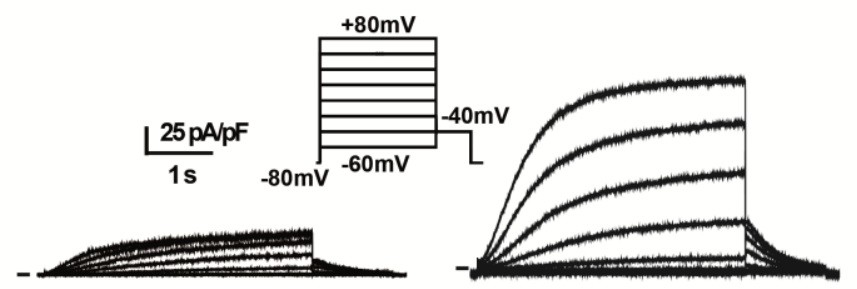

G
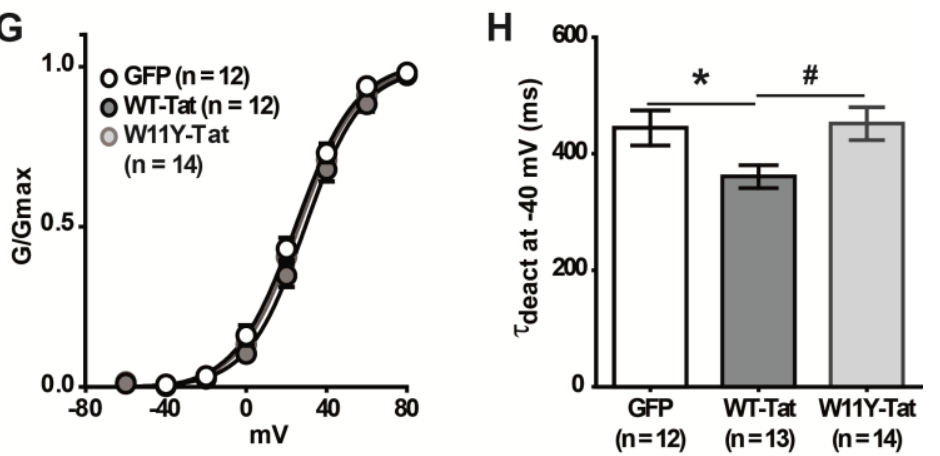

Figure 1: Tat transfection alters hERG and KCNE1-KCNQ1 currents in COS-7 cells. (A) Representative superimposed current recordings in COS-7 cells co-transfected with hERG, and either GFP, WT-Tat/GFP or W11Y-Tat/GFP, a mutant with reduced PIP $_{2}$ affinity. (B) Tukey boxplots presenting hERG maximal tail current densities; (C) activation curves and (D) time constants of deactivation (fast and slow) versus voltage in the same conditions as in A. The fast component represents 80 to $90 \%$ of the deactivating current, depending on the potential, with no effect of Tat. (E) Representative current recordings in COS-7 cells cotransfected with KCNE1-KCNQ1, and either GFP, WT-Tat/GFP or W11Y-Tat/GFP. (F) Tukey boxplots presenting KCNE1-KCNQ1 maximal tail current densities; $(G)$ activation curve and $(\mathrm{H})$ time constants of deactivation at $-40 \mathrm{mV}$ in the same conditions as in E. Current densities differences were statistically evaluated using a Mann-Whitney test, hERG $\tau_{\text {deact }}$ using a two-way ANOVA for repeated measurements, and KCNE1-KCNQ1 $\tau_{\text {deact }}$ at -40 $\mathrm{mV}$ using Student t-test. * $\mathrm{p}<0.05$; for WT-Tat $v$ s GFP. \# $\mathrm{p}<0.05$; \#\# $\mathrm{p}<0.01$; \#\#\# $\mathrm{p}<$ 0.001 for W11Y-Tat $v s$ WT-Tat. $\S \mathrm{p}<0.05$. 
Table 1: Tat transfection alters hERG and KCNE1-KCNQ1 currents in COS-7 cells: biophysical characteristics.

\begin{tabular}{|l|c|c|c|c|c|c|}
\hline \multirow{2}{*}{ Tat transfected } & \multicolumn{3}{|c|}{ COS-7 hERG } & \multicolumn{3}{c|}{ COS-7 KCNE1-KCNQ1 } \\
\cline { 2 - 7 } & GFP & WT-Tat & W11Y-Tat & GFP & WT-Tat & W11Y-Tat \\
\hline Current density & $(32)$ & $(46)$ & $(43)$ & $(15)$ & $(21)$ & $(15)$ \\
\hline $\begin{array}{l}\text { at 60 mV } \\
\text { (pA/pF) }\end{array}$ & $62.6 \pm 9.5$ & $31.2 \pm 3.9^{*}$ & $72.6 \pm 10.4^{\# \#}$ & $42.2 \pm 13.1$ & $13.0 \pm 3.9^{*}$ & $46 \pm 10.3^{\#}$ \\
\hline Activation & $(18)$ & $(29)$ & $(28)$ & $(12)$ & $(12)$ & $(14)$ \\
\hline $\mathbf{V}_{\mathbf{1} / \mathbf{2}}(\mathbf{m V})$ & $-10.2 \pm 1.7$ & $-11.1 \pm 1.5$ & $-8.98 \pm 1.6$ & $24.6 \pm 2.3$ & $29.9 \pm 2.3$ & $26.6 \pm 1.9$ \\
$\mathbf{K}(\mathbf{m V})$ & $7.6 \pm 0.3$ & $6.8 \pm 0.1^{* *}$ & $7.1 \pm 0.1$ & $13.4 \pm 0.7$ & $13.5 \pm 0.6$ & $13.9 \pm 0.4$ \\
\hline
\end{tabular}

(n): number of cells; Student t-test, *: $\mathrm{p}<0.05,{ }^{* *}$ : $\mathrm{p}<0.01$ vs GFP; \#\#: $\mathrm{p}<0.01$; \#\#: $\mathrm{p}<$ 0.001 vs WT-Tat; $\mathrm{V}_{1 / 2}$ and $\mathrm{K}$ : voltage for half-activation or -inactivation of the $\mathrm{K}^{+}$currents and slope.

A

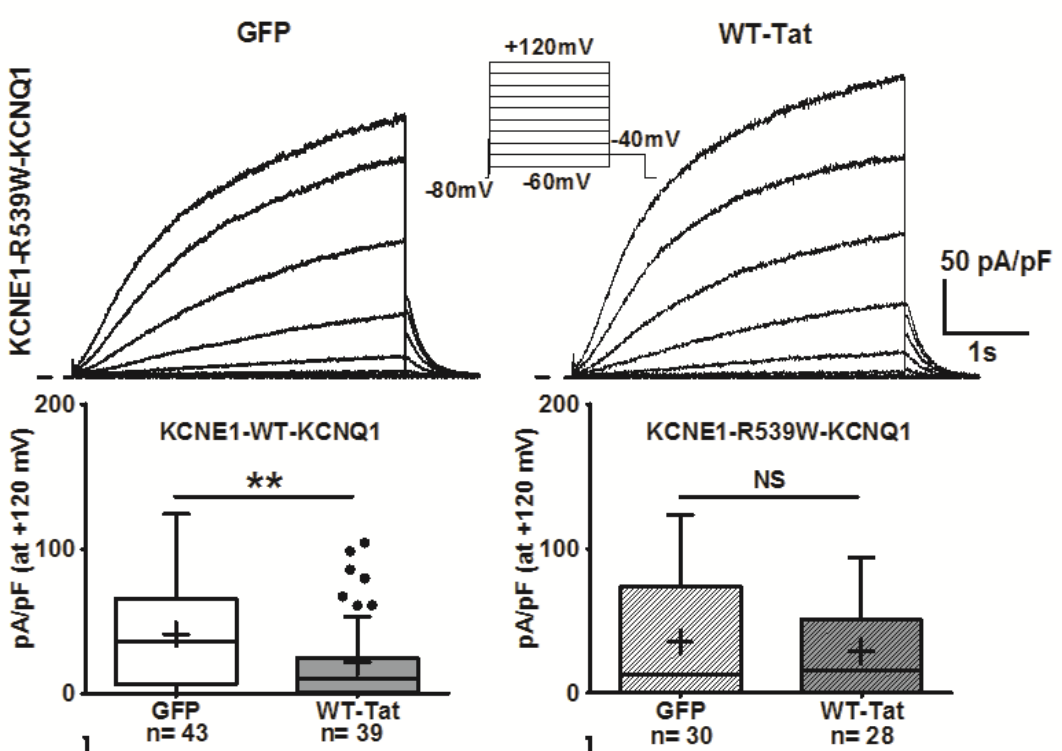

C
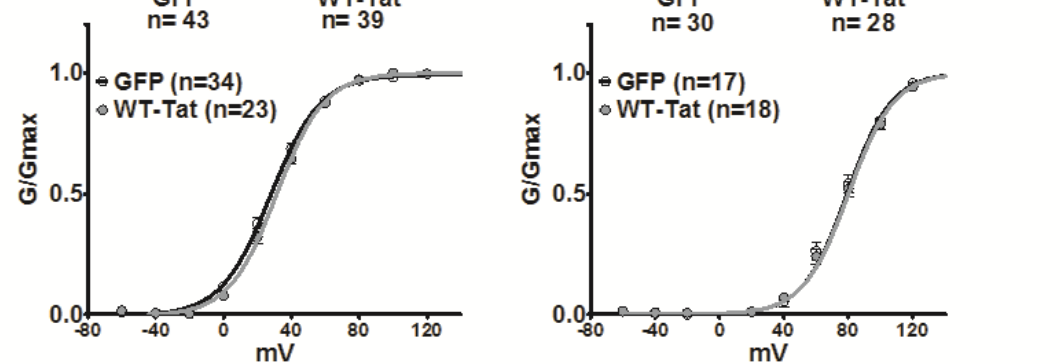

Figure 2: Tat transfection does not alter the PIP $_{2}$ insensitive mutant KCNE1-R539WKCNQ1 currents in COS-7 cells. (A) Representative superimposed current recordings in COS-7 cells co-transfected with KCNE1-R539W-KCNQ1, and either GFP (left) or WTTat/GFP (right). (B) Tukey boxplots presenting WT-Tat effect on WT (left) or KCNE1R539W-KCNQ1 (right) maximal tail current densities, using the same stimulation protocol as in A (depolarization up to $+120 \mathrm{mV}$ ); (C) activation curve in the same conditions as in A. Current densities differences were statistically evaluated using a Mann-Whitney test. ${ }^{* *} \mathrm{p}<$ 0.01 . 
To localize Tat, immunofluorescence assays were performed using the same conditions as for patch-clamp experiments, i.e. cotransfection of hERG with either WT- or W11Y-Tat/GFP bidirectional plasmids. They confirmed that WT-Tat localizes at the COS-7 plasma membrane, through its interaction with $\mathrm{PIP}_{2}$ [32]. Unlike WT-Tat, W11Y-Tat localized diffusely in the cytosol, its lack of affinity for $\mathrm{PIP}_{2}$ preventing its plasma membrane localization (Figure $3 \mathrm{~A} \& \mathrm{~B}$ ). This is consistent with the absence of W11Y-Tat effect on $\mathrm{PIP}_{2}$ dependent channels activity.

A
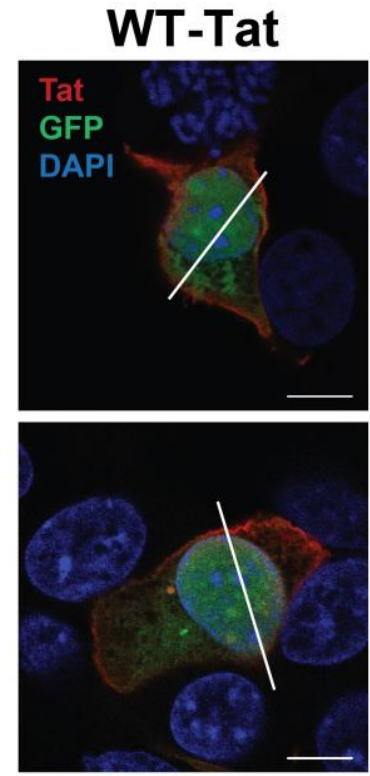

B
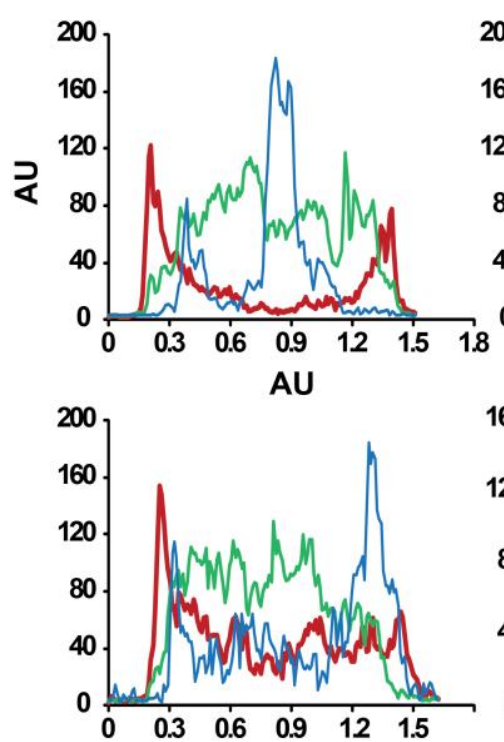

W11Y-Tat
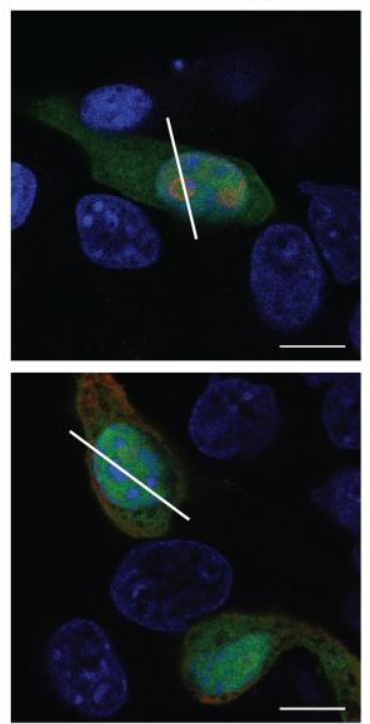

W11Y-Tat
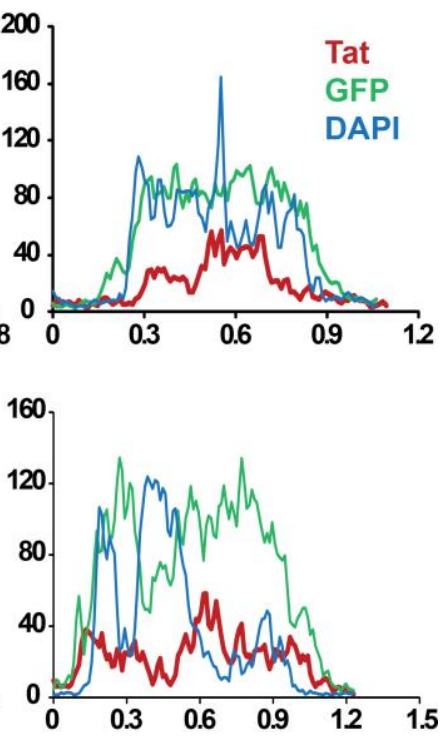

Figure 3: WT-Tat but not W11Y-Tat localizes at the plasma membrane in COS-7 cells. (A) Representative confocal immunostainings of, in red, WT-Tat or W11Y-Tat in transfected COS-7 cells. GFP is used as a transfection reporter. Nuclei are stained with DAPI. Scale $=10$ $\mu \mathrm{m}$. (B) Surface plots of Tat, GFP and DAPI fluorescence intensities in each cell at the level 
of the drawn lines in A. Higher WT-Tat densities are observed in the region of the plasma membrane, as opposed to W11Y-Tat.

\subsection{Tat incubation does not alter hERG and KCNE1-KCNQ1 currents in heterologous expression systems}

In HIV patients, T-cells-secreted Tat can enter multiple cell types, through the interaction with various ubiquitous receptors [18]. We thus tested the effect of Tat applied externally on hERG and KCNE1-KCNQ1 channels activity. We first studied the effect of Tat 24-h incubation in HEK293 cells stably expressing hERG channels. We chose a 24-h incubation since in the different biological assays in which Tat had been tested (neurosecretion [32] and phagocytosis [33]), it was found to require some time (3-4 hours) for Tat, after initial internalization, to accumulate on $\mathrm{PIP}_{2}$ and to perturb processes relying on this phosphoinositide. Moreover such a 24-h incubation, and not acute application, had already been associated with a decrease in hERG current density in this model [16]. Surprisingly and unlike the previous observations, Tat incubation (200 or $400 \mathrm{ng} / \mathrm{ml})$ did not induce any change (Supplemental figure 2A; Supplemental table 1). In addition, neither activation nor inactivation curves were modified by Tat incubation (Supplemental figure $2 \mathrm{~B} \& \mathrm{D}$; Supplemental table 1), nor the kinetics of deactivation, inactivation and recovery from inactivation (Supplemental figure 2C, E \& F). In addition, neither mRNA nor total hERG protein levels were affected (Supplemental figure 2G \& H). Tat entry into cells occurs through receptors of which expression vary from one cell type to another [34]. The observed absence of Tat effect may then be due to insufficient penetration into HEK cells. In order to evaluate whether the cell type could explain the absence of incubated Tat effect on $\mathrm{I}_{\mathrm{hERG}}$, this analysis was repeated in COS-7 cells transiently expressing hERG (Supplemental figure 3). Again $200 \mathrm{ng} / \mathrm{ml}$ Tat incubation did not lead to any change in either hERG current density or biophysical parameters. In addition, we did not observe any effect of Tat incubation on KCNE1-KCNQ1 channel activity in COS-7 cells (Supplemental figure 4). 
Supplemental table 1: Tat incubation has no effect on hERG and KCNE1-KCNQ1 currents in heterologous expression systems: biophysical characteristics.

\begin{tabular}{|l|c|c|c|c|c|c|c|}
\hline \multirow{2}{*}{ Tat incubated } & \multicolumn{3}{|c|}{ HEK-hERG } & \multicolumn{2}{c|}{ COS-7-hERG } & \multicolumn{2}{c|}{ COS-7-KCNE1-KCNQ1 } \\
\cline { 2 - 8 } & Buffer & $\begin{array}{c}\text { Tat 200 } \\
\text { ng/ml }\end{array}$ & $\begin{array}{c}\text { Tat 400 } \\
\text { ng/ml }\end{array}$ & Buffer & $\begin{array}{c}\text { Tat 200 } \\
\text { ng/ml }\end{array}$ & Buffer & $\begin{array}{c}\text { Tat 200 } \\
\text { ng/ml }\end{array}$ \\
\hline Current density & $(23)$ & $(14)$ & $(14)$ & $(38)$ & $(35)$ & $(19)$ & $(19)$ \\
\hline $\begin{array}{l}\text { at 60 mV } \\
(\mathbf{p A} / \mathbf{p F})\end{array}$ & $19.5 \pm 2.0$ & $23.3 \pm 3.7$ & $18.9 \pm 2.9$ & $54.6 \pm 10.9$ & $39.9 \pm 7.3$ & $31.7 \pm 7.5$ & $42.0 \pm 8.6$ \\
\hline Activation & $(16)$ & $(11)$ & $(12)$ & $(18)$ & $(22)$ & $(11)$ & $(11)$ \\
\hline $\mathbf{V}_{\mathbf{1} / \mathbf{2}}(\mathbf{m V})$ & $-26.9 \pm 1.4$ & $-25.0 \pm 2.8$ & $-26.6 \pm 1.4$ & $-11.1 \pm 1.4$ & $-15.1 \pm 1.8$ & $26.6 \pm 4.6$ & $26.7 \pm 4.3$ \\
$\mathbf{K}(\mathbf{m V})$ & $7.4 \pm 0.2$ & $7.6 \pm 0.3$ & $7.5 \pm 0.1$ & $7.0 \pm 0.3$ & $6.5 \pm 0.2$ & $16.6 \pm 1.4$ & $15.4 \pm 0.6$ \\
\hline Inactivation & $(12)$ & $(5)$ & $(8)$ & $(8)$ & $(6)$ & & \\
\hline $\mathbf{V}_{\mathbf{1} / \mathbf{2}}(\mathbf{m V})$ & $-66.3 \pm 1.4$ & $-67.2 \pm 3.2$ & $-71.0 \pm 2.1$ & $-54.6 \pm 7.3$ & $-57.3 \pm 2.4$ & - & - \\
$\mathbf{K}(\mathbf{m V})$ & $20.7 \pm 0.4$ & $20.9 \pm 0.5$ & $20.3 \pm 0.7$ & $22.6 \pm 0.6$ & $20.4 \pm 0.7$ & - & - \\
\hline
\end{tabular}

(n): number of cells; Student t-test. $\mathrm{V}_{1 / 2}$ and $\mathrm{K}$ : voltage for half-activation or -inactivation of the $\mathrm{K}^{+}$currents and slope. 
A HEK-hERG

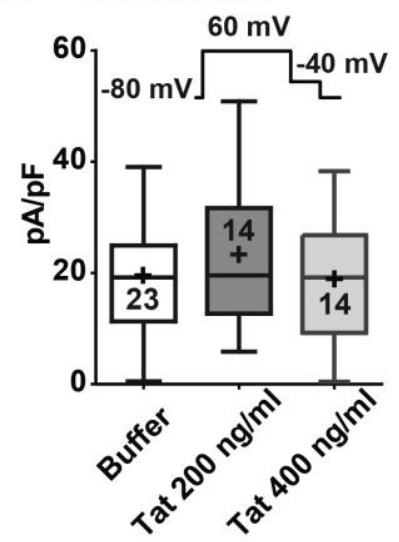

D

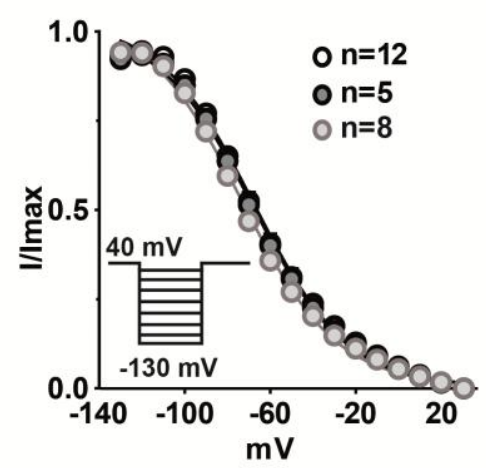

G

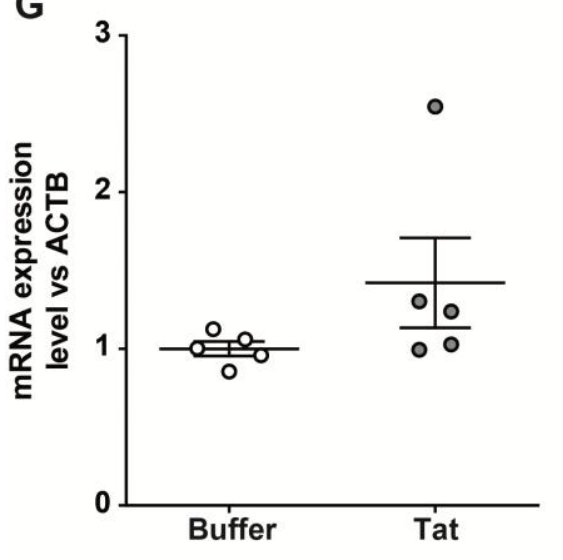

B

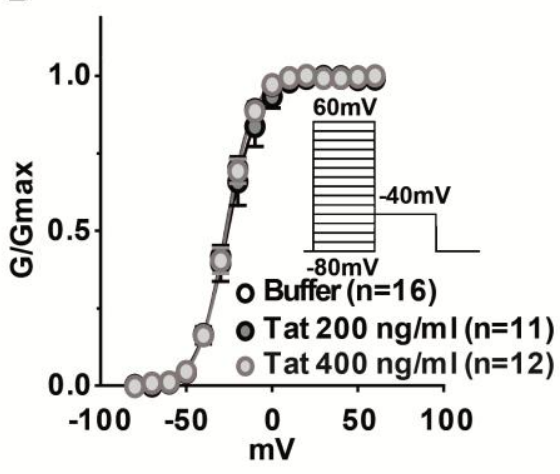

E

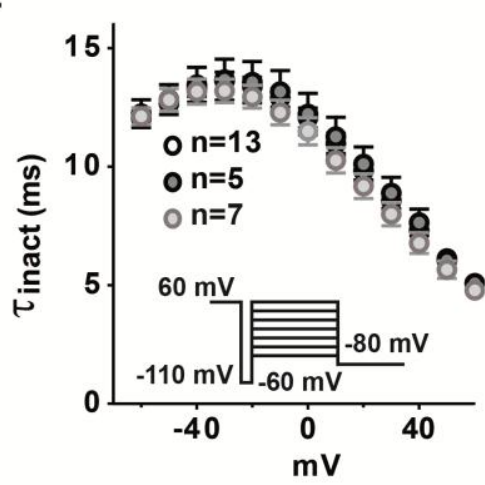

C

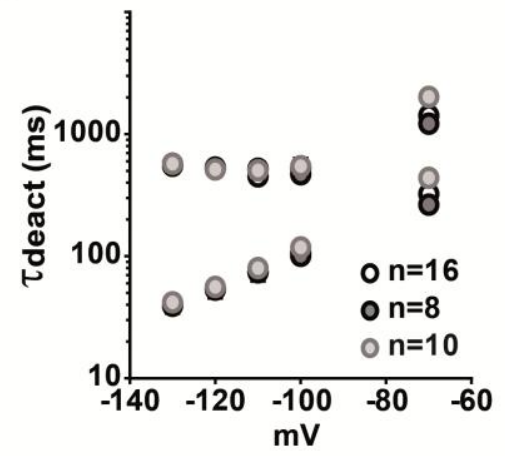

$\mathbf{F}$

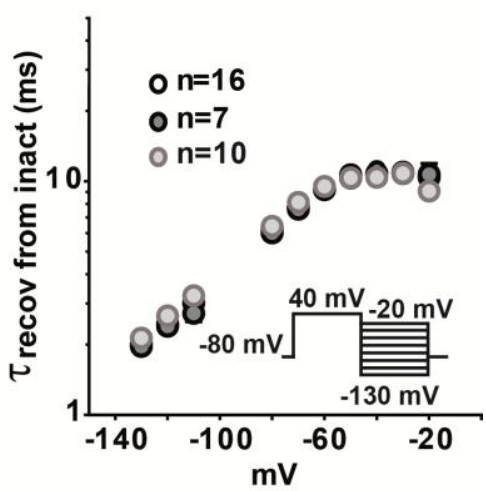

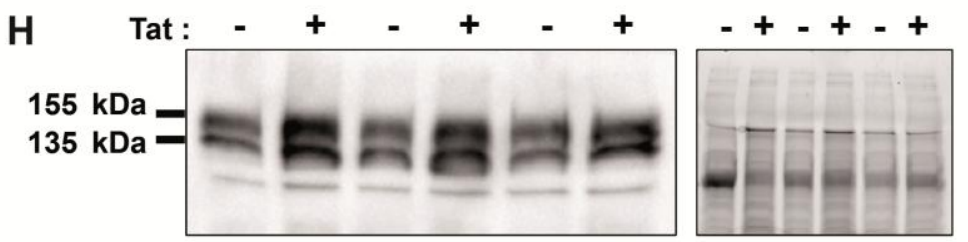
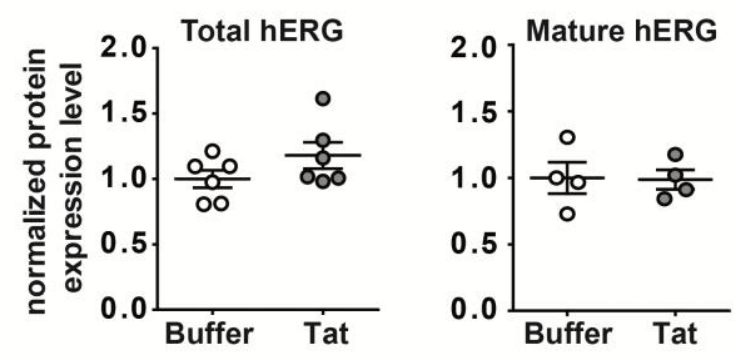

Supplemental figure 2: Tat incubation has no effect on hERG current in HEK-hERG cells. (A) Tukey boxplots presenting hERG tail current densities incubated with buffer, 200 $\mathrm{ng} / \mathrm{ml}$ or $400 \mathrm{ng} / \mathrm{ml}$ WT-Tat (Tat). (B) Activation curve measured from the tail current densities; (C) time constants of deactivation (fast and slow) versus voltage; (D) inactivation curve; (E) time constants of inactivation versus voltage; (F) time constants of recovery from inactivation versus voltage in the same conditions as A. The protocols used are shown as insets. The same protocol is used for (C) and (F). (G) hERG mRNA expression level versus ACTB mRNA. (H) Top left: Western blot analysis of hERG protein expression in HEKhERG cells. Two hERG specific bands were revealed (mature, glycosylated membrane subunit, $155 \mathrm{kDa}$, and immature, non-glycosylated cytoplasmic subunit, $135 \mathrm{kDa}$ ). Top right: Stain-free expression served as internal control of gel loading. Bottom: Normalized intensity quantification of the total and mature hERG bands. 
A Cos-7

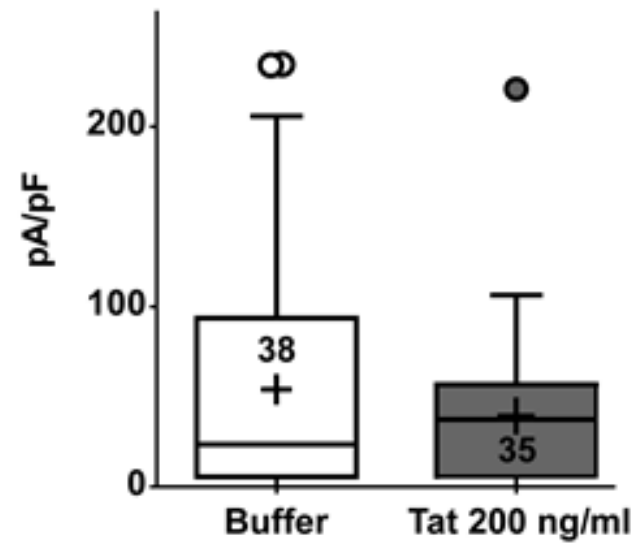

C

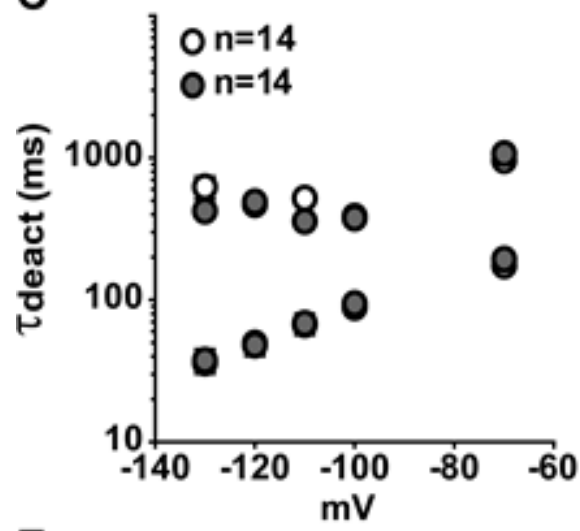

E

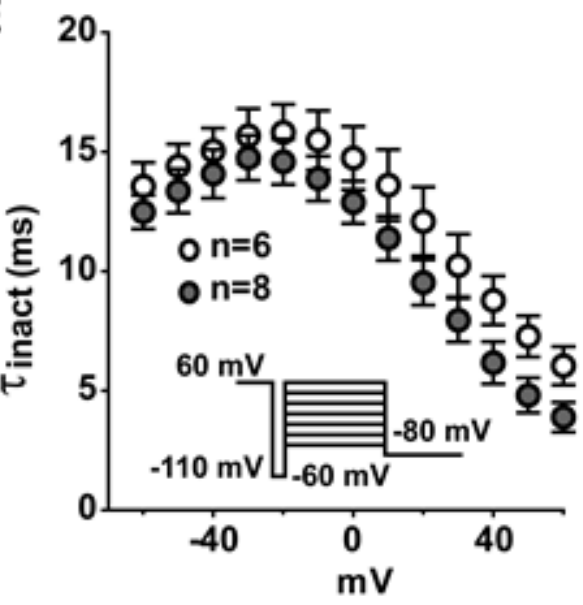

B $\quad 60 \mathrm{mv}$

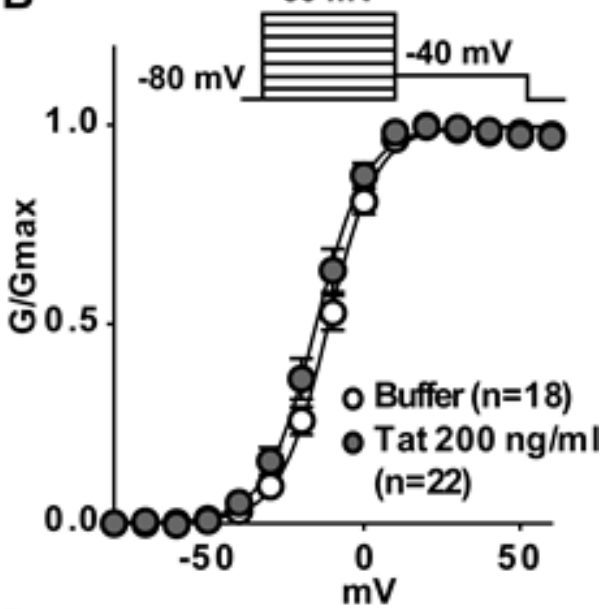

D

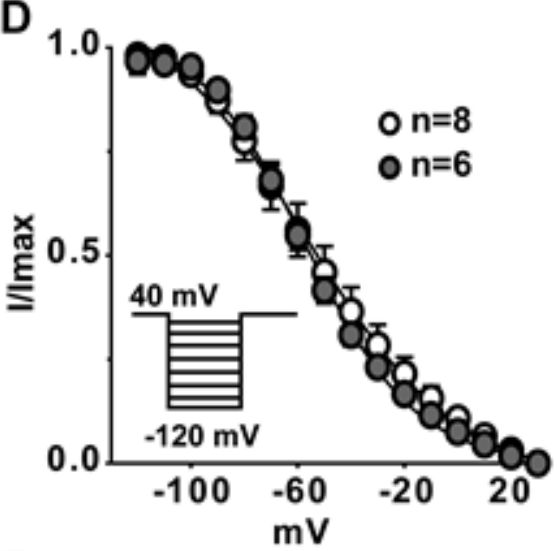

$\mathbf{F}$

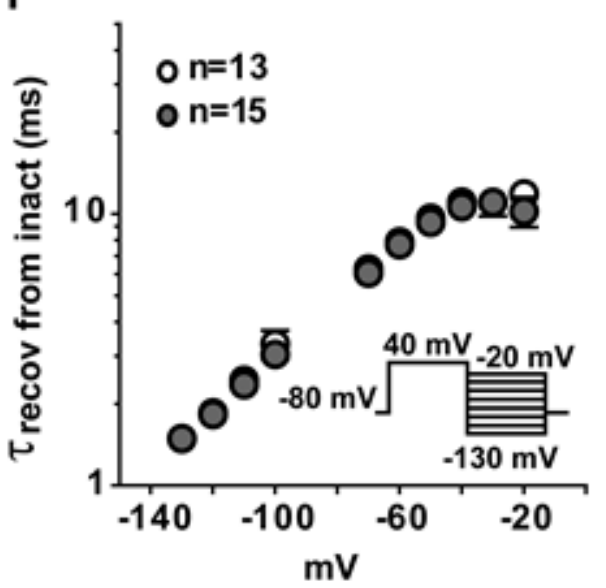

Supplemental figure 3: Tat incubation has no effect on hERG current in transfected COS-7 cells. (A) Tukey boxplots presenting hERG tail current densities recorded from cells incubated with buffer or $200 \mathrm{ng} / \mathrm{ml}$ WT-Tat (Tat). (B) Activation curves measured from the tail currents; (C) time constants of deactivation (fast and slow) versus voltage; (D) inactivation curves; (E) time constants of inactivation versus voltage; $(\mathrm{F})$ time constants of recovery from inactivation versus voltage in the same conditions as A. The protocols used are shown as insets. The same protocol is used for $(\mathrm{C})$ and $(\mathrm{F})$. 
A $\quad$ cos-7

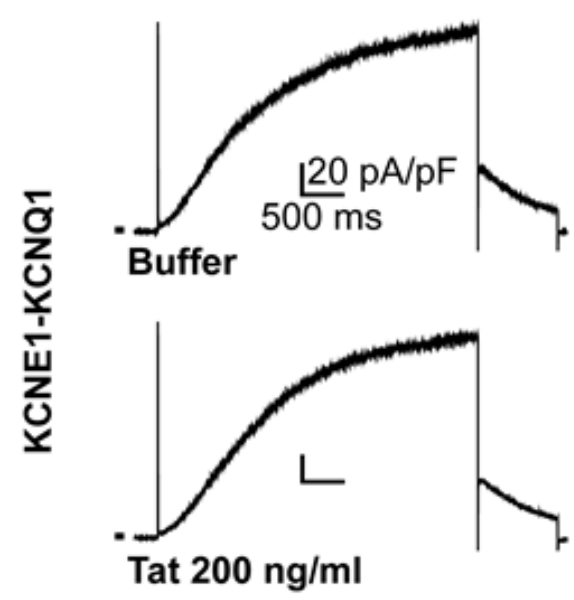

C

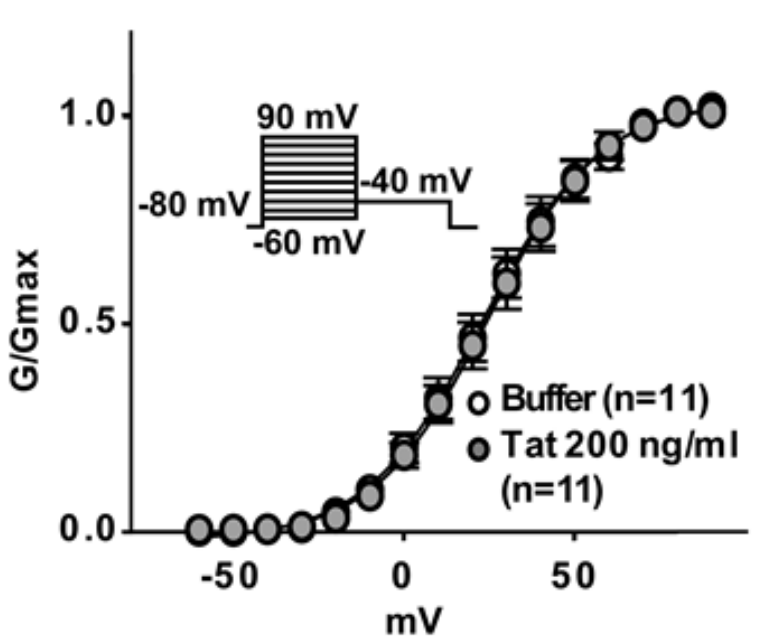

B

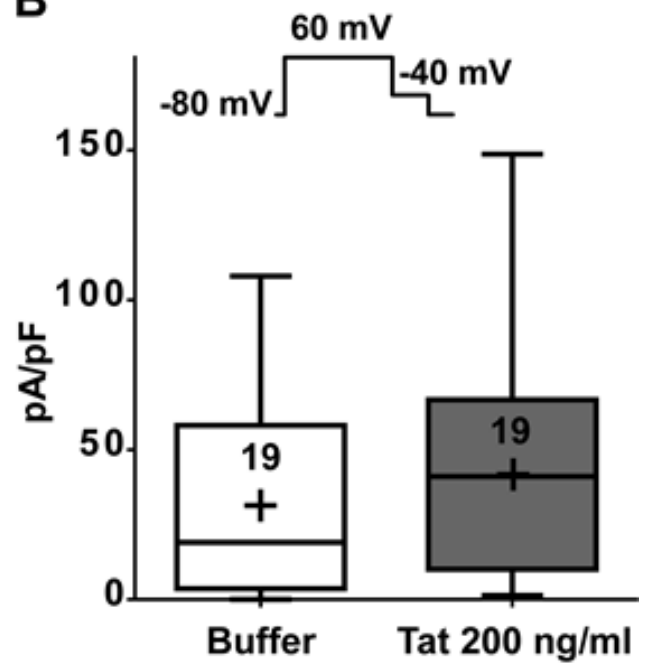

D

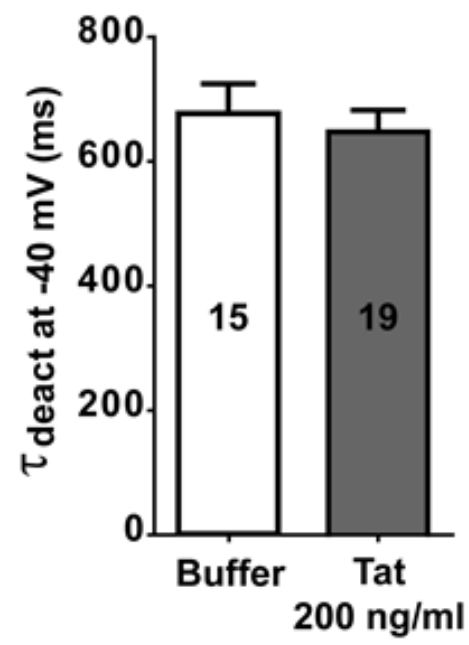

Supplemental figure 4: Tat incubation has no effect on KCNE1-KCNQ1 current in transfected COS-7 cells. (A) Representative current recordings in COS-7 cells transfected with KCNE1-KCNQ1, and incubated with either buffer or $200 \mathrm{ng} / \mathrm{ml}$ WT-Tat (Tat; voltage protocol in B). (B) Tukey boxplots presenting KCNE1-KCNQ1 tail current densities; (C) activation curves and (D) time constants of deactivation at $-40 \mathrm{mV}$ in the same conditions as in A.

3.3. Tat incubation decreases $I_{K r}$ in cardiomyocytes derived from human induced pluripotent stem cells

Cardiomyocytes differentiated from hiPS cells provided us with the opportunity to evaluate the effect of Tat incubation on a more relevant cellular model than non-cardiac cells. As shown in figure $4 \mathrm{~A} \& \mathrm{~B}, \mathrm{I}_{\mathrm{Kr}}$, isolated as the E-4031-sensitive current, was significantly reduced in hiPS-CMs incubated for $24 \mathrm{~h}$ with $200 \mathrm{ng} / \mathrm{ml}$ Tat. After full activation, the maximum tail E-4031-sensitive current density measured at $-50 \mathrm{mV}$ was reduced by $31 \%$ 
(Figure 4B; Table 2; $\mathrm{p}<0.05$ ). In addition, no detectable $\mathrm{I}_{\mathrm{Ks}}$ was observed after E-4031application. Thus, activation curve and deactivation kinetics were measured using the total $\mathrm{K}^{+}$ tail current. The activation curve was not modified but the current deactivation was accelerated (Figure 4C \& D; Table 2, p < 0.05). Therefore, we observed similar effect of Tat on the activation gate as compared to the experiments in Tat-transfected COS-7 cells, reminiscent of the effect of a decrease in $\mathrm{PIP}_{2}$. This suggests that hiPS-CMs express receptors allowing Tat integration in sufficient quantity to alter the currents, as opposed to COS-7 and HEK293 cellular models. We directly tested this hypothesis using confocal and Structured Illumination Microscopy (SIM) imaging on Tat-incubated COS-7 cells expressing hERG, and hiPS-CMs. Confocal images showed that Tat protein was comparably present in both cell types after $24 \mathrm{~h}$ incubation (Figure 5A). Higher magnification analyses highlighted that in COS-7 cells expressing hERG, Tat protein did not enter the cells. In marked contrast, in hiPSCMs, Tat was found both in the cytoplasm and/or vesicular structures that are presumably endocytic elements as well as colocalized with hERG proteins, at the plasma membrane (Figure 5B). Altogether, these experiments in hiPS-CMs show that Tat, when applied at biologically relevant concentrations is able to affect $\mathrm{PIP}_{2}$ availability, thereby affecting $\mathrm{I}_{\mathrm{Kr}}$ current.

Since Tat also affects transfected KCNE1-KCNQ1, which is related to the cardiac $\mathrm{I}_{\mathrm{Ks}}$ current, we set out to study the effect of Tat on $\mathrm{I}_{\mathrm{Ks}}$ in native tissue. However, in our model of cardiomyocytes differentiated from hiPS cells, we did no observe any tail current in presence of $1 \mu \mathrm{M}$ E-4031 (not shown), suggesting that KCNE1 and/or KCNQ1 subunits are not expressed/functional in this model. We also applied $1 \mu \mathrm{M}$ epinephrine to enhance this current $[35,36]$ but again, no tail was observed in $1 \mu \mathrm{M}$ E-4031.

Table 2: Tat reduces $I_{\mathrm{Kr}}$ recorded from hiPS-CMs: biophysical characteristics.

\begin{tabular}{|l|c|c|}
\hline \multirow{2}{*}{ Tat incubated } & \multicolumn{2}{|c|}{ iPS-CMs- $_{\mathrm{Kr}}$} \\
\cline { 2 - 3 } & Buffer & $\begin{array}{c}\text { Tat 200 } \\
\text { ng/ml }\end{array}$ \\
\hline Current density & $(15)$ & $(15)$ \\
\hline $\begin{array}{l}\text { at } \mathbf{6 0} \mathbf{~ m V} \\
\text { (pA/pF) }\end{array}$ & $0.93 \pm 0.18$ & $0.64 \pm 0.23^{*}$ \\
\hline Activation & $(21)$ & $(13)$ \\
\hline $\mathbf{V}_{\mathbf{1} / \mathbf{2}}(\mathbf{m V})$ & $-23.7 \pm 1.6$ & $-22.7 \pm 1.7$ \\
$\mathbf{K}(\mathbf{m V})$ & $5.7 \pm 0.5$ & $5.7 \pm 0.4$ \\
\hline
\end{tabular}

(n): number of cells; Student t-test, $*: \mathrm{p}<0.05 ; \mathrm{V}_{1 / 2}$ and $\mathrm{K}$ : voltage for half-activation or -inactivation of the $\mathrm{K}^{+}$currents and slope. 
A hiPS-CMs

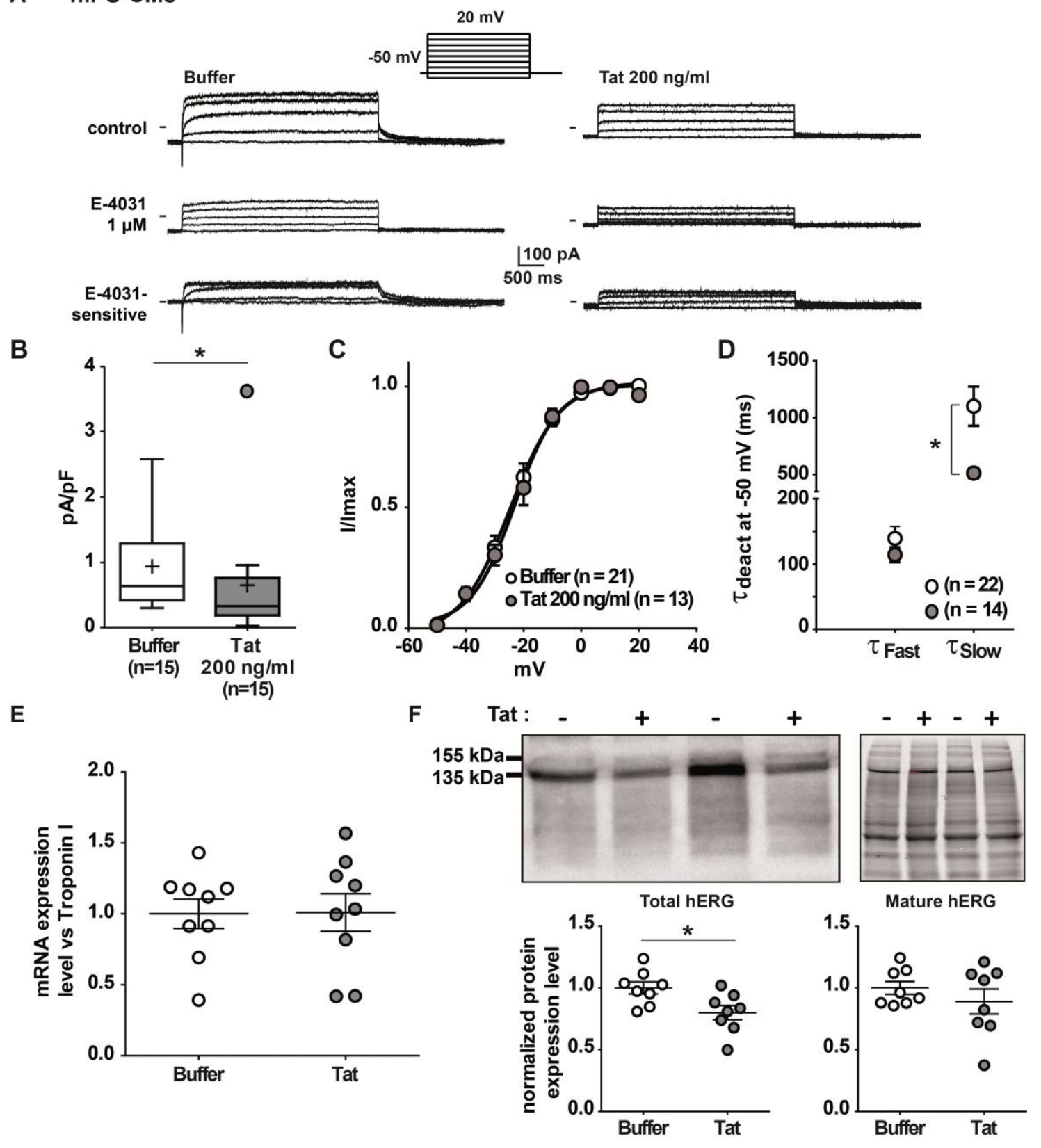

Figure 4: Tat reduces $I_{K r}$ recorded from hiPS-CMs. (A) Representative superimposed currents recorded from hiPS-CMs incubated with buffer (left) or $200 \mathrm{ng} / \mathrm{ml}$ WT-Tat (Tat; right), before (control) and after $1 \mu \mathrm{M}$ E-4031 application. The E-4031-sensitive current, $\mathrm{I}_{\mathrm{Kr}}$, was obtained by digital subtraction of the current recorded after E-4031 application to the one recorded before application (inset: voltage-clamp protocol). (B) Tukey boxplots presenting $\mathrm{I}_{\mathrm{Kr}}$ tail current density measured at $-50 \mathrm{mV}$ after depolarization at $+60 \mathrm{mV}$. Mann-Whitney test: * $\mathrm{p}<0.05$. (C) $\mathrm{I}_{\mathrm{Kr}}$ activation curves measured from the tail currents. (D) Averaged time constants of fast and slow deactivation upon repolarization at $-50 \mathrm{mV}$. Student t-test: $* \mathrm{p}<$ 0.05. The fast component represents around $50 \%$ of the deactivating current in both conditions. (E) hERG mRNA expression level versus Troponin I mRNA. (F) Top left: Western blot analysis of hERG protein expression in hiPS-CMs. Two hERG specific bands were revealed (mature, glycosylated membrane subunit, $155 \mathrm{kDa}$, and immature, nonglycosylated cytoplasmic subunit, $135 \mathrm{kDa}$ ). Top right: stain-free expression served as internal control of gel loading. Bottom: normalized intensity quantification of the total and mature hERG bands in hiPS-CMs. Student t-test: $* \mathrm{p}<0.05$. 


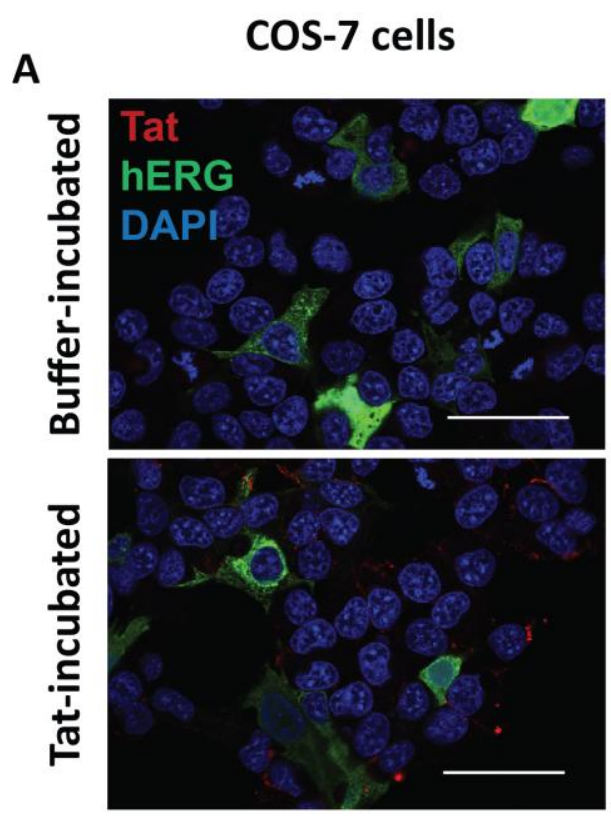

hiPS-CMs
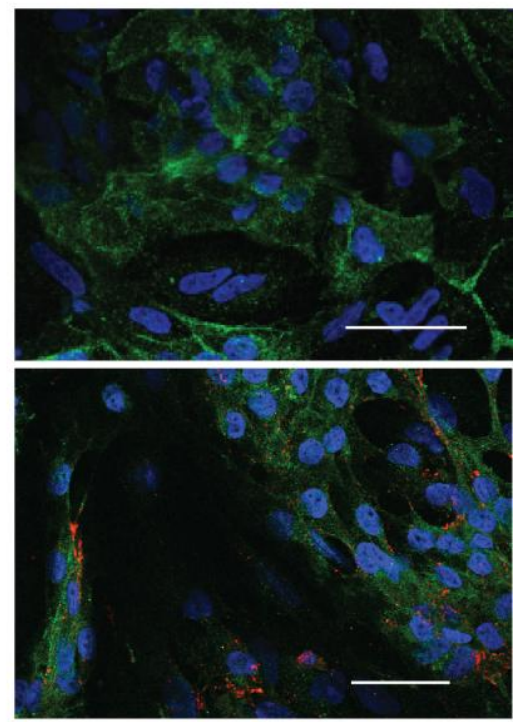

B
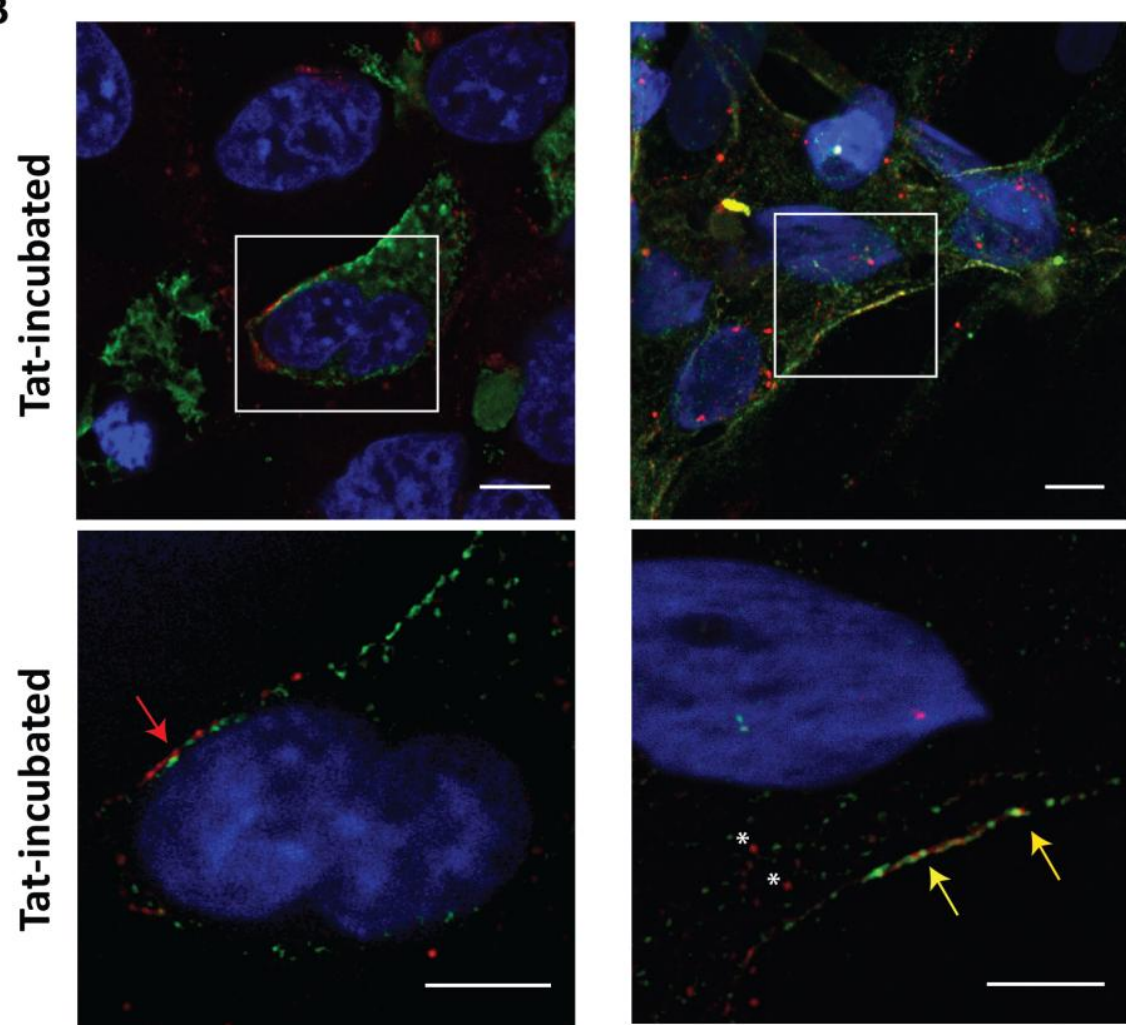

Figure 5: Tat enters hiPS-CMs but not COS-7 cells. (A) Representative confocal immunostainings of Tat (red) and hERG (green). Left: COS-7 cells expressing hERG. Right: hiPS-CMs. Top: cells incubated with control buffer. Bottom: cells incubated with Tat. Scale = $50 \mu \mathrm{m}$. (B) Top: Representative confocal immunostainings of Tat-incubated COS-7 cells and hiPS-CMs. Bottom: Representative SIM immunostainings, showing that Tat remains in the extracellular compartment of COS-7 cells (red arrow) while in hiPS-CMS, Tat is located inside the cytoplasm (asterisks) and colocalizes with hERG at the plasma membrane (yellow arrows). Scale $=5 \mu \mathrm{m}$. 
In addition to hERG and KCNQ1, $\mathrm{PIP}_{2}$ has been shown to modulate the activity of a plethora of ion channels [37], yet it is possible that many of these channels are not affected by $\mathrm{PIP}_{2}$ if variations are limited to its physio/pathophysiological range [38]. To address this issue, we tested the effect of Tat on several channels suggested to be regulated by $\mathrm{PIP}_{2}$. $\mathrm{PIP}_{2}$ has previously been shown to modulate the L-type $\mathrm{Ca}^{2+}$ current, $\mathrm{I}_{\mathrm{Ca}, \mathrm{L}}$, in neurons and in natural killer cells [39, 40] and $\mathrm{Ca}_{\mathrm{V}} 1.2$ and $\mathrm{Ca}_{\mathrm{V}} 1.3$ in heterologous expression system [41]. We investigated Tat effects on the L-type $\mathrm{Ca}^{2+}$ current in hiPS-CMs. Tat incubation did not modify $\mathrm{I}_{\mathrm{Ca}, \mathrm{L}}$ density or biophysical properties (Figure 6), showing that endogenous $\mathrm{Ca}^{2+}$ channels activity is not affected by Tat in hiPS-CMs. This observation suggests that hiPS-CM $\mathrm{Ca}^{2+}$ channels are not as sensitive as hERG to a decrease in available PIP 2 .

A

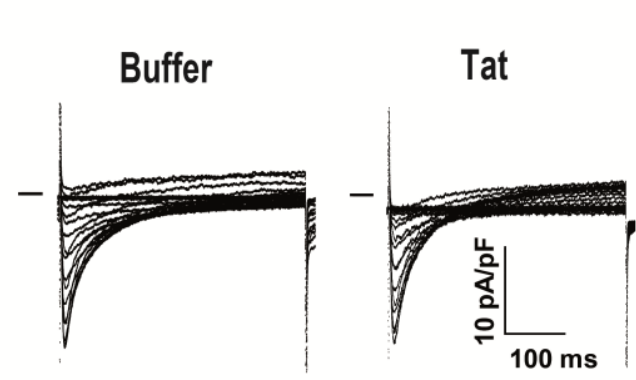

C

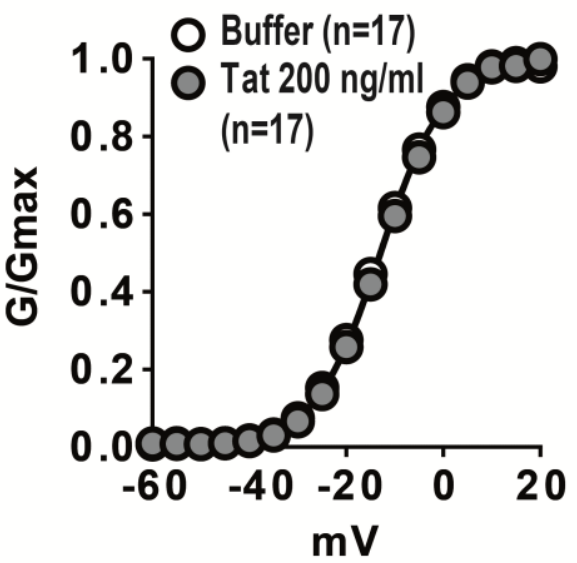

B
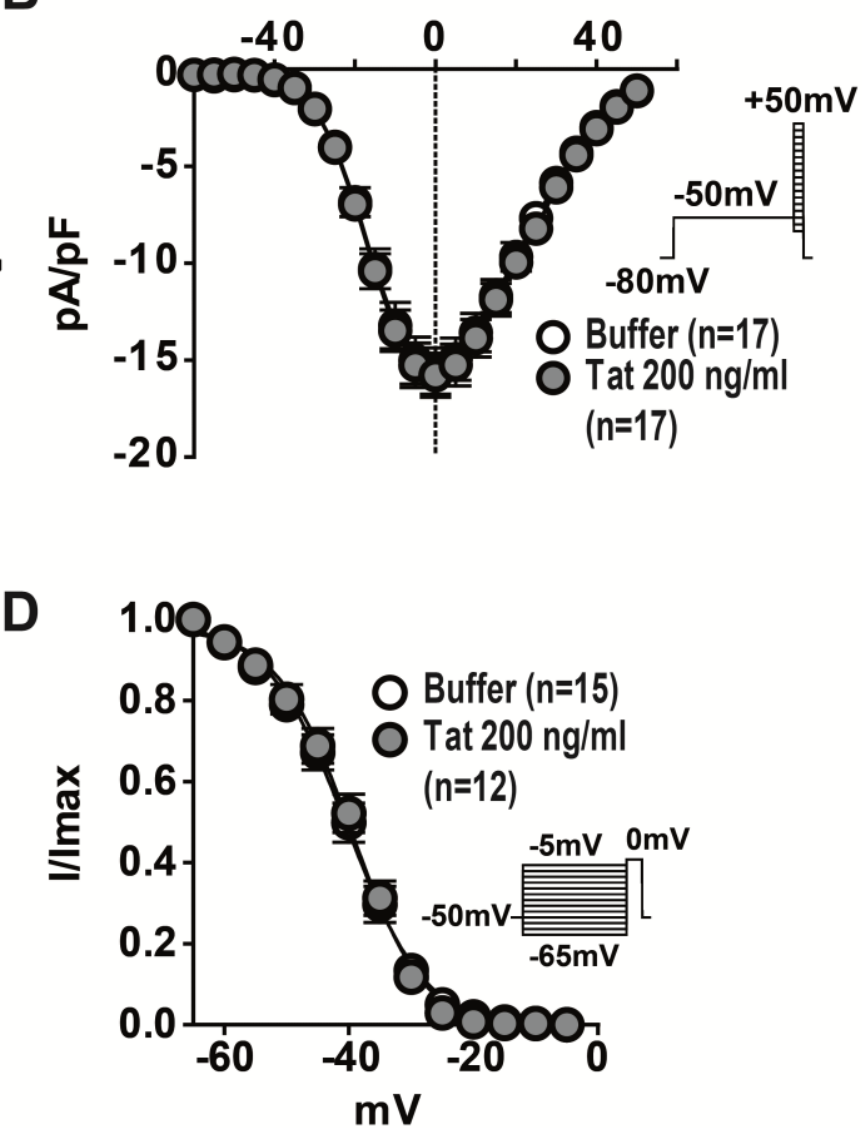

Figure 6: Tat has no effect on $\mathbf{I}_{\mathrm{Ca}, \mathrm{L}}$ recorded in hiPS-CMs. (A) Representative superimposed currents recorded from hiPS-CMs incubated with buffer or $200 \mathrm{ng} / \mathrm{ml} \mathrm{WT-Tat}$ (Tat). (B) Current density-voltage relationship. Inset: protocol used (C) $\mathrm{I}_{\mathrm{Ca}, \mathrm{L}}$ activation curves obtained from current density-voltage curves. (D) Voltage-dependence of inactivation. Inset: protocol used. 
In order to evaluate if Tat also alters the activity of an inward rectifier channel, we chose a channel which has a low apparent affinity to PIP $_{2}$. Such channel, which is less stabilized by $\mathrm{PIP}_{2}$ is more prone to a decrease in activity when available $\mathrm{PIP}_{2}$ is decreased [42]. Thus we selected the $\mathrm{K}_{\text {ATP }}$ channel, since the alpha-subunit of this channel, Kir6.2, has a low affinity to $\mathrm{PIP}_{2}$ and is more prone to be sensitive toTat [42]. As no $\mathrm{K}_{\mathrm{ATP}}$ current was detected in the hiPS-CMs as a glibenclamide-sensitive outward current measured at $+40 \mathrm{mV}$, we used neonatal mouse cardiomyocytes, in which a $24 \mathrm{~h}$ incubation with $200 \mathrm{ng} / \mathrm{ml}$ Tat led to a decrease in the $\mathrm{K}_{\text {АTP }}$ current (Supplemental figure 5). This suggests that Tat may lead to a remodeling of the electrical activity of cardiomyocytes through an alteration of the activity of several $\mathrm{PIP}_{2}$-sensitive channels.

A

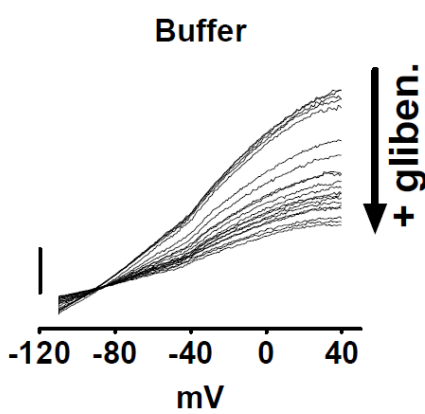

B

Tat $200 \mathrm{ng} / \mathrm{ml}$

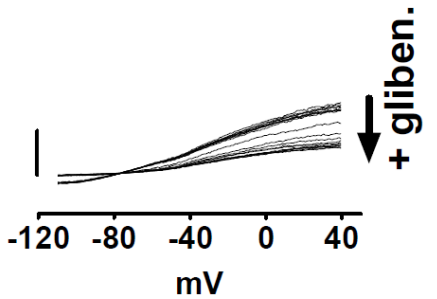

C

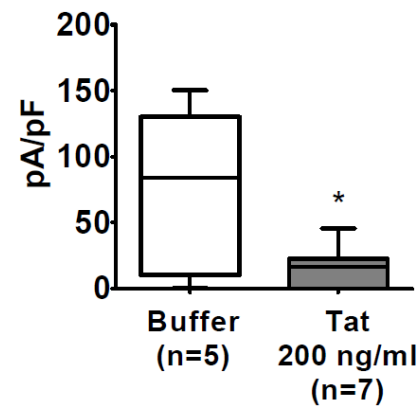

Supplemental figure 5: Tat induces a decrease in $\mathbf{I}_{K A T P}$ recorded in mouse neonatal cardiomyocytes. (A) \& (B). Representative superimposed currents recorded from hiPS-CMs incubated with buffer (A) or $200 \mathrm{ng} / \mathrm{ml}$ WT-Tat (B), during $20 \mu \mathrm{mol} / 1$ glibenclamide perfusion. Vertical bar, $500 \mathrm{pA}$. For clarity, only every other trace is shown. (C) Tukey boxplots presenting $\mathrm{I}_{\text {KATP }}$ current density measured as the glibenclamide-sensitive current measured at the end of a $350 \mathrm{~ms}$ pulse to $+40 \mathrm{mV}$. Mann-Whitney test: ${ }^{*} \mathrm{p}<0.05$.

\subsection{Tat related reduction of $I_{K r}$ is not due to a reduction in membrane hERG}

Since Tat has been shown to interfere with protein expression in host cells [43], it may also act on hERG through a reduction in its expression. To test whether Tat directly alters expression of native hERG in hiPS-CMs, we performed qRT-PCR and western blot analyses. While no reduction of hERG mRNA was observed, total hERG protein amount was reduced by about $20 \%$ only (Figure $4 \mathrm{E} \& \mathrm{~F}$ ). Moreover, the mature (i.e. glycosylated) fraction responsible for the $\mathrm{K}^{+}$current [44], was not significantly reduced (Figure 4F), suggesting that 
inhibition of hERG protein expression is not responsible for hERG current decrease and that in cardiomyocytes, Tat incubation mostly affects hERG gating.

\subsection{Tat modifies the electrical activity of cardiomyocytes derived from human induced} pluripotent stem cells

Action potentials (APs) were then recorded using the permeabilized patch configuration in hiPS-CMs. Three types of AP shapes were obtained and categorized as nodal-, atrial-, and ventricular-like APs (Table 3). Since LQTS is associated with ventricular AP prolongation, we focused on ventricular-like APs paced at two cycle lengths. As illustrated in Figure 7A, APs were prolonged in hiPS-CMs incubated for $24 \mathrm{~h}$ with $200 \mathrm{ng} / \mathrm{ml}$ Tat. Only $\mathrm{APD}_{70}$ and $\mathrm{APD}_{90}$ were prolonged as expected with hERG inhibition $(\mathrm{p}<0.05$; Figure $7 \mathrm{~B})$. In addition, most Tat-incubated cells showed a higher $\mathrm{APD}_{90}$ dispersion compared to cells incubated with buffer (Figure 8). This dispersion resulted from AP duration and amplitude alternans (Figure $8 \mathrm{~A})$. $\mathrm{APD}_{90}$ alternans were exacerbated at faster stimulation rates (shorter PCLs; Figure 8B).

Table 3: Quantitative parameters used for classification of action potentials obtained from patch-clamp experiments on control cells.

\begin{tabular}{|l|l|l|l|l|l|l|l|}
\hline $\begin{array}{l}\text { hiPS-CM } \\
\text { APs }\end{array}$ & $\begin{array}{c}\text { AP amplitude } \\
(\mathbf{m V})\end{array}$ & MDP $(\mathbf{m V})$ & $\begin{array}{c}\text { Peak to peak } \\
\text { duration }(\mathbf{m s})\end{array}$ & $\begin{array}{c}\mathbf{d V / d t} \text { max } \\
(\mathbf{V} / \mathbf{s})\end{array}$ & $\begin{array}{c}\mathbf{A P D}_{\mathbf{9 0}} \\
(\mathbf{m s})\end{array}$ & $\begin{array}{c}\mathbf{( A P D}_{\mathbf{3 0}^{-}} \\
\left.\mathbf{A P D}_{\mathbf{4 0}}\right) / \\
\left(\mathbf{A P D}_{\mathbf{7 0}}-\right. \\
\left.\mathbf{A P D}_{\mathbf{8 0}}\right)\end{array}$ & $\begin{array}{c}\mathbf{A P D}_{\mathbf{5 0}} / \\
\mathbf{A P D}_{\mathbf{9 0}}\end{array}$ \\
\hline $\begin{array}{l}\text { Nodal-like } \\
(\mathbf{n = 4})\end{array}$ & $63.0 \pm 4.4$ & $-41.7 \pm 3.7$ & $650.1 \pm 147$ & $2.1 \pm 0.4$ & $\begin{array}{c}174.4 \pm \\
2.5\end{array}$ & $2.3 \pm 0.2$ & $0.6 \pm$ \\
\hline $\begin{array}{l}\text { Atrial-like } \\
(\mathbf{n = 7})\end{array}$ & $77.3 \pm 2.2$ & $-47.2 \pm 1.5$ & $901.2 \pm 188.5$ & $4.4 \pm 0.5$ & $\begin{array}{c}215.9 \pm \\
22.9\end{array}$ & $1.0 \pm 0.1$ & $0.6 \pm 2$ \\
\hline $\begin{array}{l}\text { Ventricular- } \\
\text { like } \\
(\mathbf{n = 9})\end{array}$ & $\mathbf{1 0 2 . 6} \pm \mathbf{3 . 1}$ & $\mathbf{- 5 8 . 6} \pm \mathbf{2 . 1}$ & $\mathbf{1 3 0 1 . 2} \pm \mathbf{3 1 0 . 8}$ & $\mathbf{1 0 . 9} \pm \mathbf{1 . 2}$ & $\begin{array}{c}\mathbf{2 6 9 . 4} \\
\mathbf{3 0 . 1}\end{array}$ & $\mathbf{4 . 9} \pm \mathbf{0 . 7}$ & $\mathbf{0 . 8}$ \\
\hline
\end{tabular}

MDP: Maximum diastolic potential. $\mathrm{dV} / \mathrm{dt}_{\max }$ : maximum upstroke velocity. 
A
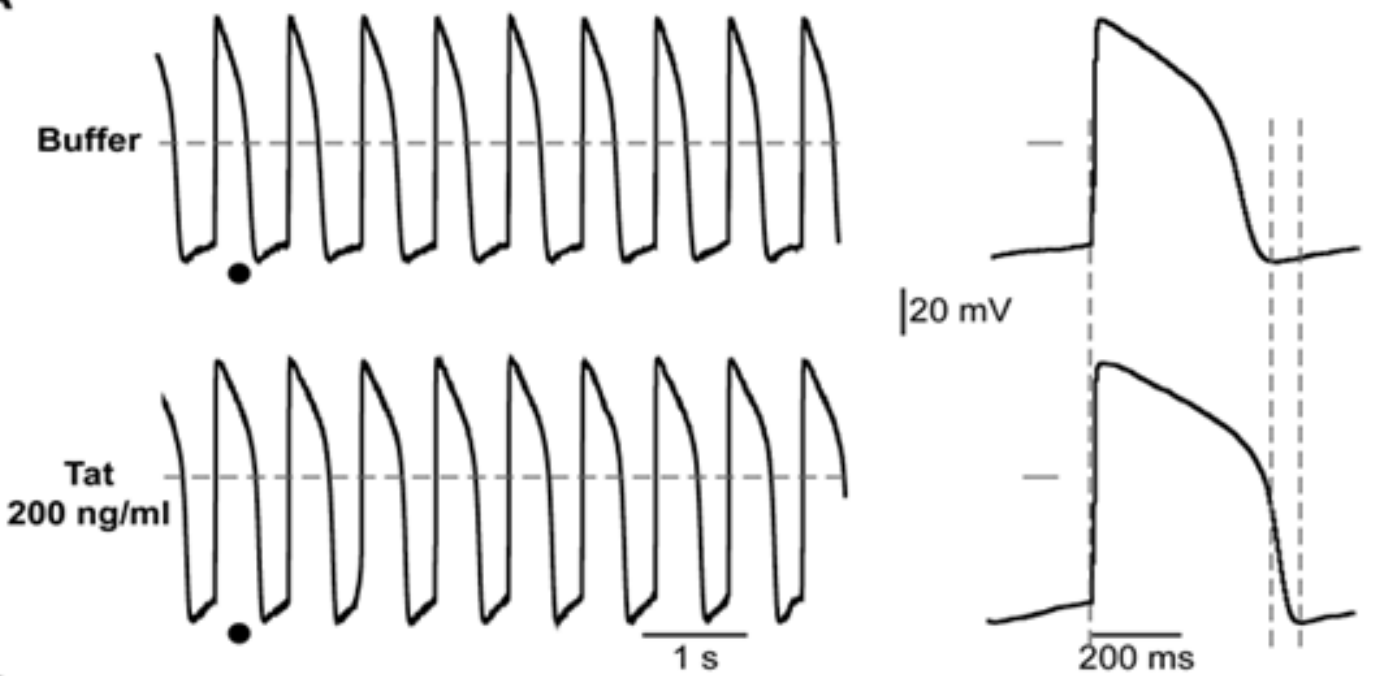

B

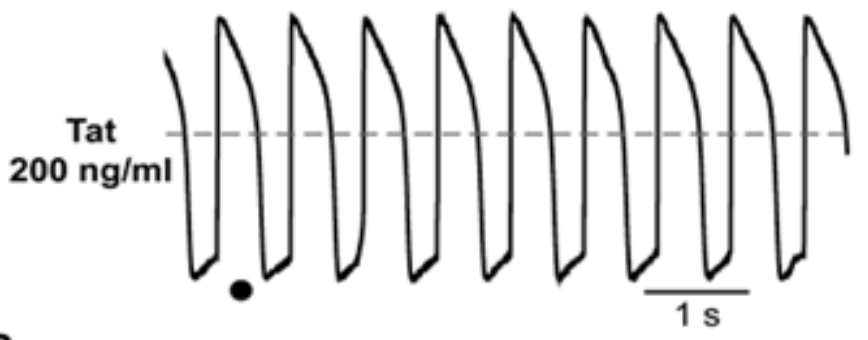

$200 \mathrm{~ms}$
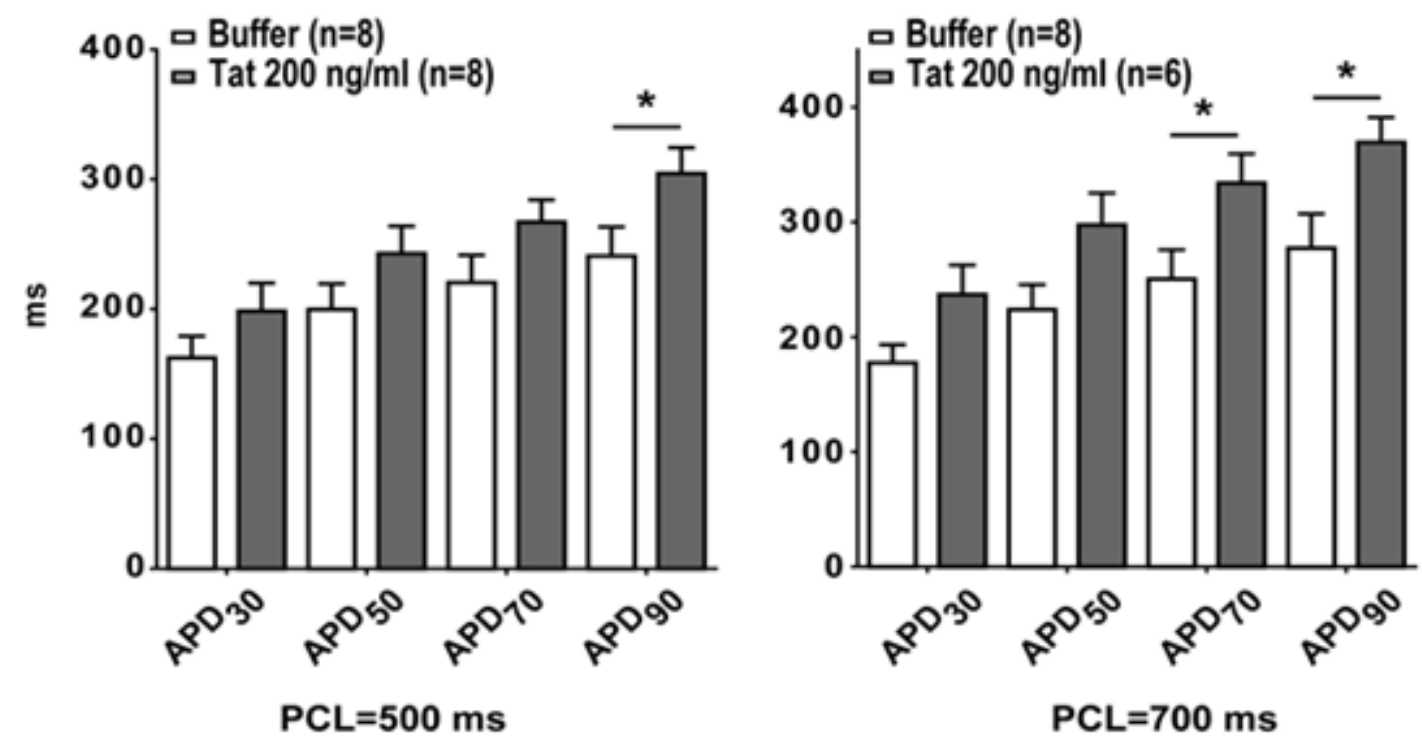

Figure 7: Tat significantly increases ventricular-like action potential durations in hiPSCMs. (A) Left, representative ventricular-like APs recorded from hiPS-CMs incubated with buffer or $200 \mathrm{ng} / \mathrm{ml} \mathrm{WT-Tat} \mathrm{(Tat),} \mathrm{stimulated} \mathrm{at} \mathrm{a} \mathrm{pacing} \mathrm{cycle} \mathrm{length} \mathrm{(PCL)} \mathrm{of} 700 \mathrm{~ms}$. Right, expanded APs tagged $\bigcirc$ in left panel. Horizontal dashed lines and bars: $0 \mathrm{mV}$. Vertical dashed lines stress the duration differences. (B) Averaged AP duration at $30\left(\mathrm{APD}_{30}\right), 50$ $\left(\mathrm{APD}_{50}\right), 70\left(\mathrm{APD}_{70}\right)$ and $90 \%\left(\mathrm{APD}_{90}\right)$ of full repolarization measured in ventricular-like cells incubated with buffer or WT-Tat at 2 different PCLs. ${ }^{*}: \mathrm{p}<0.05$ (Holm-Sidak post-hoc test). 
A

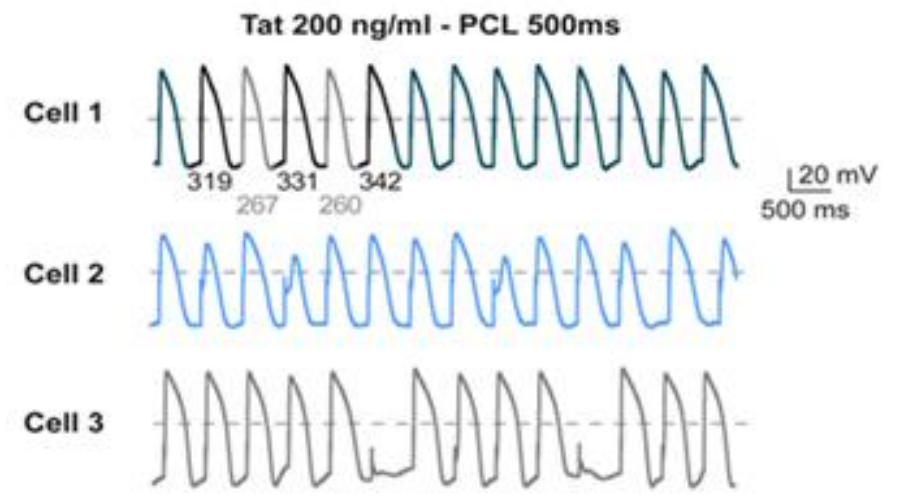

B
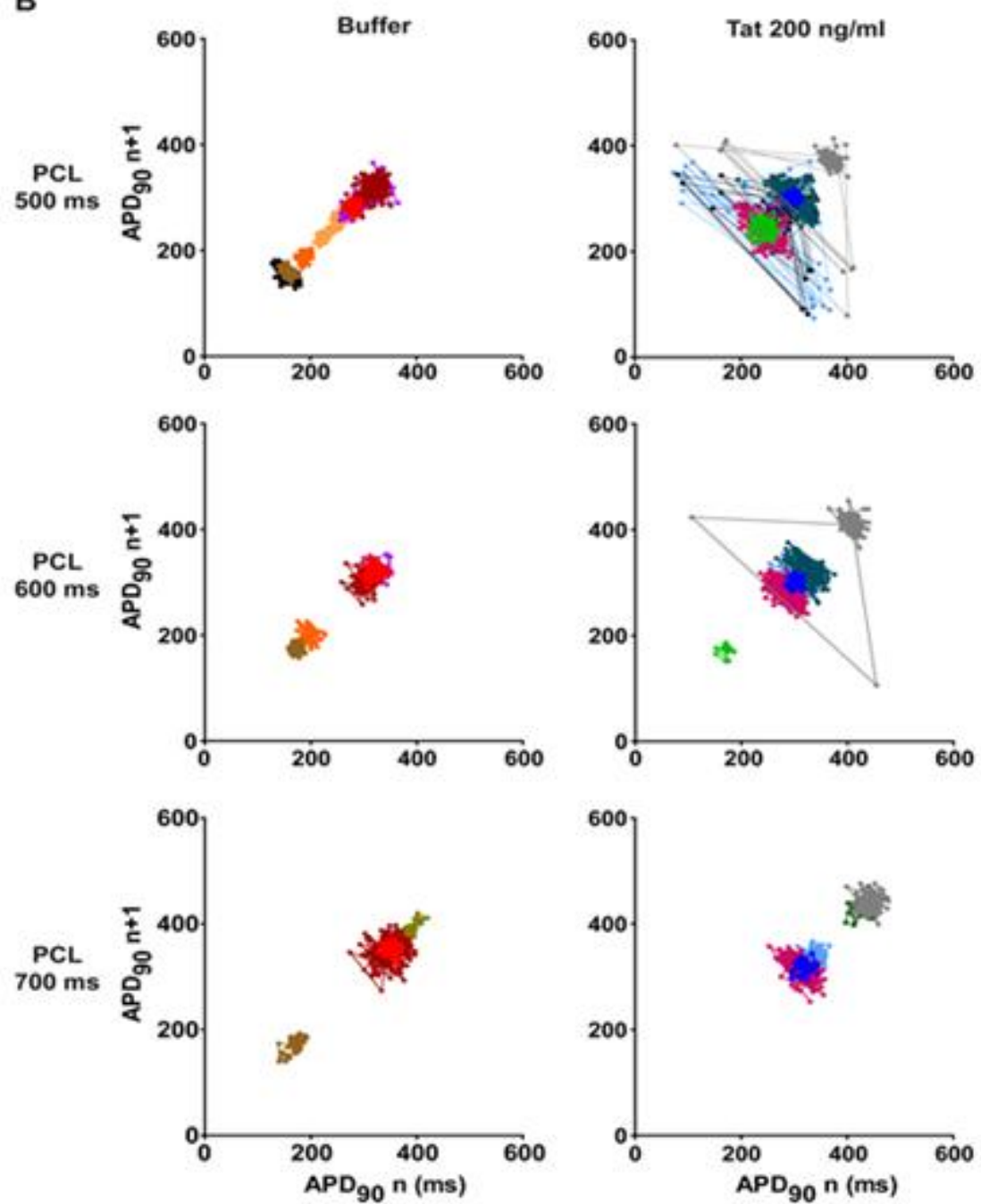

Figure 8: Tat incubation leads to alternans events in ventricular-like hiPS-CMs. (A) Representative ventricular-like action potentials recorded from three different hiPS-CMs incubated with $200 \mathrm{ng} / \mathrm{ml} \mathrm{WT-Tat} \mathrm{(Tat).} \mathrm{Cell} \mathrm{1:} \mathrm{APD}_{90}$ of five consecutive APs are indicated below. (B) Poincaré plots of $\mathrm{APD}_{90}$ (one color per cell) recorded at three different PCLs. The graphs show $\mathrm{APD}_{90}$ of each $\mathrm{AP}$ (number $\mathrm{n}+1$ ) versus the $\mathrm{APD}_{90}$ of its preceding one $(\mathrm{n})$. Same color code used in A. 


\section{DISCUSSION}

HIV Tat binds PIP $_{2}$ with a very high affinity, the $K_{d}$ being 20 to 50 times lower than the $K_{d}$ of the phospholipase $\mathrm{C}$ pleckstrin homology domain, one of the best cellular ligands for $\mathrm{PIP}_{2}$ [18]. Knowing that hERG and KCNQ1 currents are modulated by membrane PIP $_{2}$ levels, we tested whether Tat can affect those currents by sequestering PIP $_{2}$. Co-transfecting Tat with either channel led to modification of the biophysical parameters in accordance with a decrease in available $\mathrm{PIP}_{2}$. Moreover, the W11Y-Tat mutant, which is 300 times less affine for $\mathrm{PIP}_{2}$ [18], has no effect on the activity of both channels. Importantly, W11Y-Tat mutation does not alter its native transactivation activity [23], suggesting that loss of effect of W11Y-Tat on hERG and KCNE1-KCNQ1 channels activity is rather due to the disrupted interaction with $\mathrm{PIP}_{2}$ than through another mechanism, such as the regulation of gene expression. Since W11Y-Tat is not localized to the membrane, one might argue that WT-Tat effects may be mediated through alternative mechanisms independent of $\mathrm{PIP}_{2}$, such as a direct interaction with the ion channels of interest. However, a KCNE1-KCNQ1 mutant which is not sensitive to $\mathrm{PIP}_{2}$ is not affected by WT-Tat, confirming that Tat acts by sequestering $\mathrm{PIP}_{2}$. Incubation of hiPS-derived cardiomyocytes with WT-Tat also leads to a decrease in $\mathrm{I}_{\mathrm{Kr}}$ and acceleration of deactivation, consistent with a decrease in available $\mathrm{PIP}_{2}$. Finally, the cells electrical activity is affected through delayed repolarization and AP alternans. Altogether, these results indicate that Tat may affect cardiomyocytes repolarization through an interaction with $\mathrm{PIP}_{2}$, reducing the major repolarizing currents $\mathrm{I}_{\mathrm{Kr}}$ and $\mathrm{I}_{\mathrm{Ks}}$. Those results are particularly significant as, despite the proven effect of $\mathrm{PIP}_{2}$ on the gating of many channels, the relevance of such a regulation in physiological or pathophysiological conditions is still questioned. It has been suggested that in cardiac cells, PIP $_{2}$ levels are not affected enough by PLC-coupled receptors to alter $I_{K r}$ and $I_{K s}[38]$. This work enlightens a pathophysiological condition where $I_{K r}$ is indeed reduced through a decrease in available $\mathrm{PIP}_{2}$. We also show that other $\mathrm{PIP}_{2}$-sentitive channels, such as the $\mathrm{K}_{\mathrm{ATP}}$ channel [45] may also be affected. Since this channel is implicated in the ischemic preconditioning, this could explain at least partly the increase in acute myocardial infarction in HIV-patients adjusted for hypertension, diabetes, and dyslipidemia [46]. In human cardiomyocytes, we did not observe any effect of Tat incubation on the transient calcium current $\mathrm{I}_{\mathrm{CaL}}$, despite its described $\mathrm{PIP}_{2}$ sensitivity [41]. This observation supports the hypothesis that channel activity is differentially modulated depending on its affinity for $\mathrm{PIP}_{2}$ [47]. 
Tat incubation affected $\mathrm{I}_{\mathrm{Kr}}$ in human cardiomyocytes, but not in COS-7 and HEK293 models. This highlights the usefulness of hiPS-derived cardiomyocytes as a more reliable model than heterologous systems. Most importantly, it validates the use of hiPS-CMs to study cardiac non-genetic diseases such as infectious diseases like AIDS. One could consider the absence of detectable $\mathrm{I}_{\mathrm{Ks}}$ in non-stimulated condition as a limit of this model. But this characteristic makes this model closer to hardly available human cardiomyocytes [48, 49] as compared to guinea pig cardiomyocytes [50] in which $\mathrm{I}_{\mathrm{Ks}}$ presents a much larger contribution to the repolarizing currents without any adrenergic stimulus.

Bai and collaborators did observe an effect of Tat incubation on hERG current amplitude in a similar HEK293 model as we used [16]. However, these authors used a short isoform of Tat encoded by the first exon of the protein only (72 residues; Tat-72). The Tat protein used in our study is a 86 residues long (Tat-86), two-exon form of Tat that is present in viral isolates [34]. Although both Tat-72 and Tat-86 contain the transactivation domain, and are frequently used for in vitro studies, Tat-86 is more readily taken up than Tat-72 by various cell types [51]. In addition, the second exon endows Tat with additional activities and is critical for both in vitro and in vivo HIV replication [52]. Therefore, the use of Tat-86 appears to be more relevant to evaluate HIV impact on human cardiomyocyte electrical activity.

In LQT patients, T-wave alternans mirroring ventricular AP alternans are associated with delayed repolarization and are a known risk factor for sudden death [53]. In hiPS-derived cardiomyocytes, Tat incubation resulted in a significant reduction in $\mathrm{I}_{\mathrm{Kr}}$ current, associated with ventricular AP prolongation, as would be expected, and alternans occurrence. Up to now, such human AP alterations could be addressed with in silico studies only. For example, similar AP prolongation at low rate and APD alternans at elevated rate were observed when $\mathrm{I}_{\mathrm{Kr}}$ alterations due to a human LQT-related hERG mutation were implemented in a mathematical model of the human ventricular action potential [54]. Similarly, mild reduction in repolarization reserve due to alteration of $\mathrm{I}_{\mathrm{Kr}}$ parameters led to APD alternans using another in silico model [55]. These results are also in agreement with the observations in canine cardiomyocytes of AP alternans suppression by overexpression of hERG [56]. However, in silico or animal models are limited to investigate the potential multiple effects of actors such as Tat on their various mechanistic targets, in a situation far more complex than a single mutation. 
In conclusion, this study strongly suggests that $\mathrm{PIP}_{2}$ is the link between HIV-Tat and the cardiac arrhythmias observed in HIV-positive individuals. In neurosecretory cells, it has been proposed that Tat perturbs the recruitment of several $\mathrm{PIP}_{2}$-dependent key players of the exocytotic machinery [32]. Combined with this previous investigation, our work suggests a general remodeling of $\mathrm{PIP}_{2}$-dependent processes by HIV via Tat. It would be interesting to test whether other processes, immune or not immune, are also affected by Tat through $\mathrm{PIP}_{2}$.

\section{DISCLOSURES}

None

\section{ACKNOWLEDGEMENTS}

We thank the iPS cell core facility and MicroPiCell facility of SFR Santé F. Bonamy (Nantes), the Nikon Center of Excellence of Nantes, Patricia Charpentier from Therassay facility, Béatrice Leray, and Morteza Erfanian for their technical support.

\section{SOURCES OF FUNDING}

This work was funded by grants from the Fédération Française de Cardiologie, the Fondation Genavie, the Marie Curie European Actions (PIIF-GA-2012-331436 and PIOFGA-2011-298280), the French Regional Council of Pays-de-la-Loire (Regional grant VACARME - www.vacarme-project.org) and the Agence Nationale de Recherche (ANR-15CE14-0019-01). Dr Z. Es-Salah-Lamoureux was supported by grants from the Lefoulon Delalande Foundation, the Fondation pour la Recherche Médicale (SPF20111223614; FRM) and the Fondation Genavie. M. Jouni was awarded a scholarship from the Association of Scientific Orientation and Specialization (ASOS). Olfat Malak was laureate of the Line Pomaret-Delalande prize of the Fondation pour la Recherche Médicale (PLP20141031304; FRM). Zeina Reda Al Sayed was awarded by a Eiffel program from Campus France. 


\section{REFERENCES}

[1] Zwahlen M, Harris R, May M, Hogg R, Costagliola D, de WF et al. Mortality of HIV-infected patients starting potent antiretroviral therapy: comparison with the general population in nine industrialized countries. Int J Epidemiol 2009;38:1624-33.

[2] April MD, Wood R, Berkowitz BK, Paltiel AD, Anglaret X, Losina E et al. The survival benefits of antiretroviral therapy in South Africa. J Infect Dis 2014;209:491-9.

[3] World Health Oganization. Towards universal access : scaling up priority HIV/AIDS interventions in the health sector : progress report 2008. 2008. 1-7-2015.

[4] World Health Oganization. Global update on the health sector response to HIV, 2014. 1-72014. 1-7-2015.

[5] Tseng ZH, Secemsky EA, Dowdy D, Vittinghoff E, Moyers B, Wong JK et al. Sudden cardiac death in patients with human immunodeficiency virus infection. J Am Coll Cardiol 2012;59:1891-6.

[6] Goldberg RJ, Bengtson J, Chen ZY, Anderson KM, Locati E, Levy D. Duration of the QT interval and total and cardiovascular mortality in healthy persons (The Framingham Heart Study experience). Am J Cardiol 1991;67:55-8.

[7] Qaqa AY, Shaaban H, DeBari VA, Phung S, Slim J, Costeas CA et al. Viral load and CD4+ cell count as risk factors for prolonged QT interval in HIV-infected subjects: a cohort-nested casecontrol study in an outpatient population. Cardiology 2010;117:105-11.

[8] Reinsch N, Buhr C, Krings P, Kaelsch H, Neuhaus K, Wieneke $\mathrm{H}$ et al. Prevalence and risk factors of prolonged QTc interval in HIV-infected patients: results of the HIV-HEART study. HIV Clin Trials 2009;10:261-8.

[9] Haverkamp W, Breithardt G, Camm AJ, Janse MJ, Rosen MR, Antzelevitch C et al. The potential for QT prolongation and proarrhythmia by non-antiarrhythmic drugs: clinical and regulatory implications. Report on a policy conference of the European Society of Cardiology. Eur Heart J 2000;21:1216-31.

[10] Fantoni M, Autore C, Del BC. Drugs and cardiotoxicity in HIV and AIDS. Ann N Y Acad Sci 2001;946:179-99.

[11] Vallecillo G, Mojal S, Roquer A, Martinez D, Rossi P, Fonseca F et al. Risk of QTc prolongation in a cohort of opioid-dependent HIV-infected patients on methadone maintenance therapy. Clin Infect Dis 2013;57:1189-94.

[12] Charbit B, Rosier A, Bollens D, Boccara F, Boelle PY, Koubaa A et al. Relationship between HIV protease inhibitors and QTc interval duration in HIV-infected patients: a cross-sectional study. Br J Clin Pharmacol 2009;67:76-82.

[13] Kocheril AG, Bokhari SA, Batsford WP, Sinusas AJ. Long QTc and torsades de pointes in human immunodeficiency virus disease. Pacing Clin Electrophysiol 1997;20:2810-6. 
[14] Hanna Z, Kay DG, Cool M, Jothy S, Rebai N, Jolicoeur P. Transgenic mice expressing human immunodeficiency virus type 1 in immune cells develop a severe AIDS-like disease. J Virol 1998;72:121-32.

[15] Brouillette J, Grandy SA, Jolicoeur P, Fiset C. Cardiac repolarization is prolonged in CD4C/HIV transgenic mice. J Mol Cell Cardiol 2007;43:159-67.

[16] Bai YL, Liu HB, Sun B, Zhang Y, Li Q, Hu CW et al. HIV Tat protein inhibits hERG K+ channels: a potential mechanism of HIV infection induced LQTs. J Mol Cell Cardiol 2011;51:876-80.

[17] Poggi A, Carosio R, Fenoglio D, Brenci S, Murdaca G, Setti M et al. Migration of V delta 1 and $V$ delta 2 T cells in response to CXCR3 and CXCR4 ligands in healthy donors and HIV-1infected patients: competition by HIV-1 Tat. Blood 2004;103:2205-13.

[18] Rayne F, Debaisieux S, Yezid H, Lin YL, Mettling C, Konate K et al. Phosphatidylinositol-(4,5)bisphosphate enables efficient secretion of HIV-1 Tat by infected T-cells. EMBO J 2010;29:1348-62.

[19] Charpentier F, Merot J, Loussouarn G, Baro I. Delayed rectifier $\mathrm{K}(+)$ currents and cardiac repolarization. J Mol Cell Cardiol 2010;48:37-44.

[20] Loussouarn G, Park KH, Bellocq C, Baro I, Charpentier F, Escande D. Phosphatidylinositol-4,5bisphosphate, PIP2, controls KCNQ1/KCNE1 voltage-gated potassium channels: a functional homology between voltage-gated and inward rectifier K+ channels. EMBO J 2003;22:5412-21.

[21] Rodriguez N, Amarouch MY, Montnach J, Piron J, Labro AJ, Charpentier F et al. Phosphatidylinositol-4,5-bisphosphate (PIP(2)) stabilizes the open pore conformation of the Kv11.1 (hERG) channel. Biophys J 2010;99:1110-8.

[22] Vendeville A, Rayne F, Bonhoure A, Bettache N, Montcourrier P, Beaumelle B. HIV-1 Tat enters $T$ cells using coated pits before translocating from acidified endosomes and eliciting biological responses. Mol Biol Cell 2004;15:2347-60.

[23] Yezid H, Konate K, Debaisieux S, Bonhoure A, Beaumelle B. Mechanism for HIV-1 Tat insertion into the endosome membrane. J Biol Chem 2009;284:22736-46.

[24] Si-Tayeb K, Noto FK, Nagaoka M, Li J, Battle MA, Duris C et al. Highly efficient generation of human hepatocyte-like cells from induced pluripotent stem cells. Hepatology 2010;51:297305.

[25] Zhang J, Klos M, Wilson GF, Herman AM, Lian X, Raval KK et al. Extracellular matrix promotes highly efficient cardiac differentiation of human pluripotent stem cells: the matrix sandwich method. Circ Res 2012;111:1125-36.

[26] Jouni M, Si-Tayeb K, Es-Salah-Lamoureux Z, Latypova X, Champon B, Caillaud A et al. Toward Personalized Medicine: Using Cardiomyocytes Differentiated From Urine-Derived Pluripotent Stem Cells to Recapitulate Electrophysiological Characteristics of Type 2 Long QT Syndrome. J Am Heart Assoc 2015;4:e002159.

[27] Terrenoire C, Wang K, Tung KW, Chung WK, Pass RH, Lu JT et al. Induced pluripotent stem cells used to reveal drug actions in a long QT syndrome family with complex genetics. J Gen Physiol 2013;141:61-72. 
[28] Loussouarn G, Baro I, Escande D. KCNQ1 K+ channel-mediated cardiac channelopathies. Methods Mol Biol 2006;337:167-83.

[29] Gurtler A, Kunz N, Gomolka M, Hornhardt S, Friedl AA, McDonald K et al. Stain-Free technology as a normalization tool in Western blot analysis. Anal Biochem 2013;433:105-11.

[30] Rivero-Gutierrez B, Anzola A, Martinez-Augustin O, de Medina FS. Stain-free detection as loading control alternative to Ponceau and housekeeping protein immunodetection in Western blotting. Anal Biochem 2014;467:1-3.

[31] Coyan FC, Abderemane-Ali F, Amarouch MY, Piron J, Mordel J, Nicolas CS et al. A long QT mutation substitutes cholesterol for phosphatidylinositol-4,5-bisphosphate in KCNQ1 channel regulation. PLoS One 2014;9:e93255.

[32] Tryoen-Toth P, Chasserot-Golaz S, Tu A, Gherib P, Bader MF, Beaumelle B et al. HIV-1 Tat protein inhibits neurosecretion by binding to phosphatidylinositol 4,5-bisphosphate. J Cell Sci 2013;126:454-63.

[33] Debaisieux S, Lachambre S, Gross A, Mettling C, Besteiro S, Yezid H et al. HIV-1 Tat inhibits phagocytosis by preventing the recruitment of $\mathrm{Cdc} 42$ to the phagocytic cup. Nat Commun 2015;6:6211.

[34] Debaisieux S, Rayne F, Yezid H, Beaumelle B. The ins and outs of HIV-1 Tat. Traffic 2012;13:355-63.

[35] Christ T, Horvath A, Eschenhagen T. LQT1-phenotypes in hiPSC: Are we measuring the right thing? Proc Natl Acad Sci U S A 2015;112:E1968.

[36] Moretti A, Bellin M, Welling A, Jung CB, Lam JT, Bott-Flugel L et al. Patient-specific induced pluripotent stem-cell models for long-QT syndrome. N Engl J Med 2010;363:1397-409.

[37] Logothetis DE, Petrou VI, Adney SK, Mahajan R. Channelopathies linked to plasma membrane phosphoinositides. Pflugers Arch 2010;460:321-41.

[38] Kruse $M$, Hille B. The phosphoinositide sensitivity of the $K(v)$ channel family. Channels (Austin ) 2013;7:530-6.

[39] Napier TC, Chen L, Kashanchi F, Hu XT. Repeated cocaine treatment enhances HIV-1 Tatinduced cortical excitability via over-activation of L-type calcium channels. J Neuroimmune Pharmacol 2014;9:354-68.

[40] Zocchi MR, Rubartelli A, Morgavi P, Poggi A. HIV-1 Tat inhibits human natural killer cell function by blocking L-type calcium channels. J Immunol 1998;161:2938-43.

[41] Suh BC, Leal K, Hille B. Modulation of high-voltage activated $\mathrm{Ca}(2+)$ channels by membrane phosphatidylinositol 4,5-bisphosphate. Neuron 2010;67:224-38.

[42] Du X, Zhang H, Lopes C, Mirshahi T, Rohacs T, Logothetis DE. Characteristic interactions with phosphatidylinositol 4,5-bisphosphate determine regulation of kir channels by diverse modulators. J Biol Chem 2004;279:37271-81.

[43] Wright CM, Felber BK, Paskalis H, Pavlakis GN. Expression and characterization of the transactivator of HTLV-III/LAV virus. Science 1986;234:988-92. 
[44] Lin EC, Moungey BM, Lim E, Concannon SP, Anderson CL, Kyle JW et al. Mouse ERG K(+) channel clones reveal differences in protein trafficking and function. J Am Heart Assoc 2014;3:e001491.

[45] Shyng SL, Nichols CG. Membrane phospholipid control of nucleotide sensitivity of KATP channels. Science 1998;282:1138-41.

[46] Triant VA, Lee H, Hadigan C, Grinspoon SK. Increased acute myocardial infarction rates and cardiovascular risk factors among patients with human immunodeficiency virus disease. J Clin Endocrinol Metab 2007;92:2506-12.

[47] Hernandez CC, Falkenburger B, Shapiro MS. Affinity for phosphatidylinositol 4,5bisphosphate determines muscarinic agonist sensitivity of Kv7 K+ channels. J Gen Physiol 2009;134:437-48.

[48] lost N, Virag L, Opincariu M, Szecsi J, Varro A, Papp JG. Delayed rectifier potassium current in undiseased human ventricular myocytes. Cardiovasc Res 1998;40:508-15.

[49] Jost N, Virag L, Bitay M, Takacs J, Lengyel C, Biliczki P et al. Restricting excessive cardiac action potential and QT prolongation: a vital role for IKs in human ventricular muscle. Circulation 2005;112:1392-9.

[50] Sanguinetti MC, Jurkiewicz NK. Two components of cardiac delayed rectifier K+ current. Differential sensitivity to block by class III antiarrhythmic agents. J Gen Physiol 1990;96:195215.

[51] Ma M, Nath A. Molecular determinants for cellular uptake of Tat protein of human immunodeficiency virus type 1 in brain cells. J Virol 1997;71:2495-9.

[52] Smith SM, Pentlicky S, Klase Z, Singh M, Neuveut C, Lu CY et al. An in vivo replicationimportant function in the second coding exon of Tat is constrained against mutation despite cytotoxic T lymphocyte selection. J Biol Chem 2003;278:44816-25.

[53] Zareba W, Moss AJ, le CS, Hall WJ. T wave alternans in idiopathic long QT syndrome. J Am Coll Cardiol 1994;23:1541-6.

[54] Schweigmann U, Biliczki P, Ramirez RJ, Marschall C, Takac I, Brandes RP et al. Elevated heart rate triggers action potential alternans and sudden death. translational study of a homozygous KCNH2 mutation. PLoS One 2014;9:e103150.

[55] Fox JJ, McHarg JL, Gilmour RF, Jr. Ionic mechanism of electrical alternans. Am J Physiol Heart Circ Physiol 2002;282:H516-H530.

[56] Hua F, Johns DC, Gilmour RF, Jr. Suppression of electrical alternans by overexpression of HERG in canine ventricular myocytes. Am J Physiol Heart Circ Physiol 2004;286:H2342-H2351. 

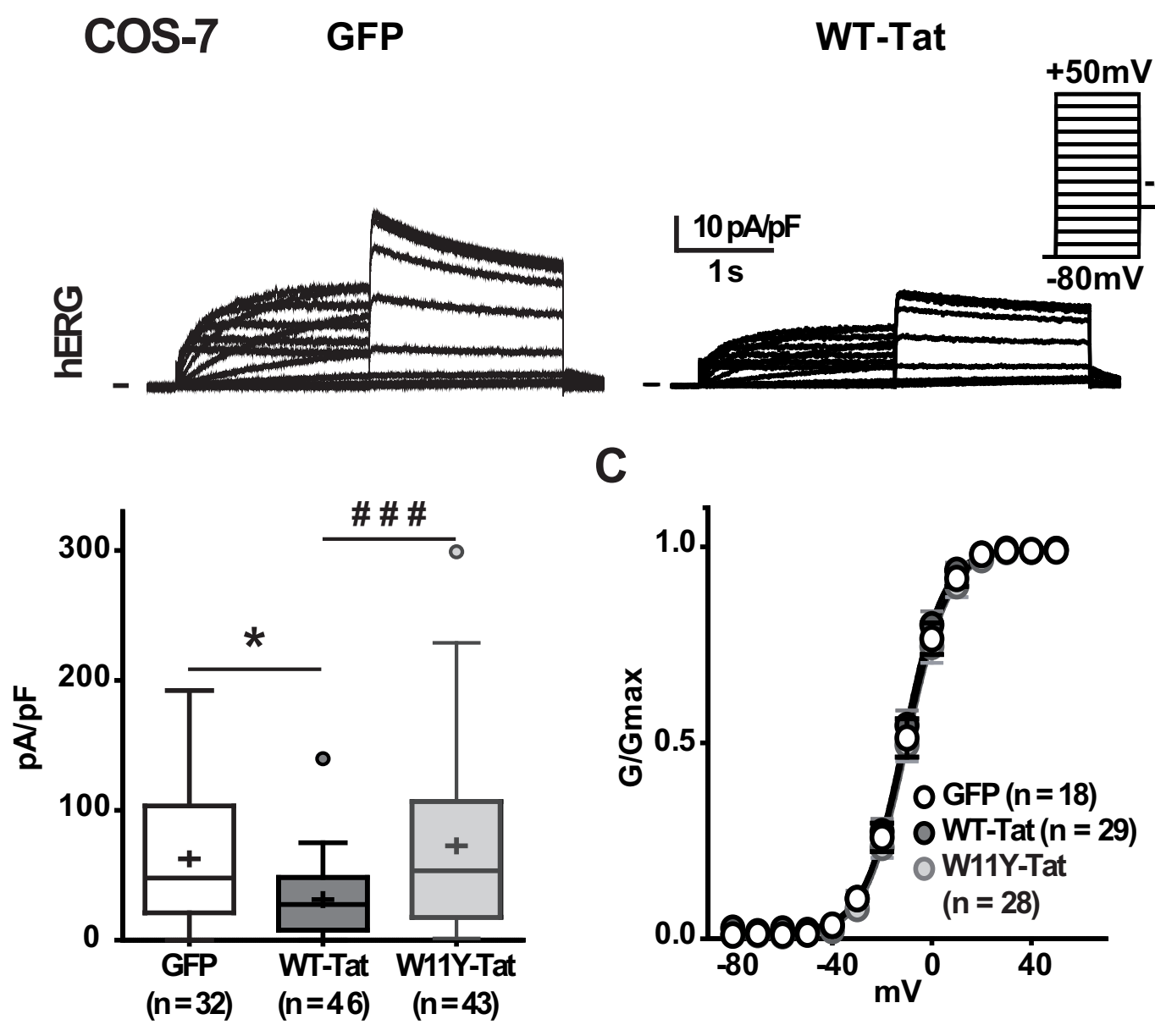

W11Y-Tat

A
B

$E$

GFP

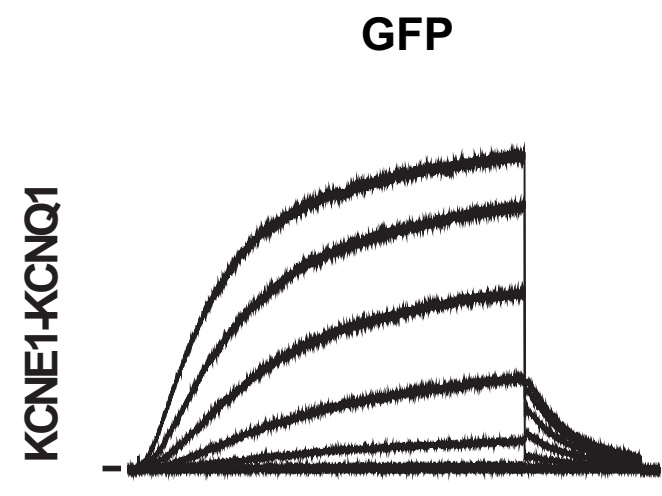

WT-Tat
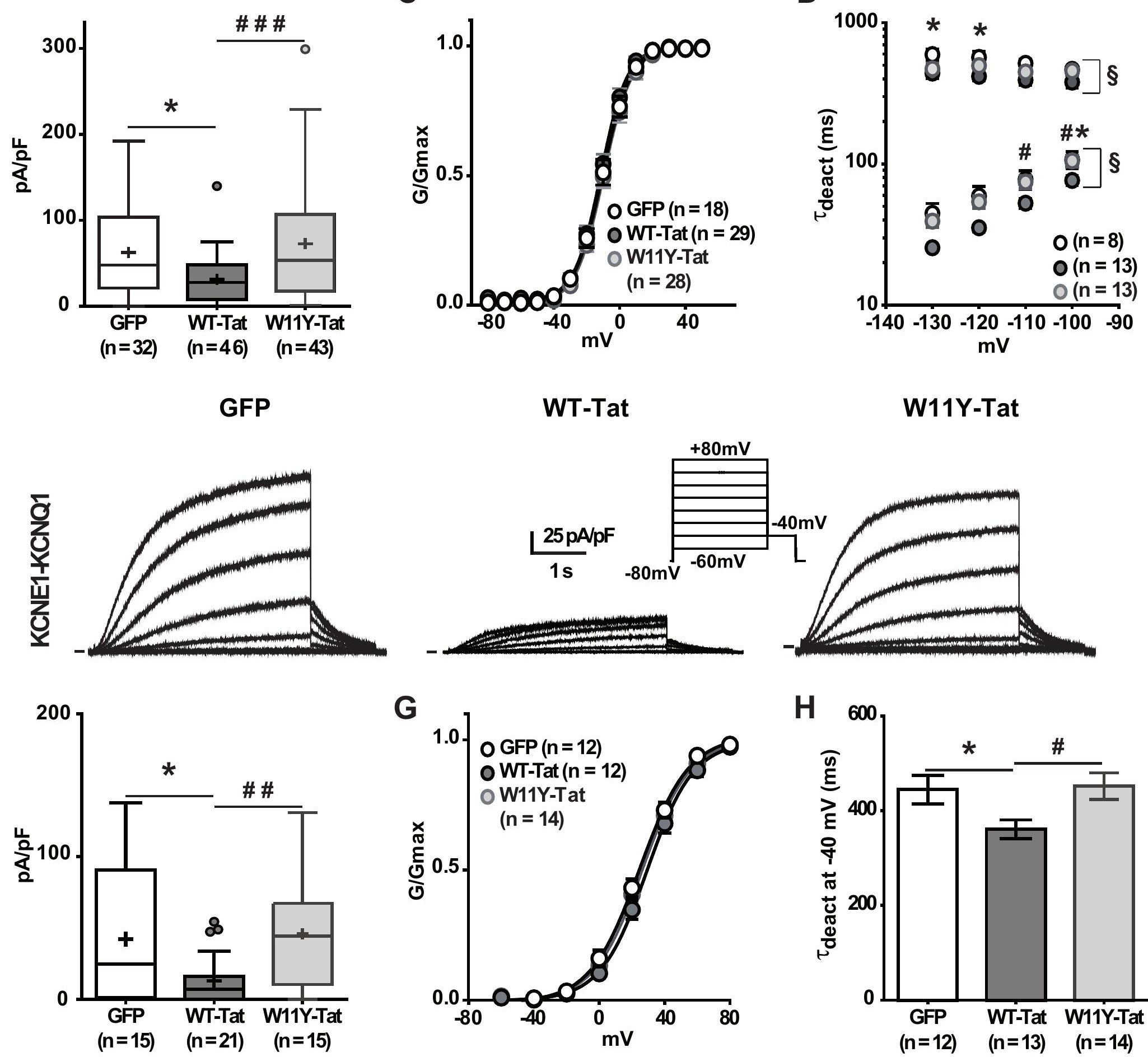
A

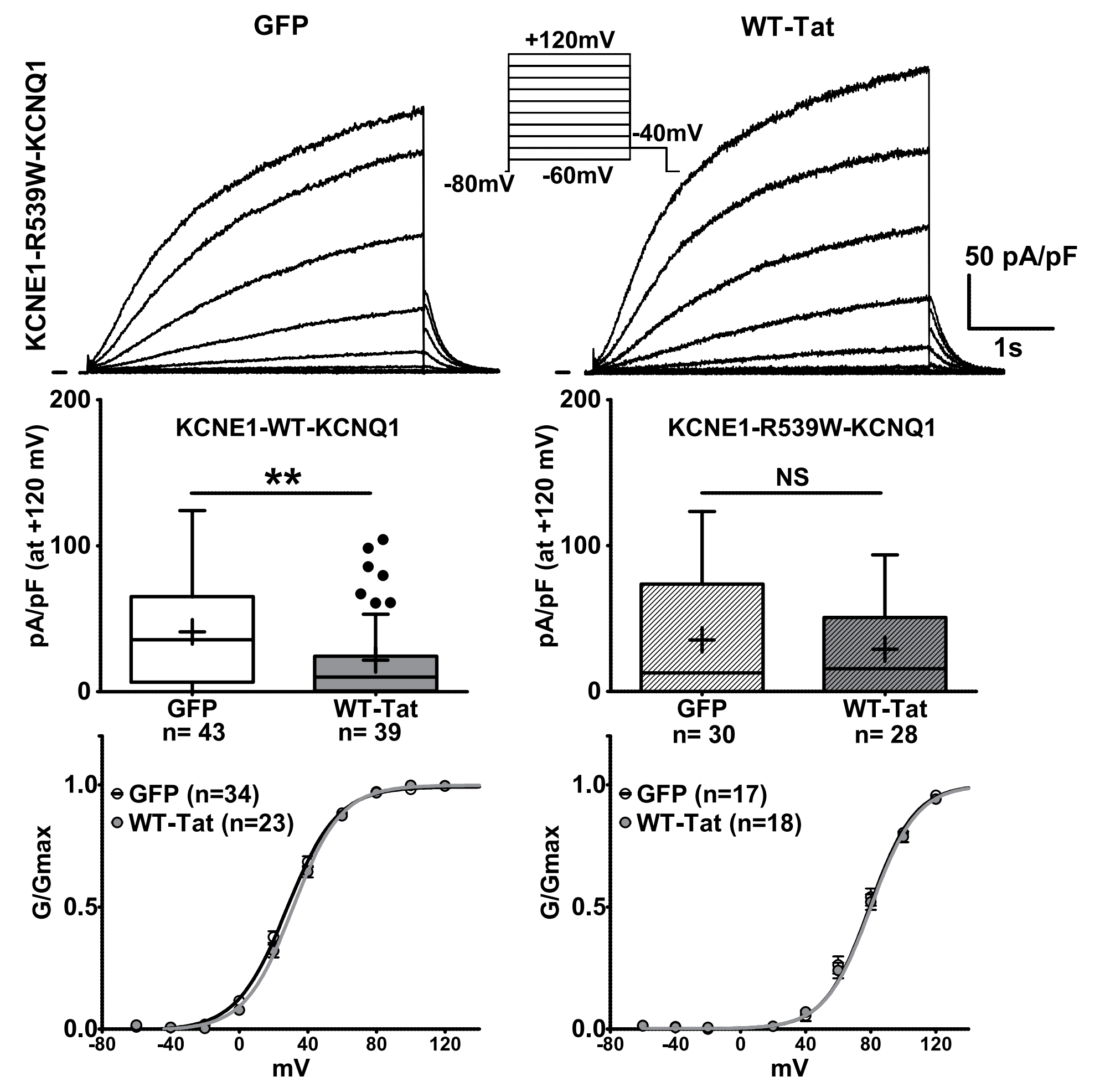

c 
WT-Tat

W11Y-Tat
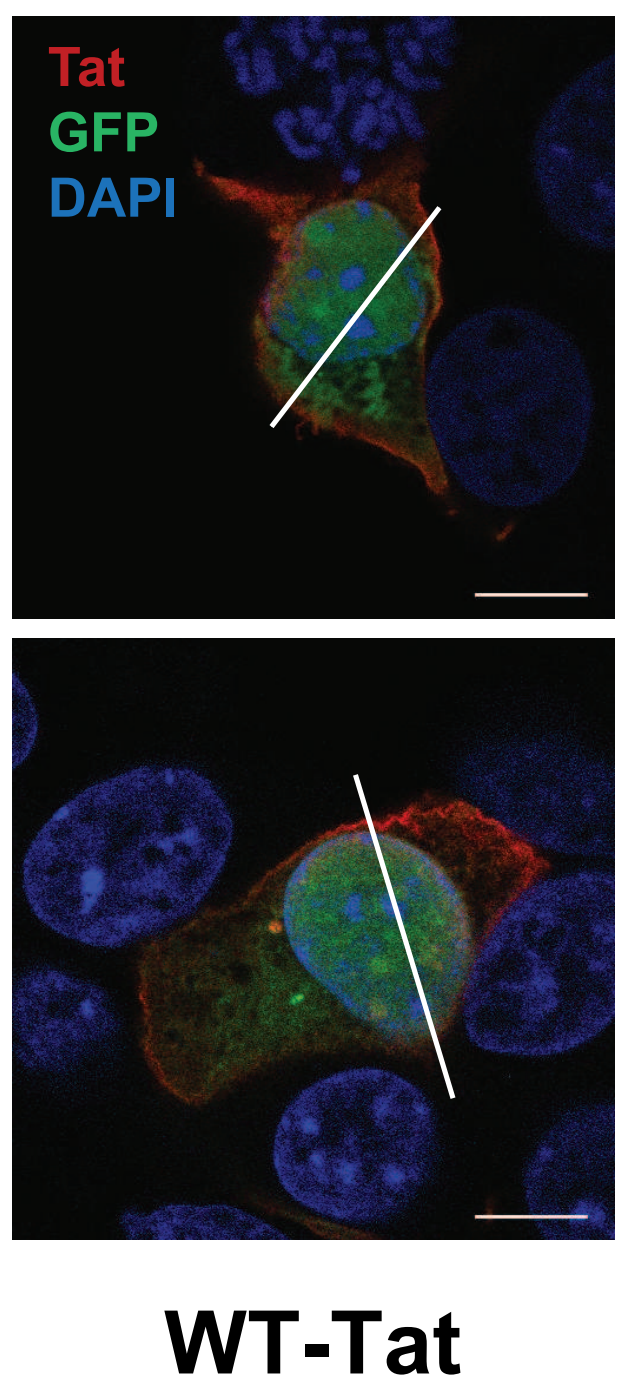

B

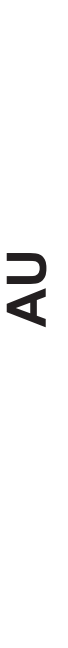
2
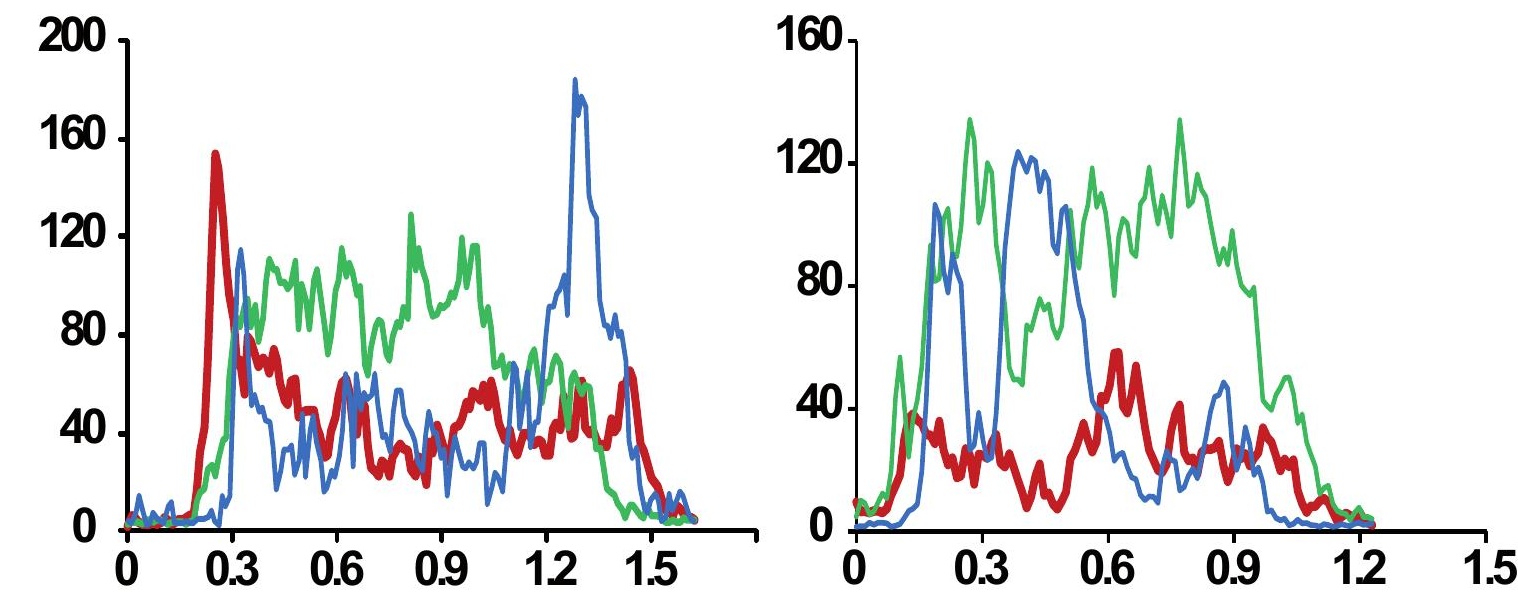
A hiPS-CMs
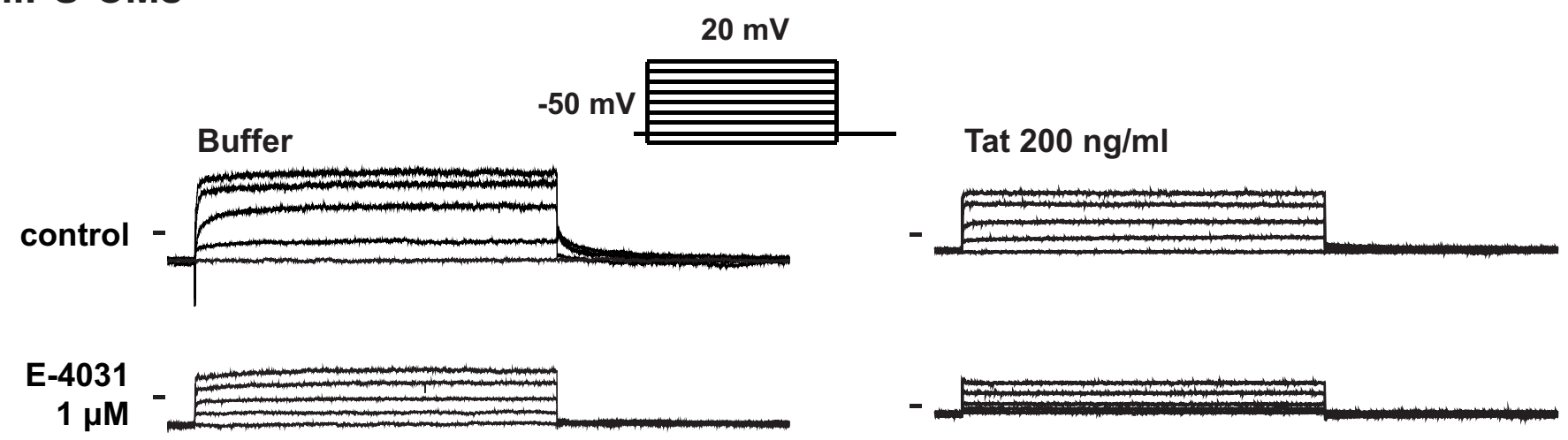

100 pA

$500 \mathrm{~ms}$
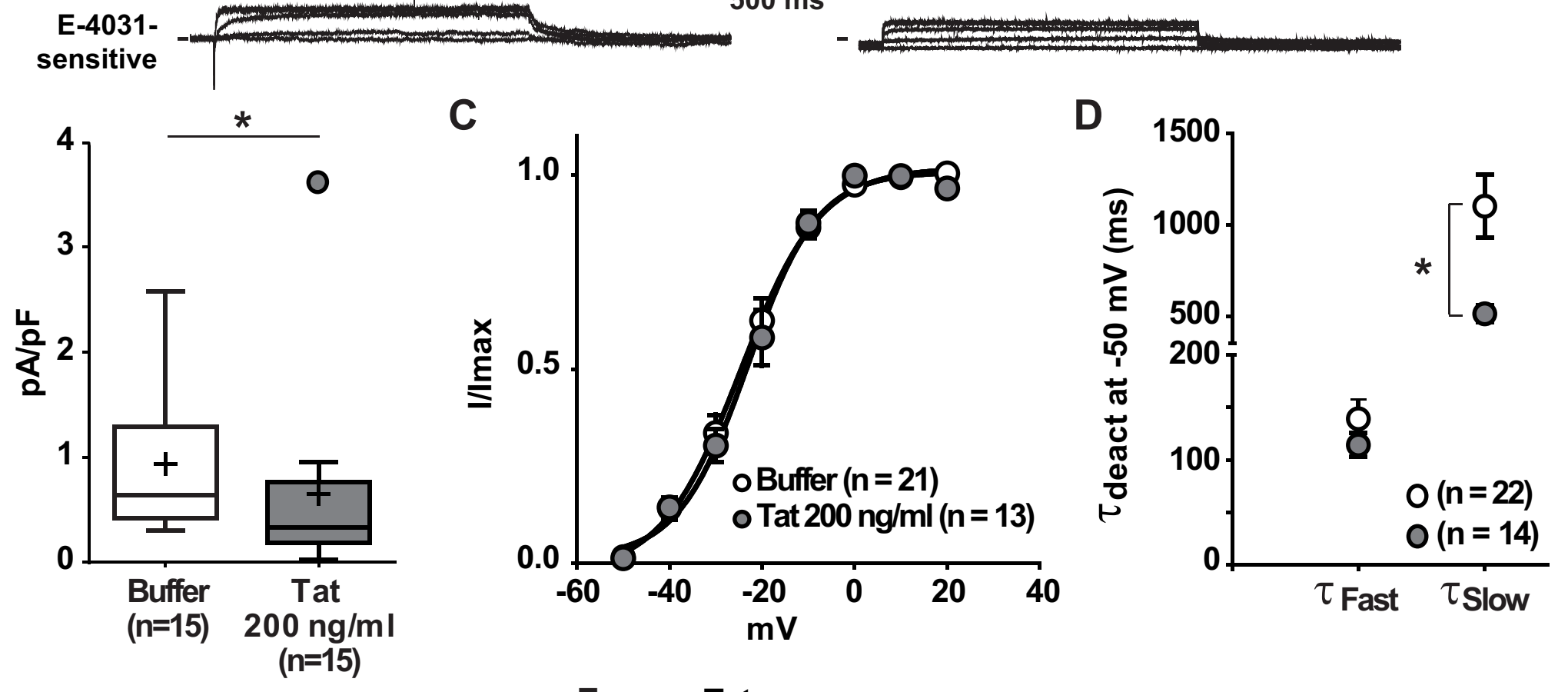

E
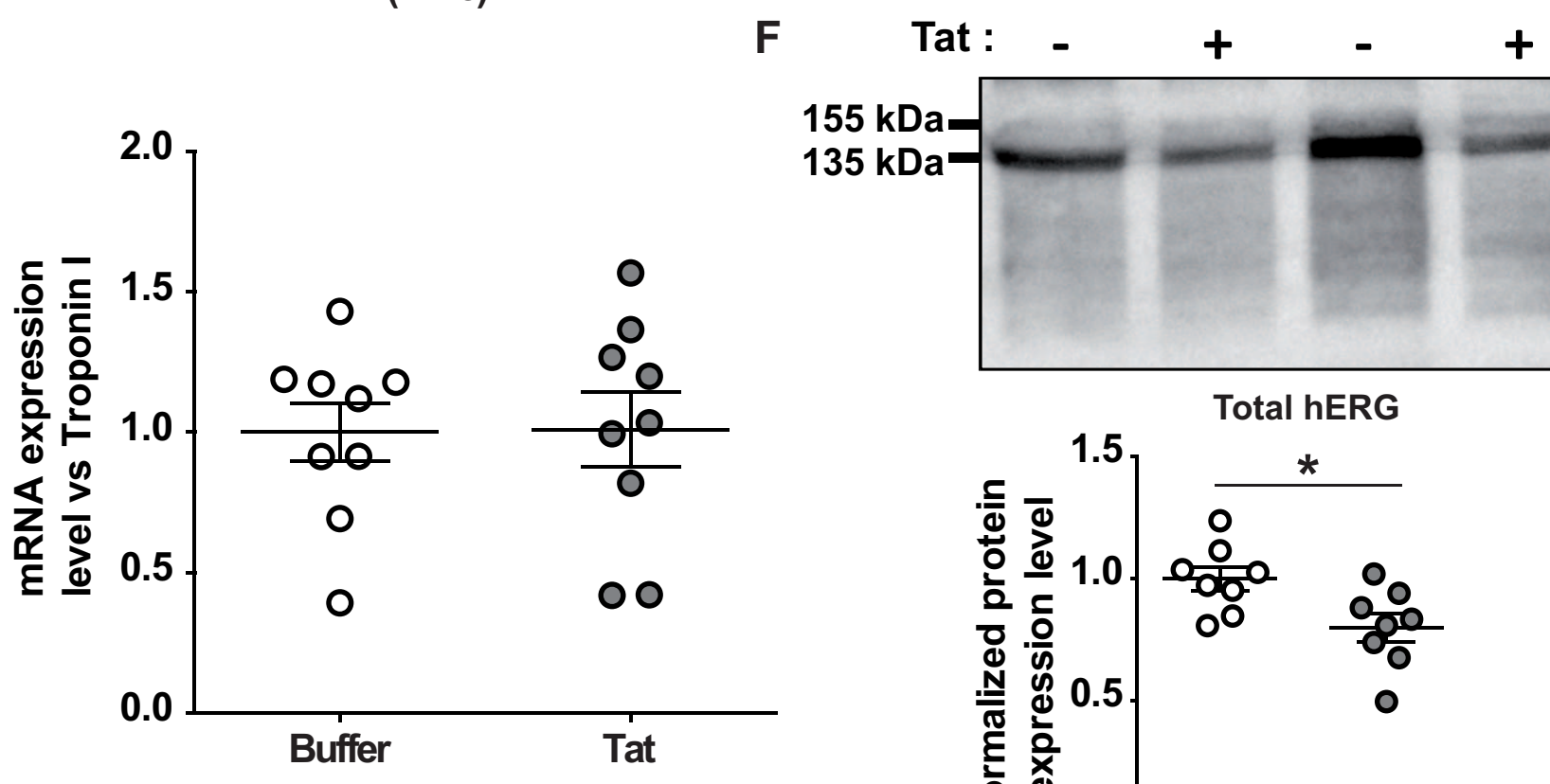

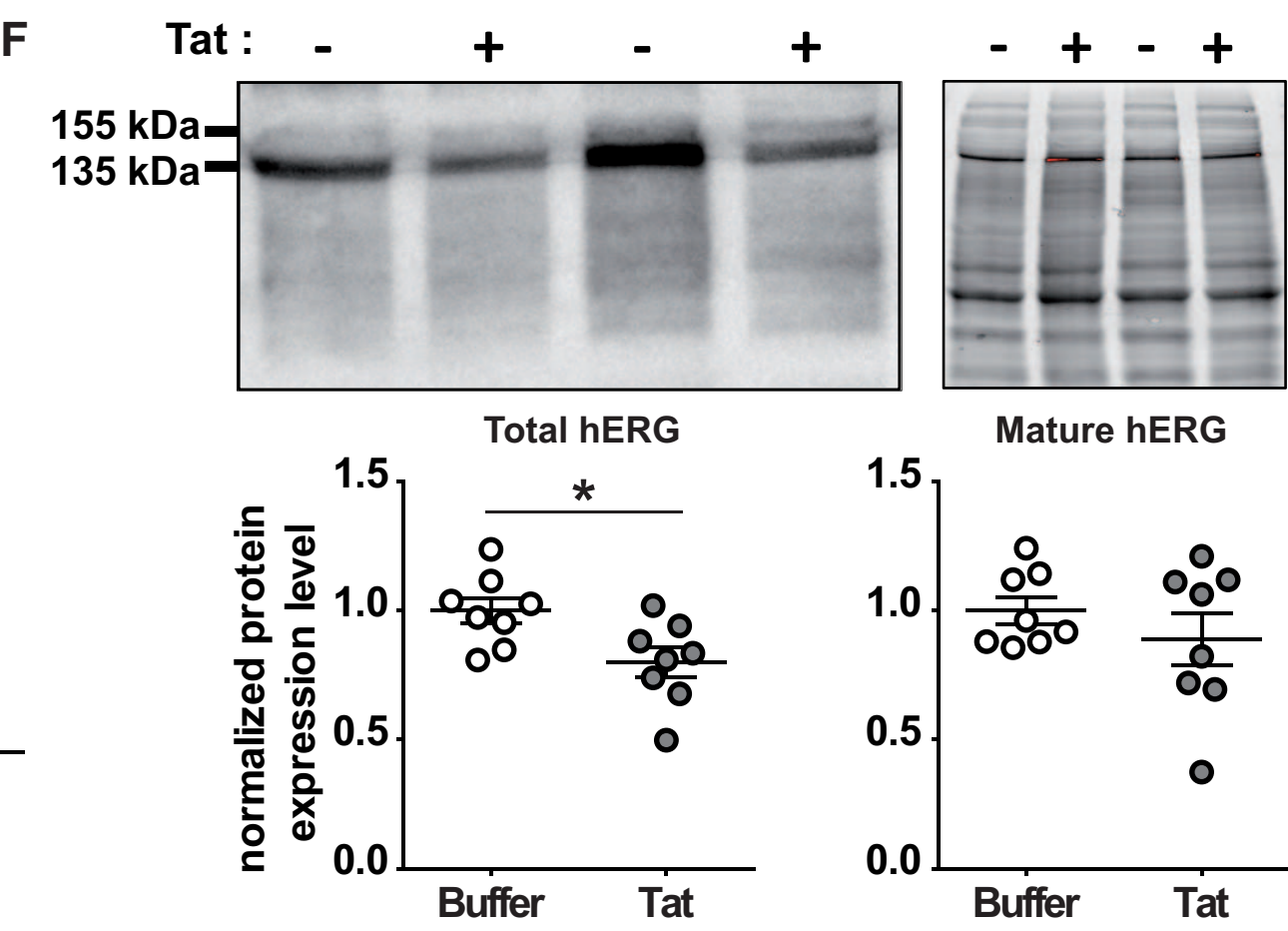


A
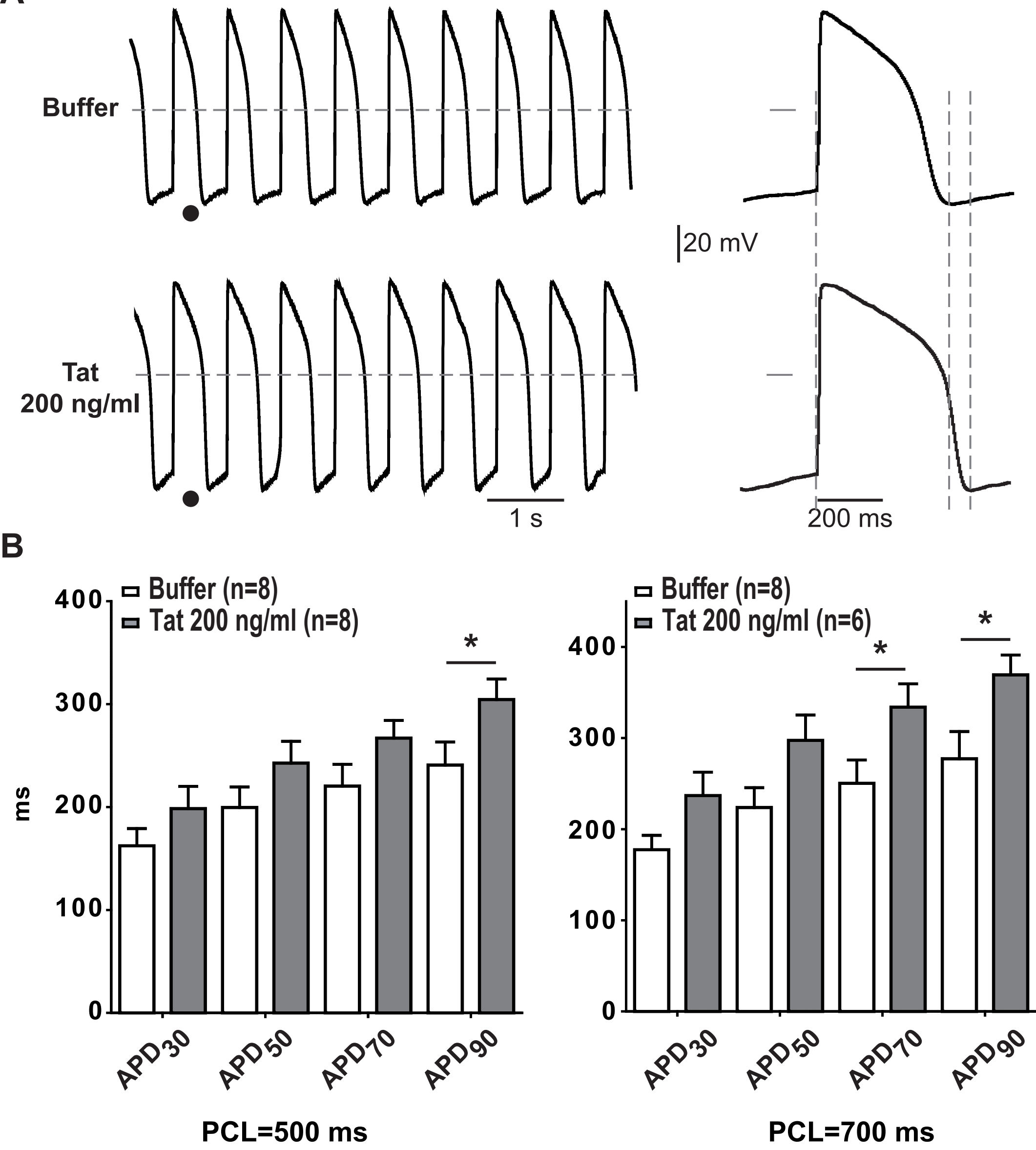
Click here to download high resolution image

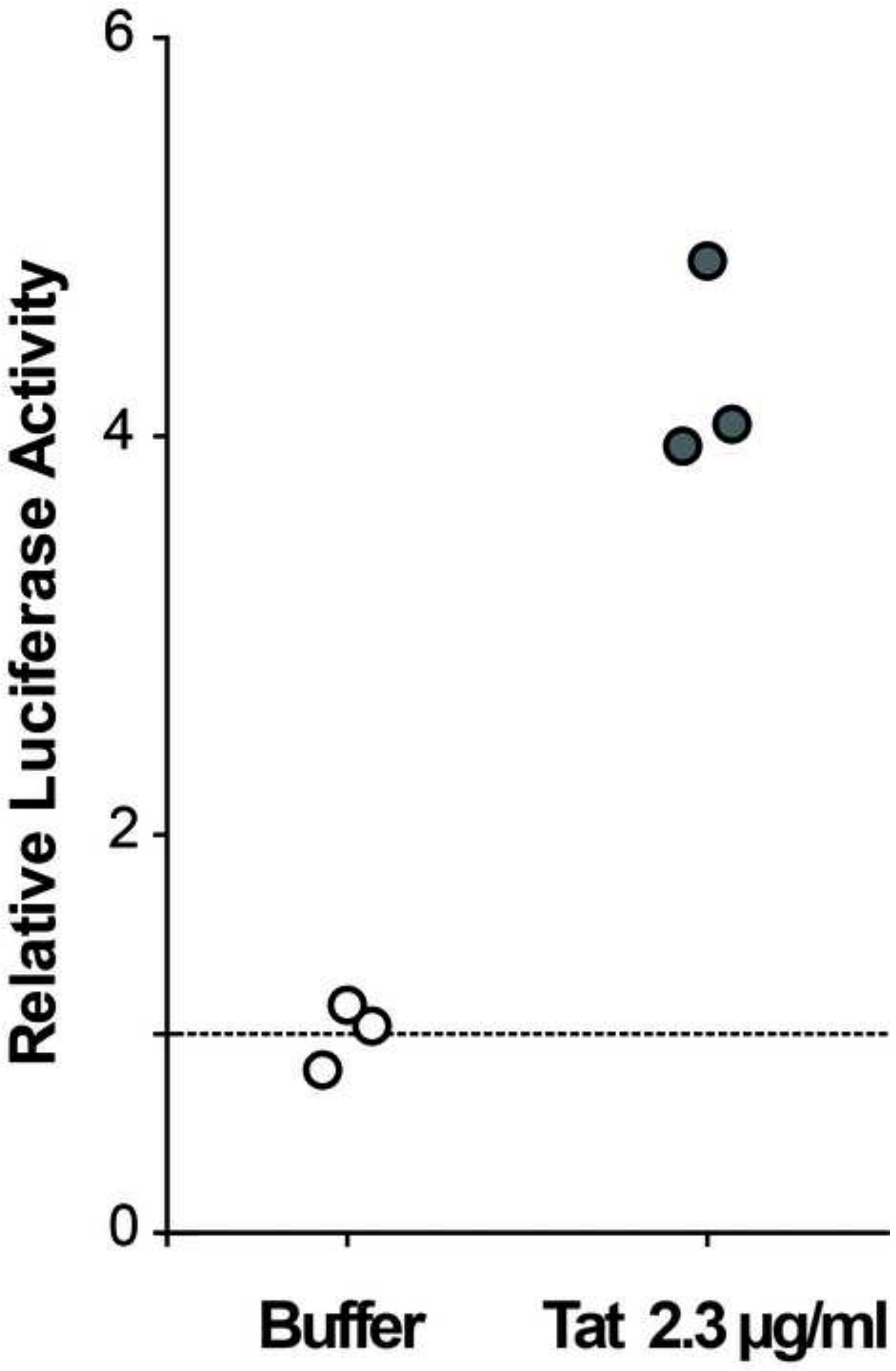


A HEK-hERG

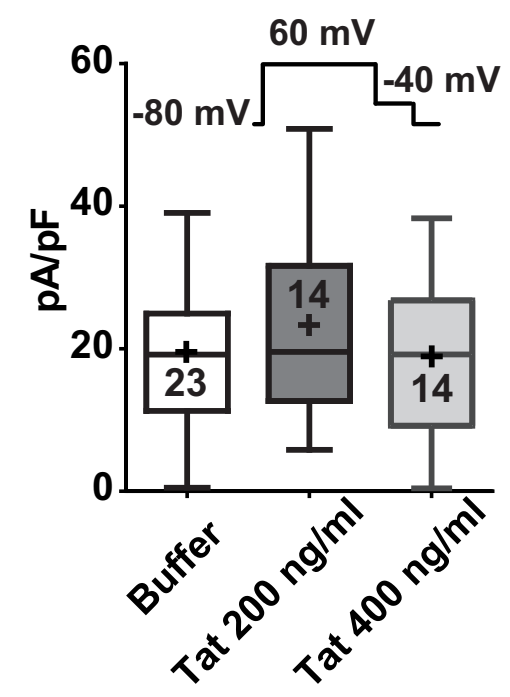

D

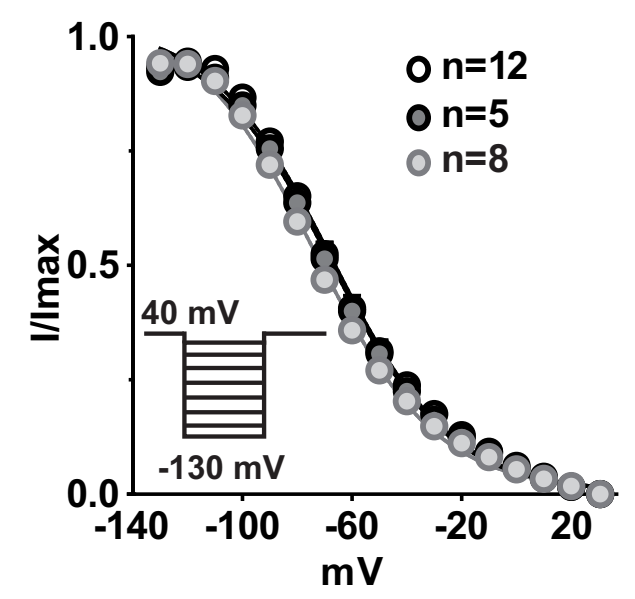

G

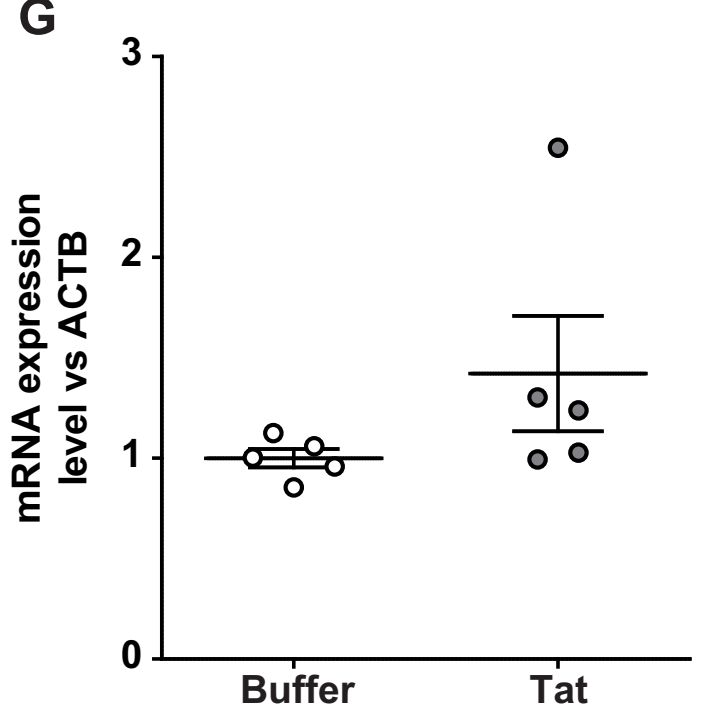

B

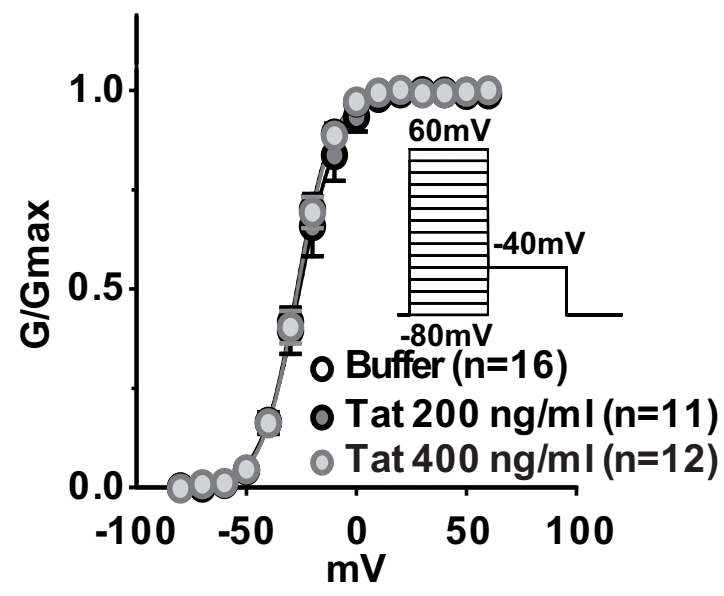

E

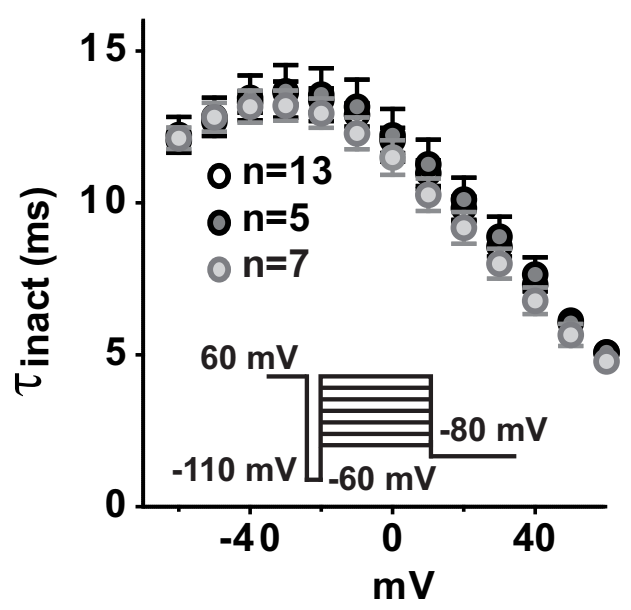

C

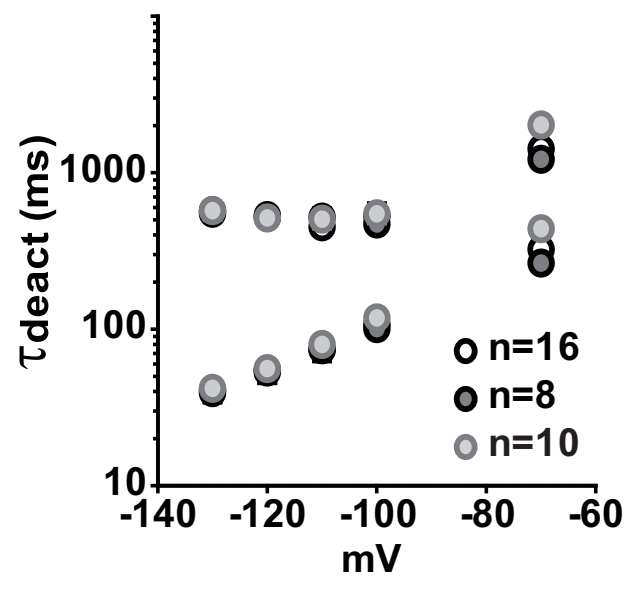

F

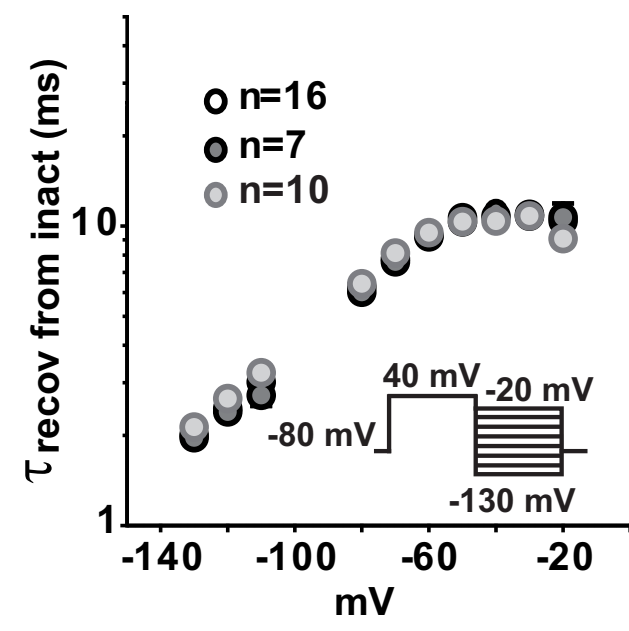

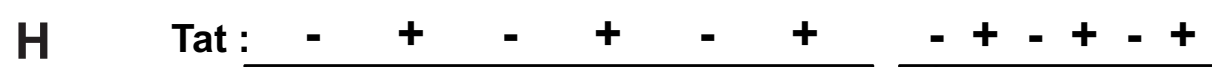
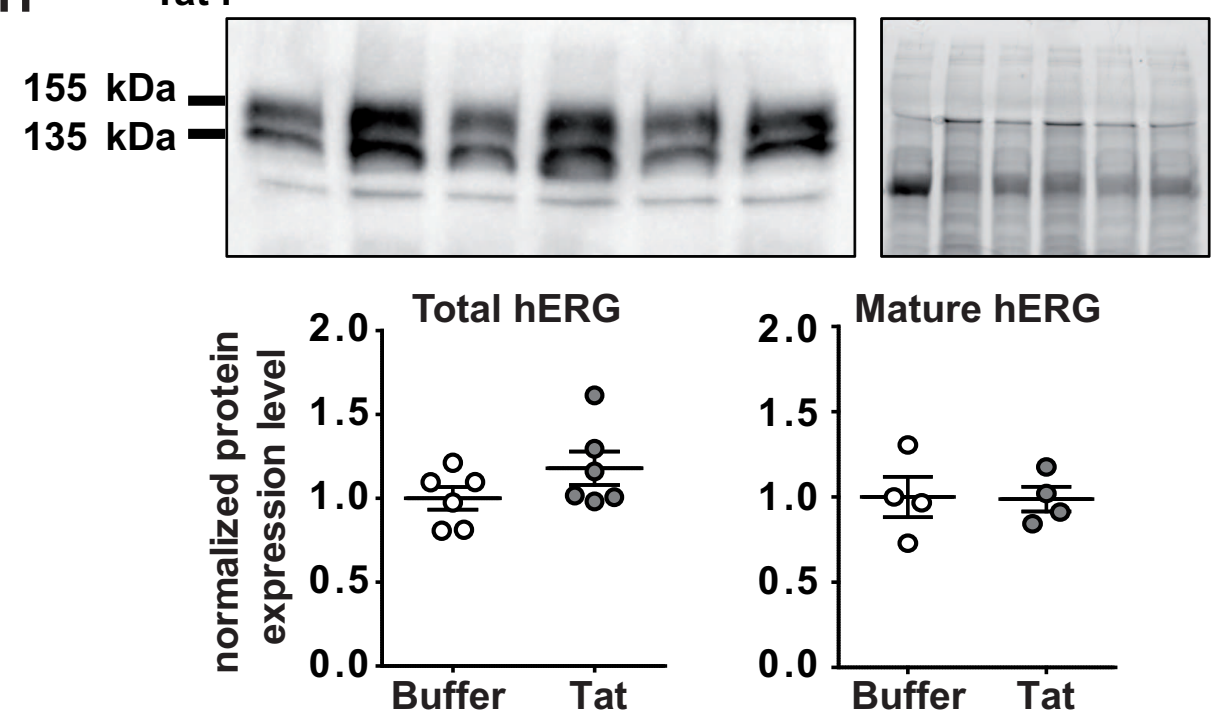


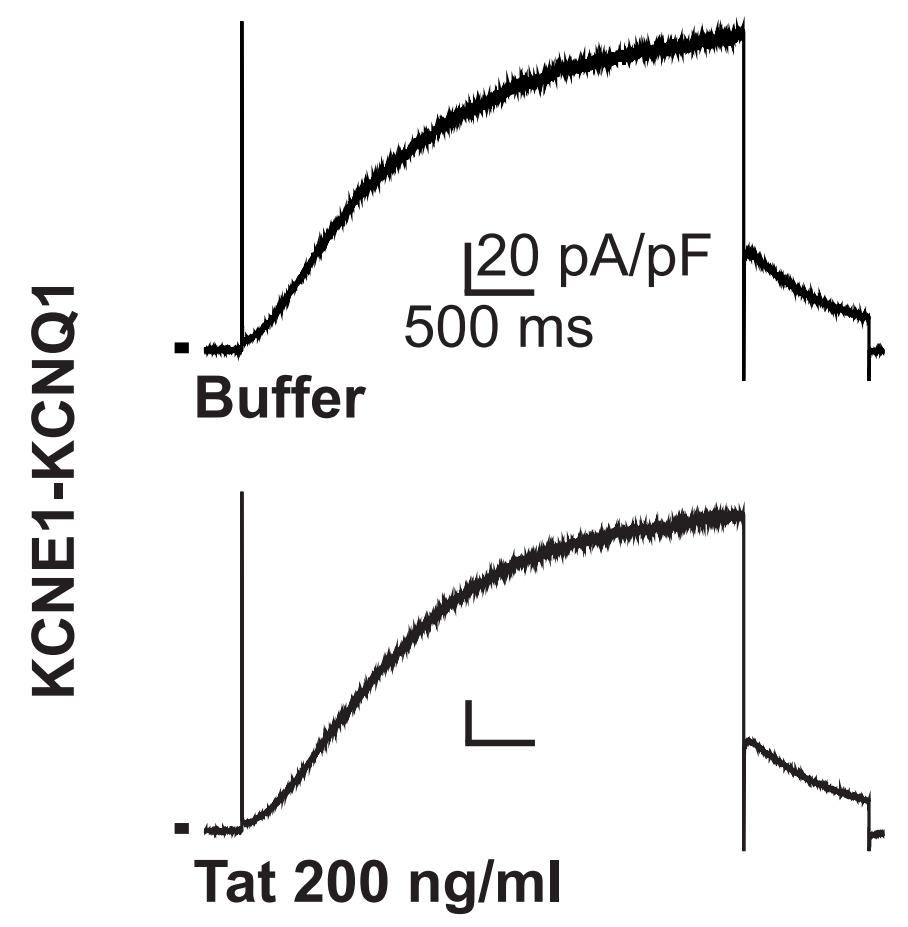

A $\quad$ COS-7

B

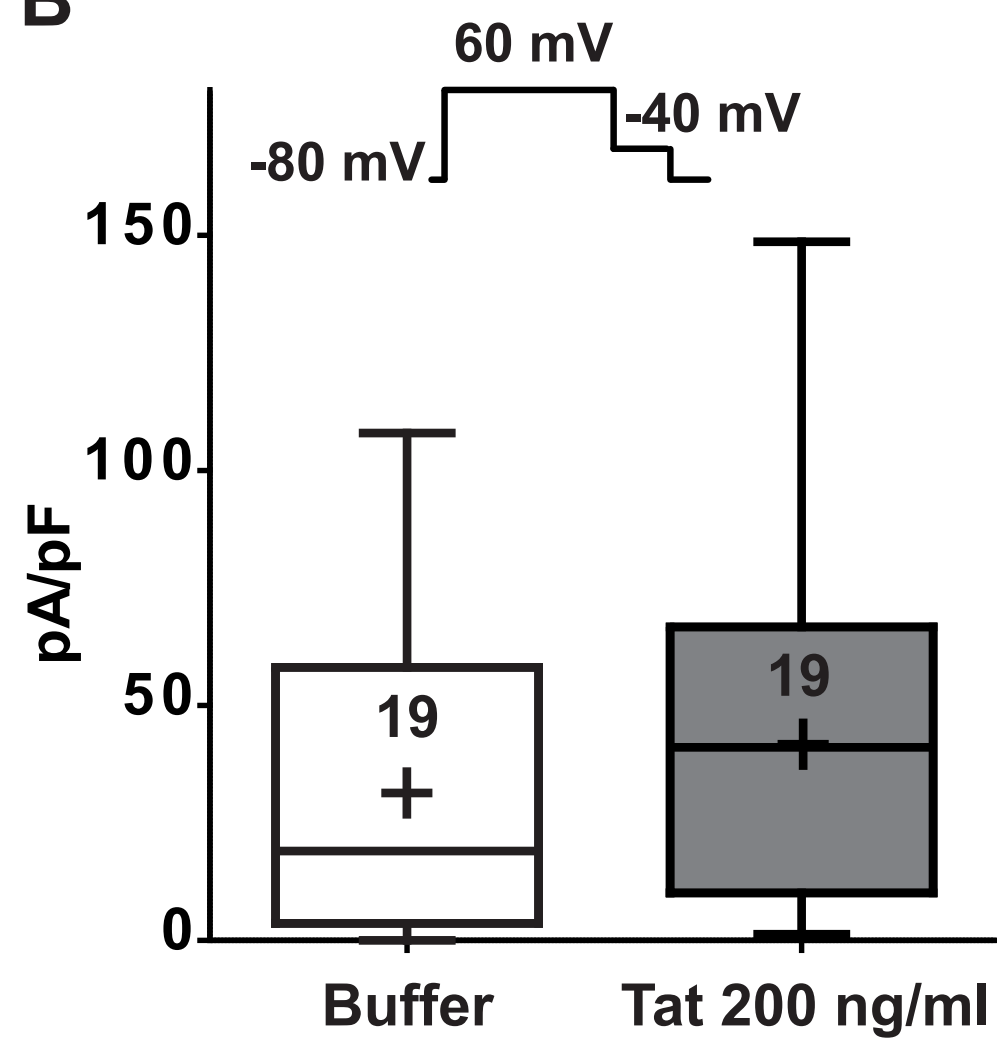

D
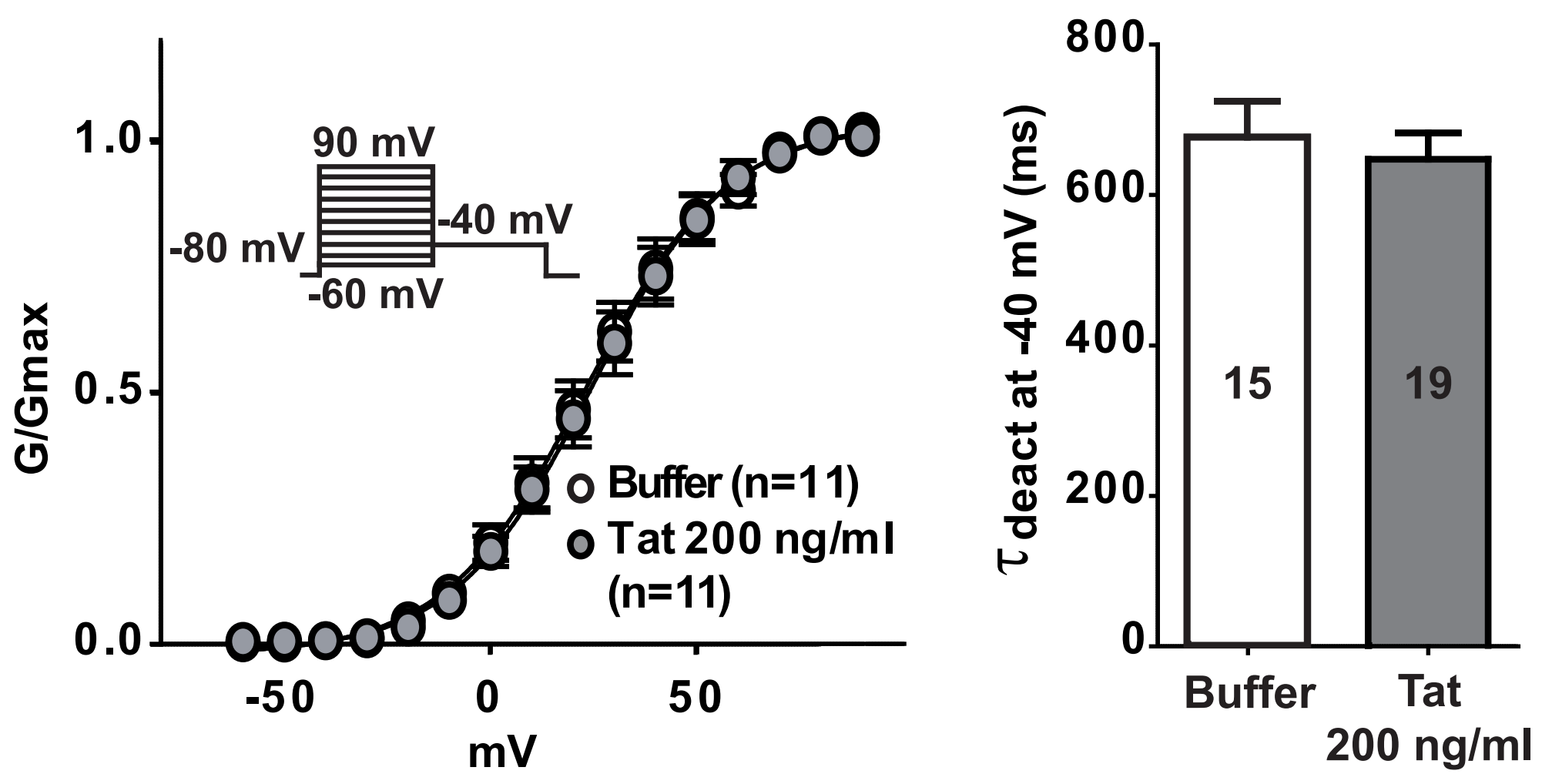
A

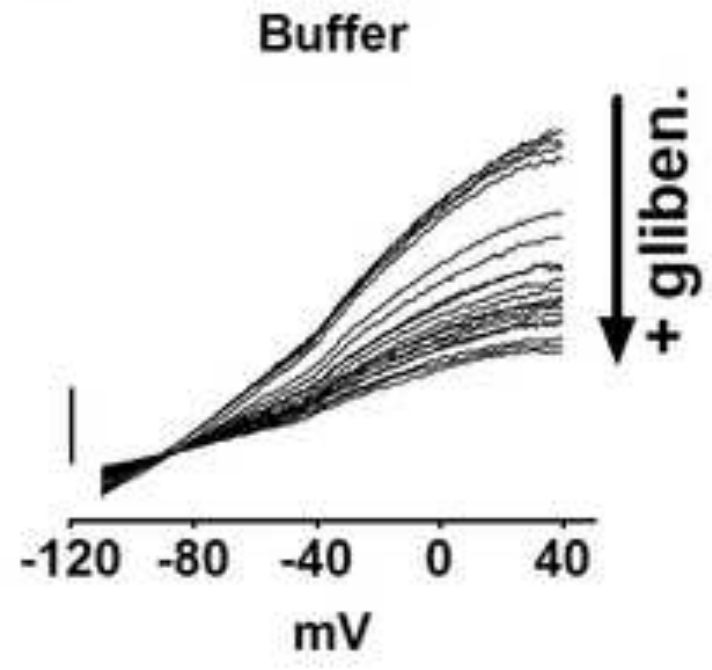

B

\section{Tat $200 \mathrm{ng} / \mathrm{ml}$}

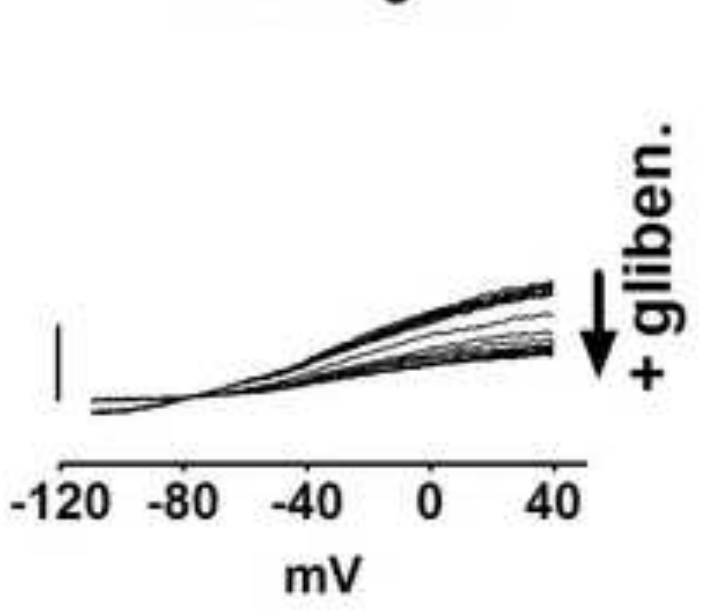

C

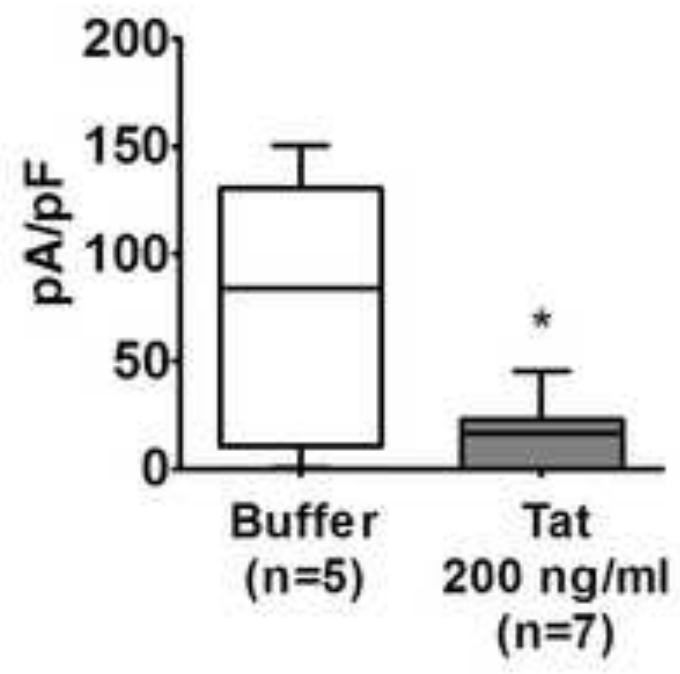

